ARGONNE CANCER RESEARCH HOSPITAL 950 EAST FIFTY-NINTH STREET - CHICAGO 37 : ILLINOIS

Semiannual Report to

\title{
THE ATOMIC ENERGY COMMISSION
}

MARCH 1957

LEON O. JACOBSON, M.D.

Editor

ANTREEN PFAU

Associate Editor

OPERATED BY THE UNIVERSITY OF CHICAGO

UNDER

CONTRACT AT-(11-1)-69 


\section{DISCLAIMER}

This report was prepared as an account of work sponsored by an agency of the United States Government. Neither the United States Government nor any agency Thereof, nor any of their employees, makes any warranty, express or implied, or assumes any legal liability or responsibility for the accuracy, completeness, or usefulness of any information, apparatus, product, or process disclosed, or represents that its use would not infringe privately owned rights. Reference herein to any specific commercial product, process, or service by trade name, trademark, manufacturer, or otherwise does not necessarily constitute or imply its endorsement, recommendation, or favoring by the United States Government or any agency thereof. The views and opinions of authors expressed herein do not necessarily state or reflect those of the United States Government or any agency thereof. 


\section{DISCLAIMER}

Portions of this document may be illegible in electronic image products. Images are produced from the best available original document. 


\section{LEGAL NOTICE}

This report was prepared as an account of Government sponsored work. Neither the United States, nor the Commission, nor any person acting on behalf of the Commission:

A. Makes any warranty or representation, express or implied, with respect to the accuracy, completeness, or usefulness of the information contained in this report, or that the use of any information, apparatus, method, or process disclosed in this report may not infringe privately owned rights; or

B. Assumes any liabilities with respect to the use of, or for damages resulting from the use of any information, apparatus, method, or process disclosed in this report.

As used in the above, "person acting on behalf of the Commission" includes any employee or contractor of the Commission to the extent that such employee or contractor prepares, handles or distributes, or provides access to, any information pursuant to his employment or contract with the Commission.

Price 50 cents. Available from the Office of Technical Services, Department of Commerce, Washington 25, D.C. 


$$
\text { ACRH-7 }
$$

ARGONNE CANCER RESEARCH HOSPITAL 950 EAST FIFTY-NINTH STREET - CHICAGO 37 • ILLINOIS

\section{Semiannual Report to}

\section{THE ATOMIC ENERGY COMMISSION}

MARCH 1957

LEON O. JACOBSON, M.D. Editor ANTREEN PFAU

Associate Editor

OPERATED BY THE UNIVERSITY OF CHICAGO

UNDER

CONTRACT AT-(11-1)-69 


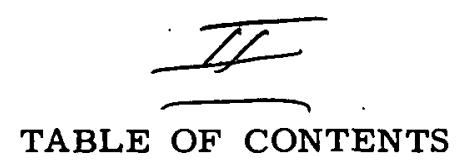

Page

Some observations on the biological effects of deuterium with special reference to effects on neoplastic processes.

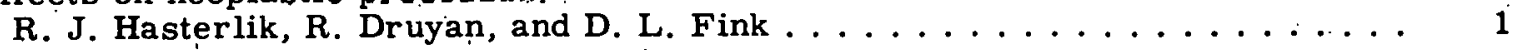

The effect of cell suspensions upon the development of cataracts in irradiated mice.

F. W. Newell, T. C. Beaman, L. O. Jacobson, E. K. Marks, and E. O. Gaston .

Hormones in human reproduction. I. Metabolism of progesterone.

M. E. Davis, E. J. Plotz, G. V. LeRoy, R. G. Gould, and H. Werbin . . . . .

Hormones in human reprndustion. II. Radioaetivity in malerial and felal llssues following intramuscular administration of $\mathrm{C}^{14}-4$-progesterone.

E. J. Plotz, M. E. Davis, G. T. Okita, and G. V. LeRoy. . . . . . . . . . 20

Cholesterol - A precursor of estrone in vivo.

H. Werbin, E. J. Plotz, G. V. LeRoy, and M. E. Davis . . . . . . . . .

The role of cholesterol in steroidogenesis in man.

G. V. LeRoy . . . . . . . . . . . . . . . . . . . . . . .

A test for the determination of taurine in urine.

E. I. Pentz, C. H. Davenport, W. Glover, and D. D. Smith . . . . . . . .

In vivo radiotracer stability of a tritium "self-radiation" labeled compound.

J. L. Spratt, G. T. Okita, E. M. K. Geiling . . . . . . . . . . . .

Studies with radioactive digitalis.

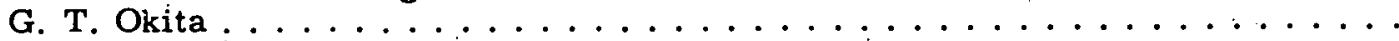

Simultaneous radioassay of compounds containing tritium and carbon-14 using a liquid scintillation counter.

G. T. Okita, J, J. Kabara, F. Richardson, and G. V. LeRoy . . . . . . . . .

Theoretical studies of the ACRH linear electron accelerator.

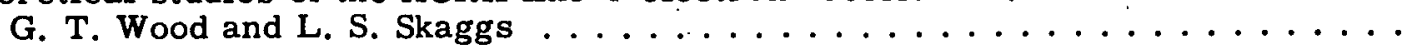

Staff publications $\ldots \ldots \ldots \ldots \ldots \ldots \ldots \ldots \ldots \ldots$ 


\section{ACRA-7}

SOME OBSERVATIONS ON THE BIOLOGICAL EFFECTS OF DEUTERIUM

WITH SPECIAL REFERENCE' TO EFFECTS ON

NEOPLASTIC PROCESSES*

By

R. J. Hasterlik, R. Druyan, ${ }^{\dagger}$ and D. L. Fink ${ }^{\ddagger}$

The profound biologic consequences of the deuteration of living organisms were noted very soon after the discovery of the heavy isotope of hydrogen. However, very little research has been directed specifically to the elucidation of the complex physiologic consequences of extensive deuteration.

The purposes of this paper are to describe some of the biologic effects of deuterium in mice and to give the preliminary results of studies undertaken to ascertain the possible influence of deuterium on neoplastic processes.

\section{MATERIALS AND METHODS}

CF No. 1 young adult female mice were used in these studies. Deuterium was provided ad libitum in the drinking water in appropriate concentrations.

The urine was collected by manual expression from the bladder. Assays and analyses were carried out on tissues from sacrificed animals, except in some experiments where blood was obtained by cardiac puncture under light ether anesthesia.

Water distilled from various tissues was also analyzed for deuterium content. The distillations were performed under vacuum $\left(<10^{-5} \mathrm{~cm} \mathrm{Hg}\right)$ in small " $h$ "-shaped vessels. Distillation of small samples of water of known deuterium content (from 20 to 50 per cent) indicated less than one atom-per cent dilution with $\mathrm{H}_{2} \mathrm{O}$ under the conditions of manipulation. In combustion analyses the tissues were finally dried in vacuum at $105^{\circ} \mathrm{C}$ for 24 hours. The combustion procedure, a modification of that used by Smith, Trace, and Barbour, ${ }^{1}$ consisted of oxidation in an ordinary combustion furnace and collection of the water in a $U$-tube immersed in a solid carbon dioxide-acetone $\left(-78^{\circ} \mathrm{C}\right)$ bath.

\section{RESULTS}

The course of deuteration: The rate of deuteration of mice is indicated in Figure 1, in which the mean deuterium concentration in urine is plotted against the sum of per cent intake of $\mathrm{D}_{2} \mathrm{O}$ per day multiplied by the number of days deuterium was administered. Deu-

* The text of the paper has been taken from one having the same title that appears in the Journal of the National Cancer Institute, 18:641, 1957.

+ Peter Bent Brigham Hospital, Boston, Massachusetts.

$\neq$ Hospital of the University of California, San Francisco, California. 


\section{DEUTERATION SCHEDULE}

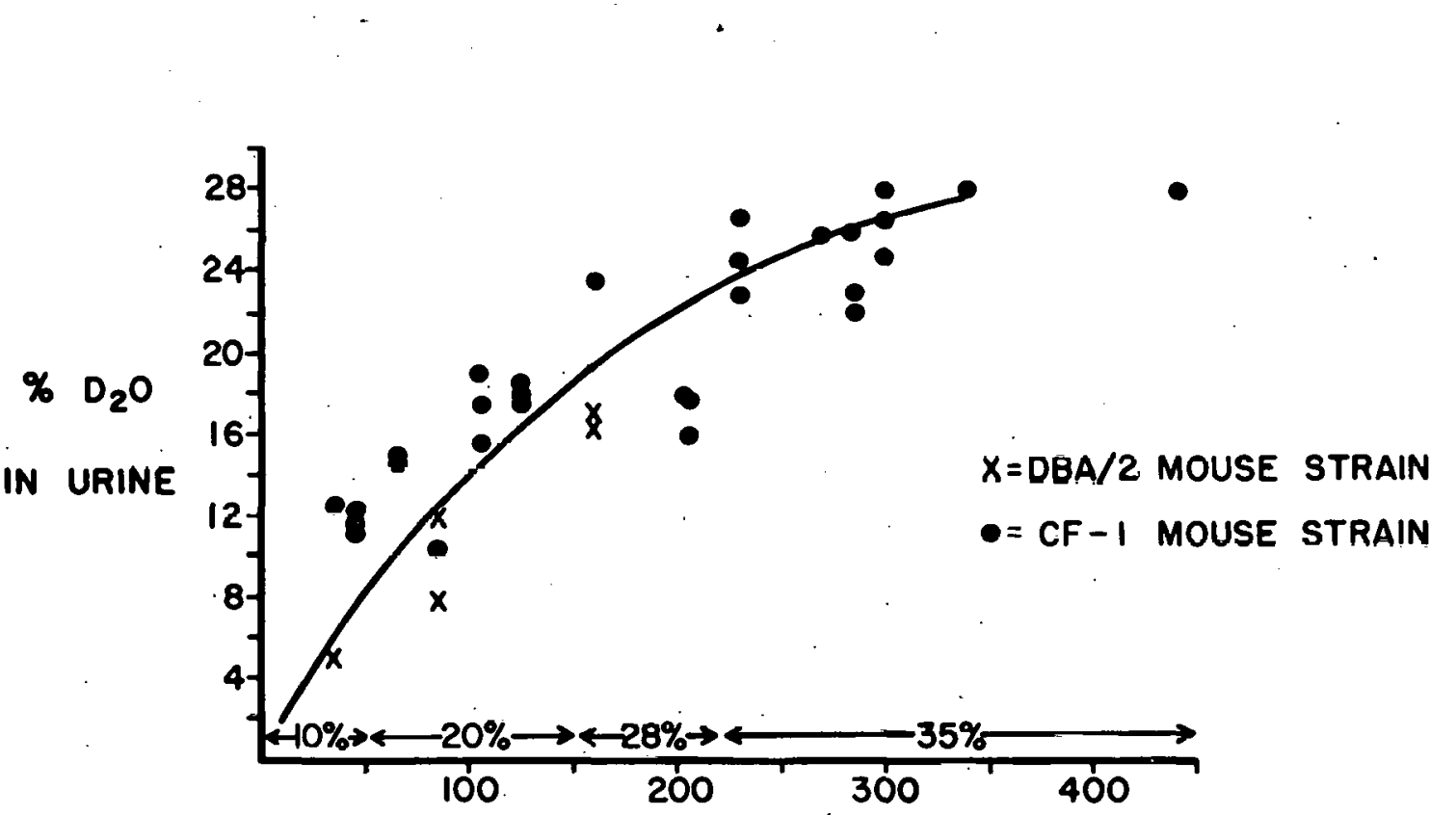

\section{$\%$ DAYS $=\left(\Sigma \%\right.$ INTAKE $D_{2} O \times$ DAYS ADMINISTERED $)$}

Figure 1. The course of body-fluid deuteration of mice with constant deuterium composition of the drinking water. Each point represents a mean of from 5 to 22 determinations of urinary deuterium.

teration quickly approaches a steady state that is determined by the deuterium ingested in the drinking water and the hydrogen content of the food.

The deuterium level in the urine after 3 weeks intake of deuterated drinking water had a mean value of 79.0 per cent of the drinking water when water containing 30 per cent $\mathrm{D}_{2} \mathrm{O}(\nu / \nu)$ was administered, and 80.0 per cent when water of 25 per cent $\mathrm{D}_{2} \mathrm{O}$ content was supplied. The lower the deuterium content of the drinking water, the more closely the deuterium content of the urine approached that of the drinking water. These data undoubtedly reflect a lower intake of the more highly deuterated drinking water, a finding consistent with the observations of Barbour and Allen. ${ }^{2}$

General consequences of deuteration: The findings of Barbour and Trace ${ }^{3}$ on the toxicity of heavy water in mice have been confirmed. As the concentration of heavy water in the body fluids increased beyond 20 atom-per cent, signs of hyperirritability were observed. As the concentration of heavy water approached 30 atom-per cent, symptoms of weakness, neuromuscular hyperexcitability and pilomotor stimulation became general. Bradycardia, stupor, and death supervened as the level of deuteration reached 30 to 35 atom-per cent. The body weight of mice was essentially unaffected by levels of deuteration maintained by 30 atom-per cent deuterium in the drinking water.

It should be pointed out that we have concerned ourselves primarily with subacute 
toxicity studies. We have no new information on the acute reaction that is induced by rapidly bringing the animal to levels of 40 atom-per cent in as short a time as possible. Under such conditions the animals become very sick; the body temperature drops sharply, all physiologic functions seem greatly depressed, and death occurs within a short time. ${ }^{4}$ We do not know whether these two modes of response are identical or whether there exists a specific acute mechanism that responds to the toxic action of deuterium.

Proceeding from the knowledge that the dissociation of weak electrolytes is markedly different in deuterium oxide as compared with ordinary water, we considered the possibility that the toxic symptoms in deuterated organisms might be related to disturbances in the carbon dioxide-bicarbonate equilibrium. To examine this point, four mice, deuterated to the extent of 20 atom-per cent, were placed together with 5 control mice in an 80 per cent oxygen-20 per cent carbon dioxide atmosphere. All mice immediately became tachypneic. However, in contrast to the control mice, the deuterated mice showed, in order: 1) marked neuromuscular hyperexcitability within one to three minutes; 2) narcosis beginning between three and five minutes; 3) gradual change of respiration from marked tachypnea to hypopnea; 4) marked bradycardia after five to ten minutes; and 5) deepening narcosis. Removal of the animals to room air resulted in the disappearance of the above signs in reverse order of their occurrence. We conclude that deuteration does alter the response of animals to high concentrations of carbon dioxide. How this relates to the toxicity of deuterium remains unknown.

Effects on kidneys: The kidneys of those mice succumbing to deuterium poisoning were grossly enlarged and pale in color. Histologic examination showed marked destruction of' the tubules. The glomeruli, on the other hand, were essentially unchanged, and. microscopic examination of the urine was negative. These findings are consistent with the observations of Dybing, Guldberg, and Hansen ${ }^{5}$ who found mild pathologic changes in mouse liver, kidney, and spleen as the level of deuteration approached 30 atom-per cent.

On the basis of these observations, it would appear that no serious kidney disturbances are evident in animals maintained for periods up to several weeks at deuterium levels below 25 atom-per cent.

Effect of deuteration on mouse leukemia: Work by Simmons ${ }^{6}$ on leukemia induced in DBA-2 mice by the intraperitoneal injection of specific numbers of splenic cells from mice dying of P1534 lymphatic leukemia indicates that a family of cumulative mortality curves with parallel slopes can be derived. The position of these curves is dependent on the number of leukemia cells injected. Accordingly, three groups of DBA-2 mice were injected intraperitoneally with $10^{5}$ splenic cells. Group 1 consisted of 10 mice deuterated to 24-26 atom-per cent before injection and maintained at this level until death; group 2 consisted of 10 mice that were given ordinary water until they were injected with splenic cells, and thereafter were deuterated gradually to 24-26 atom-per cent and maintained at this level until death; group 3 consisted of 20 control mice maintained on ordinary water. In Figure 2 the data are plotted as per cent cumulative mortality versus day of death.

Half of the control mice (group 3) were dead after 20.5 days, whereas the time for 


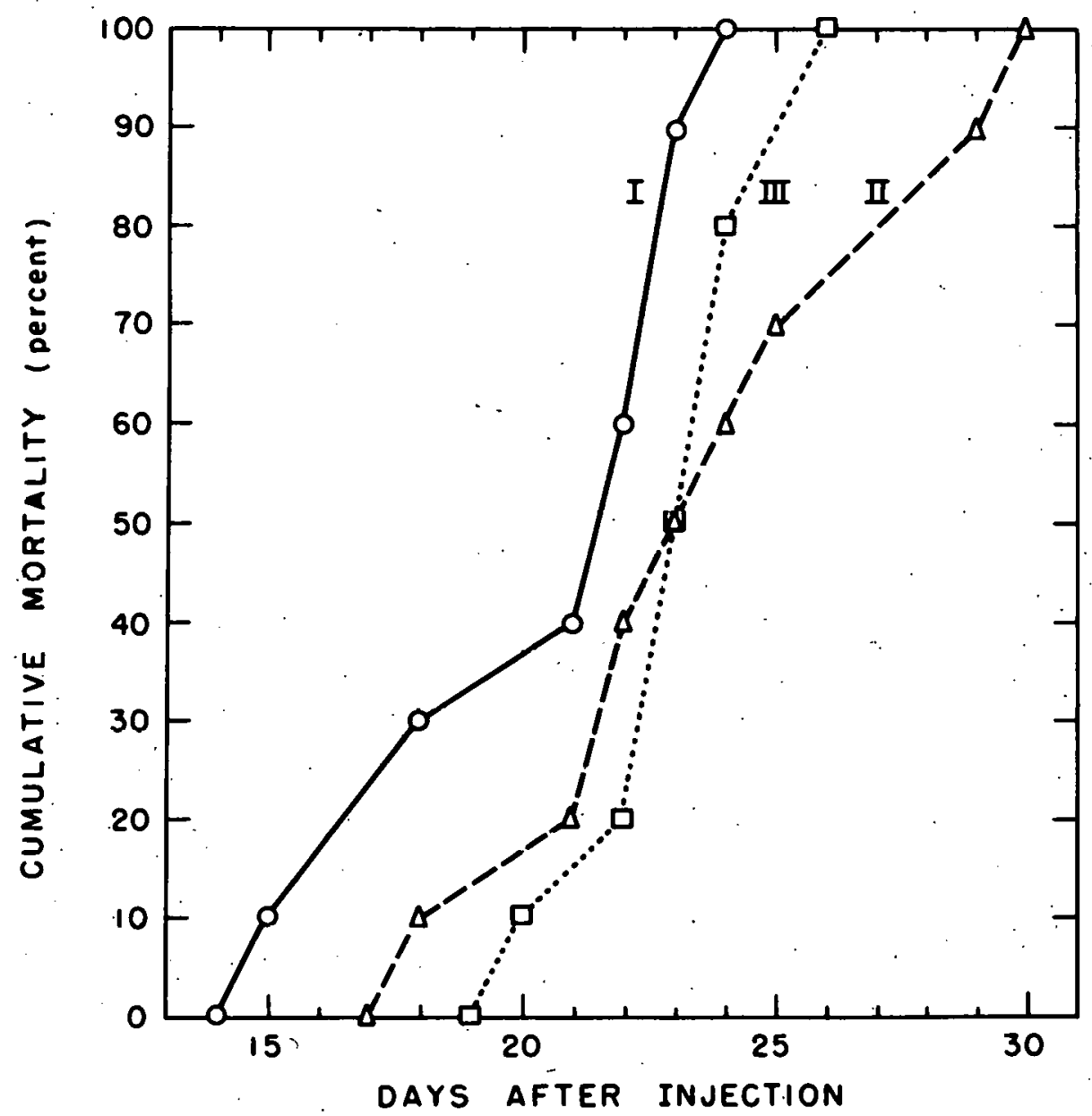

Figure 2. Effect of deuteration on mortality of mice injected with P1534 leukemia. Curve I, control mice, fed $\mathrm{H}_{2} \mathrm{O}$. Curve II, mice maintained at 24 to 26 atom-per cent deuterium throughout experiment. Curve III, mice given $\mathrm{D}_{2} \mathrm{O}$ immediately after inoculation, brought up to 24 to 26 atom-per cent deuterium.

comparable mortality in groups 1 and 2 was 23 days. From Figure 2 it can be seen that there is a slight but consistent prolongation of life in the leukemic mice receiving deuterium. Deuteration appears to displace the mortality curve to the position normally expected to follow the injection of less than half the number of leukemic cells actually used on this occasion.

Effect of deuteration on radiation sensitivity: One of the consequences that may be expected to follow extensive deuteration of a living organism is a change in radiosensitivity. In the case of $\gamma$ radiation, it has been shown that the free radicals formed from $\mathrm{D}_{2} \mathrm{O}$ react more readily with other substances than do those formed from $\mathrm{H}_{2} \mathrm{O}{ }^{7}$. The cross section for neutron capture by deuterium is well known to be very much less than that of ordinary hydrogen, and it has been estimated that replacement of one-fourth of the body hydrogen in the mouse by deuterium will render the animal 20 per cent less susceptible 
to slow neutrons. ${ }^{8}$ It was therefore of some interest to begin an examination of the effects of combinations of external radiation and deuteration on survival.

Two hundred and forty CF No. 1 mice, 12 to 14 weeks old, were divided randomly into 24 groups for deuteration and irradiation. All animals were brought to the desired body content of deuterium before irradiation by supplying drinking water of varied deuterium content. All irradiations were done on the same day with a G-E Maxitron X-ray unit operating at $250 \mathrm{kvp}$ at $30 \mathrm{ma}$. with $0.25-\mathrm{mm}$. copper and $1-\mathrm{mm}$. aluminum filtration of the beam. The radiation doses in rads were $550,600,650,700$, and 750 . Body water deuterium contents at the time of irradiation were $0,8-10,15-18$, and 25-28 atom-per cent. All animals were maintained at the predetermined deuteration level until death or termination of the experiment, more than 30 days after $\mathrm{X}$ irradiation.

This experiment was repeated with doses of 700,750 , and 800 rads. The deuterium levels in the animals and the radiation factors were the same as in the first experiment. Each group consisted of $10 \mathrm{CF}$ No. 1 mice of the same age and weight distribution as described previously.

Examination of the data derived from the first two experiments (Tables 1 and 2) shows that, for the most part, a higher percentage of animals survived in all groups deuterated to the 8-10 and 15-18 atom-per cent levels than in the non-deuterated mice. The increase in the LD50's is of interest, although not of statistical significance in view of the limited number of animals employed. Conflicting results were obtained with animals deuterated to the 25-28 atom-per cent level, perhaps due to a slight variation in the deuteration level because of this being the region in which the toxic effects of heavy water are multiplied rapidly.

It is quite obvious that an experiment involving deuteration and irradiation can be carried out in a considerable number of ways. An experiment was therefore conducted in an

Table 1

EFFECT OF DIFFERENT BODY LEVELS OF DEUTERIUM ON. SURVIVAL FOLLOWING VARYIING DOSES OF TOTAL-BODY X RADIATION.

\begin{tabular}{c|c|c|c|r}
\hline \multirow{2}{*}{$\begin{array}{c}\text { Radiation } \\
\text { dose } \\
\text { (rads) }\end{array}$} & \multicolumn{4}{|c}{ Deuteration (\%) } \\
\cline { 2 - 5 } & 0 & $8-10$ & $15-18 \cdot$ & $25-28$ \\
\hline \multirow{3}{*}{550} & 90 & 100 & 100 & 100 \\
600 & 100 & 90 & 70 & 50 \\
650 & 60 & 90 & 90 & 60 \\
700 & 40 & 70 & 70 & 60 \\
750 & 10 & 40 & 50 & 40 \\
\cline { 2 - 5 } & & \multicolumn{4}{|c}{ Survival (\%) } \\
\hline
\end{tabular}


Table 2

EFFECT OF DIFFERENT BODY LEVELS OF DEUTERIUM

ON. SURVIVAL FOLLOWING VARYING DOSES

OF TOTAL-BODY X RADIATION

\begin{tabular}{|c|c|c|c|c|}
\hline \multirow{2}{*}{$\begin{array}{c}\text { Radiation } \\
\text { dose } \\
\text { (rads) }\end{array}$} & \multicolumn{4}{|c|}{ Deuteration (\%) } \\
\hline & 0 & $8-10$ & $15-18$ & $25-28$ \\
\hline & \multicolumn{4}{|c|}{ Survival (\%) } \\
\hline 700 & 20 & 50 & 60 & 0 \\
\hline 750 & 20 & .20 & 40 & 0 \\
\hline 800 & 0 & 0 & 20 & 0 \\
\hline
\end{tabular}

attempt to establish a schedule of deuteration that would give maximum protection agáinst $X$ irradiation. The animals in 4 groups each received a dose of 750 rads total-body radiation: group 1, 20 mice were given ordinary water at all times; group 2, 10 mice were maintained at a constant body water deuterium content of 23-26.6 atom-per cent throughout the experiment; group 3,10 mice were maintained at a constant body water deuterium content of 23-26.6 atom-per cent before irradiation and thereafter until 4 days postirradiation, after which time they were given ordinary water; group 4, 10 mice were maintained at a constant body water deuterium content of 23-26.6 atom-per cent before irradiation, immediately after which they were given ordinary water. The results of this experiment are illustrated by Figure 3. The findings indicate that those animals did best ( 30 per cent survival) that were deuterated before irradiation and for 4 days afterwards. The control mice had 15 per cent survival. Groups 2 and 4 suffered 100 per cent mortality after 18 days.

\section{DISCUSSION}

In the course of the present work we have verified and extended many of the classical observations of Barbour concerning the effects of deuterium in the mammalian organism. In view of the confusion that exists in the literature dealing with the biologic effects of deuterium, we consider such verification important. Deuterium has been shown to be easily absorbed, to be toxic at elevated concentrations, and to be fixed slowly in stable, non-exchangeable positions of compounds present in tissues. In short-term experiments, mice may be deuterated to the 25 atom-per cent level before acute symptomis appear. In the 30 to 35 atom-per cent region the animal dies.

On the basis of our studies there appears to be. a fairly abrupt transition from the asymptomatic state, at 20-25 atom-per cent, to the severe reaction manifested above 30 atom-per cent. In a large organism this 5 per cent difference may actually represent a sizeable margin of safety. 


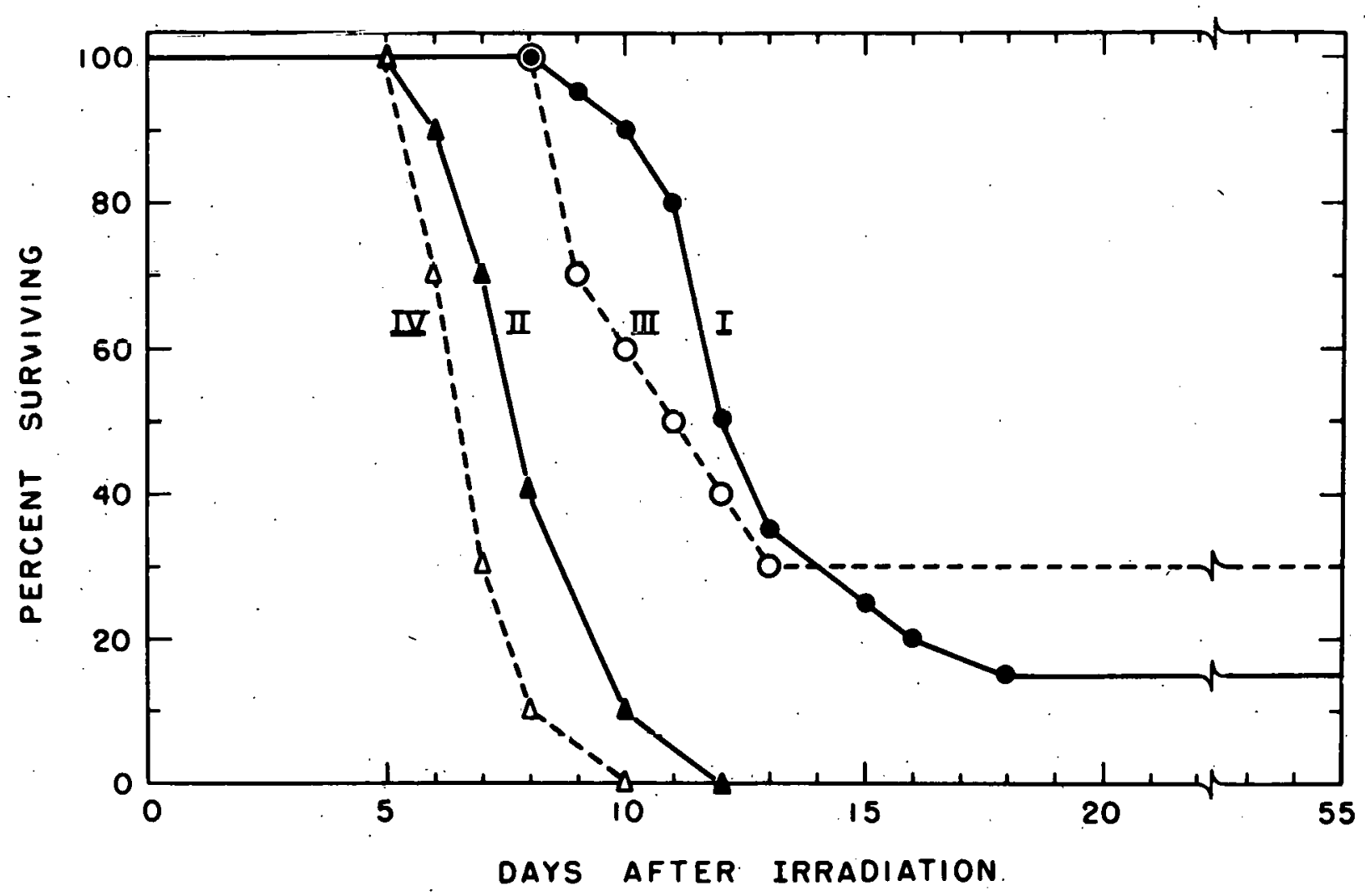

Figure 3. Effect of deuteration on survival of mice exposed to 750 rads total-body $\mathrm{X}$ irradiation. Curve I, $\mathrm{H}_{2} \mathrm{O}$-fed control mice. Curve II, mice maintained at 23 to 26.6 atom-per cent deuterium from time of irradiation until death. Curve III, mice maintained on deuterium oxide until 4 days after irradiation, then given $\mathrm{H}_{2} \mathrm{O}$. Curve IV, mice transferred from $\mathrm{D}_{2} \mathrm{O}$ to $\mathrm{H}_{2} \mathrm{O}$ immediately after irradiation.

Except for a few early experiments by Barbour, ${ }^{4}$ little has been done on the survival of animals maintained for long periods of time at and below concentrations of 25 atom-per cent. It is mandatory that the chronic effects of deuteration be explored fully before a clear assessment of the toxic nature of deuterium can be made.

In animals that have been killed by deuteration, we have observed extensive lesions in the kidney. At lower levels of deuteration, however, there appeared to be no significant impairment either of renal function or of kidney metabolism. Disturbances of the central neryous system, primarily hyperexcitability, became manifest at levels between 20 and 25 atom-per cent. Although the role of the central nervous system in the death of the animal is uncertain, there may be a relationship between the terminal narcosis and the lowered blood glucose.

The relation between deuteration and radiosensitivity is exceedingly complex. In certain experiments we have observed that deuterium effects a slight prolongation of the life span of irradiated mice. An interest in this aspect of the subject derives from the possibility of modifying the effect of $\mathrm{X}$ irradiation by deuteration. From a consideration of fundamental principles it is reasonable to anticipate that deuteration may alter sensitivity to 
other varieties of radiation as well. Many possibilities exist for combining deuteration with compounds of pharamacologic interest.

At levels below the toxic limit, deuteration has been observed to retard neoplastic growths in mice.

In an experiment in which P1534 lymphatic leukemia was introduced into leukemiasusceptible mice, a slight but probably significant increase in life span was noted in the deuterated animals. It would seem from these results that rapidly metabollzing tissues are more susceptible to the inhibitory action of deuterium than the more slowly metabolyzing tissues of the animals.

It would be easy to exaggerate the carcinocidal action of deuterium. Nevertheless, in our opinion, the deuterium isotope effect does present a relatively unexplored and promising approach to the control of these pathologic entities. In point of fact, there does appear to be a demonstrable difference in response to deuterium of neoplastic as compared with normal tissue. Despite the absence of detailed knowledge as to the way in which the deuterium isotope substitution, even if only to a limited extent, is one of the few ways in which the total body of an organism can be changed. The consequences of such isotopic replacement can be far reaching, and may serve to magnify the metabolic differences existing between normal and neoplastic tissue. In this sense, we consider isotopic substitution, particularly deuteration, as a promising approach.

\section{SUMMARY}

1. A simple infrared spectrophotometric method, developed by Drs. J. J. Katz and H. L. Crespi, was employed for the analysis of deuterium in biological media.

2. Satisfactory schedules for the achievement of pre-determined levels of deuteration have been worked out.

3. Symptoms of deuterium intoxication in mice include weakness, neuromuscular hyperexcitability, bradycardia, and eventually, stupor and death; these symptoms occur at body deuteration levels of 30 to 35 atom-per cent.

4. Deuteration of mice resulted in reduced growth rates of inoculated P1534 lymphatic leukemia.

5. At certain levels of deuteration, the sensitivity of mice to. $\mathbf{X}$ irradiation was decreased slightly.

\section{ACKNOWLEDGMENT}

We wish to express our sincere thanks to Drs. Joseph J. Katz and H. L. Crespi for developing the infrared spectrophotometric method that we used to determine some of the biologic effects of deuterium, to Dr. Louis Kaplan for analyses of the tritium content of deuterium oxide, and to Drs. Asher Finkel and John F. Thompson for their interest and aid. 


\section{LITERATURE CITED}

1. Smith, P. K., J. Trace, and H. G. Barbour. J. Biol. Chem., 116:317, 1936.

2. Barbour, H. G. and E. Allen. Am. J. Cancer, 32:440, 1938.

3. Barbour, H. G. and J. Trace. J. Pharm. Exper. Therap., 58:460, 1936.

4. Barbour, H. G. Yale J. Biol. Med., 9:551, 1937.

5. Dybing, O., G. Guldberg, and K. Hansen. Klin. Wochschr., 17:1585, 1938.

6. Simmons, E. L. and L. O. Jacobson. Argonne Cancer Research Hospital Semiannual Report to the AEC, ACRH-2, p. 97, 1954.

7. Hart, E. J., W. R. McDonell, and S. Gordon. Proc. Inter. Congress on the Peaceful Uses of Atomic Energy, Vol. 7, p. 593. Geneva, 1955.

8. Brues, A. M. Personal Communication, July, 1955. 


\section{THE EFFECT OF CELL SUSPENSIONS UPON THE DEVELOPMENT OF CATARACTS IN IRRADIATED MICE*}

By

F. W. Newell, ${ }^{\dagger}$ T. C. Beaman, ${ }^{\dagger}$ L. O. Jacobson, E. K. Marks, and E. O. Gaston

Cysteine, administered parenterally to rats prior to total-body $\mathbf{X}$ irradiation, has been reported by Patt and his co-workers ${ }^{1}$ to increase the survival of the treated animals, whereas sodium chloride given prior to irradiation, or cysteine given afterwards does not. Von Sallmann ${ }^{2}$ has described a deterrent effect of cysteine administered intravenously to rabbits before a single exposure of $1500 \mathrm{r}$ delivered to the eye: Jacobson and his associates ${ }^{3}$ and Lorenz et al. ${ }^{4}$ have described the significant effect of hematopoietic cell suspensions or tissue transplants administered subsequent to $X$ irradiation upon the survival of rats, mice, and rabbits. There have been no reports suggesting that such postirradiation treatment might influence the development of cataracts.

It was observed that postirradiation treatment with mouse embryo cells appeared to significantly decrease the development of cataracts in a single group of mice that had been exposed to $750 \mathrm{r}$ total-body $X$ radiation as part of a long-term study of radiation injury. The investigation described in this paper was conducted to learn whether the injection of cellular substances after irradiation might modify the development of cataract.

\section{MATERIALS AND METHODS}

CF No. 1 female mice, each weighing about $22 \mathrm{~g}$, were used as the recipient animals. The cells for postirradiation injection were obtained from the tissues of CF No. 1 mouse embryos or from baby mouse spleen, livers, or bone marrow. The donor mice were killed by cervical fracture. Embryo tissue was obtained by making a median incision in the abdominal cavity of the pregnant mouse, removing the entire embryonic sac and placing it in cold Locke's solution. The livers and spleens were then removed from the embryos, and a homogeneous cell suspension was produced by repeatedly drawing the mixture into a 2-cc. syringe and expelling it. The number of nucleated cells per cu $\mathrm{mm}$ was determined by making a dilution with $2 \%$ acetic acid in $a^{\prime}$ white blood-counting pipette and counting the cells in a standard hemocytometer. Cell suspensions were diluted with Locke's solution so that each $0.5 \mathrm{cc}$ contained the required number of cells. All injections were made a few minutes after the cell suspensions had been prepared and within 4 hours after irradiation. Cells from the baby mouse tissues and bone marrow were prepared in a similar

\footnotetext{
* Accepted for publication in the American Medical Association Archives of Ophthalmology.

+ From the Department of Surgery (Ophthalmology), The University of Chicago.
} 
manner.

Mice were subjected to a total-body $X$ irradiation ranging between 800 and $975 \mathrm{r}$ before administration of the cell suspensions. Nonirradiated mice and mice that were spleenshielded and body-shielded during irradiation served as controls. $X$ rays were generated by 250-Kvp Maxitron machine operating at $30 \mathrm{ma}$. A $1.0-\mathrm{mm}$. Al and a $0.25-\mathrm{mm}$. Cu filter were used. The half-value layer in copper of the filtered beam was $1.04 \mathrm{~mm}$. The exposure rate averaged 63:8 $\mathrm{r}$ per minute. at a distann.e of $7.9 \mathrm{rm}$.

The pupils were dilated with $2 \%$ homotropine hydrobromide solution, and the lenses examined by means of a Zeiss slit-lamp. The treatment to which the animals had been subjected was unknown to the observer. However, the animals were presented in turn from a given cage so that animals receiving the same treatment were presented in groups of 6 to 12 , depending upon survival rates.

The severity of cataract was graded according to the scheme of Christenberry and Furth. Values ranged from 0 for a transparent lens to 4 for a complete cataract. Thus, bilateral complete lens opacities constituted a severity of 8 . The severity of cataract in each treatment group was then averaged.

At the suggestion of Professor Leonard J. Savage* animals were divided into two groups: no cataract (a severity of 3 or less) and cataract (a severity of 4 or more). It was believed this would reveal intra-group differences in the event that the cell treatment combined with some unknown (and entirely postulated) physiologic or environmental factor to modify the development of radiation-induced cataract.

Table 1 gives the results obtained from the first series of mice whose lenses were graded at 10 to 12 months following irradiation. A possible deterrent effect caused by the injection of 0.3 to $0.75 \times 10^{6}$ embryo cells and 0.5 to $3.5 \times 10^{6}$ spleen cells was suggested by both the mean severity of cataract and the division of animals into cataract and noncataract groups.

In the second study, the animals were examined before irradiation to eliminate all with cataract or other ocular anomalies. In addition to the postirradiation administration of cells, the body or the spleen of the mouse was shielded. The lenses of the se animals were studied 5 months after irradiation, and the results are given in Table 2.

The data indicate that there is a fairly wide range in the rate of development of cataract under the conditions of the experiment. It is evident, however, that the administration of cell suspensions does not modify the development of radiation-induced cataract. A study of the lenses of all mice that had received cell suspensions during the period of study indicated an absence of protective effect upon the lenses.

\section{DISCUSSION}

The chance observation of the failure of cataracts to develop in mice that had survived a lethal and cataract-inducing exposure to radiation after being treated with cell

Chairman of the Committee on Statistics, The University of Chicago, Chicago, Ill. 
Table 1

AVERAGE SEVERITY OF CATARACT IN MICE STUDIED 10 TO 12 MONTHS FOLLOWING A SINGLE EXPOSURE TO $750 \mathrm{r}$

\begin{tabular}{|c|c|c|c|c|c|}
\hline $\begin{array}{c}\text { Number } \\
\text { of cells } \\
\text { injected } \\
\times 10^{6}\end{array}$ & Treatment & $\begin{array}{l}\text { Number } \\
\text { in group }\end{array}$ & $\begin{array}{c}\text { Average } \\
\text { severity } \\
\text { of } \\
\text { cataract }\end{array}$ & $\begin{array}{c}\text { Number } \\
\text { with } \\
\text { cataracts }\end{array}$ & $\begin{array}{c}\text { Number } \\
\text { without } \\
\text { cataracts }\end{array}$ \\
\hline $0.3-0.75$ & Embryo cells & 4 & $13 / 7$ & 1 & 3 \\
\hline$\ldots \ldots$ & Spleen shielded & 6 & $73 / 5$ & 6 & 0 \\
\hline $1.5-5.0$ & Bone marrow cells & 9 & $71 / 9$ & 9 & 0 \\
\hline 9.0 & Embryo cells & 7 & $72 / 7$ & 7 & 0 \\
\hline $0.75-1.5$ & 2-day liver cells & 2 & $71 / 2$ & 2 & 0 \\
\hline 1.3 & Liver cells & 3 & $72 / 3$ & 3 & 0 \\
\hline 2.1 & Spleen cells & 2 & 8 & 2 & 0 \\
\hline $0.07-0.27$ & Embryo cells & 9 & $35 / 9$ & 6 & 3 \\
\hline 2.5 & Bone marrow cells & 5 & $63 / 5$ & 4 & 1 \\
\hline 3.5 & Spleen/liver cells & 7 & 6 & 7. & 0 \\
\hline 0.5 & Liver cells & 8 & 7 & 8 & 0 \\
\hline$\ldots . .$. & None - control & 10 & 0.6 & 0 & 10 \\
\hline 3.5 & Liver cells & 5 & $71 / 5$ & 5 & 0 \\
\hline 0.5 & Bone marrow cells & 2 & 4 & 2 & 0 \\
\hline $0.5-3.5$ & Spleen cells & 9 & $25 / 9$ & 3 & 6 \\
\hline
\end{tabular}

suspension led to this study. Since it is known that pretreatment with cysteine enhances survival and minimizes the development of cataract, it was postulated that postirradiation injections of cell suspensions might have a similar effect. However, the lenses were not found to be protected under these circumstances.

Investigation revealed that the animals that failed to develop cataracts were all irradiated upon the same day. Although their survival rates were similar to other irradiated and treated animals, an experimental artifact seems to be the most likely explanation.

\section{SUMMARY}

The postirradiation administration of various cell suspensions that have been found . to be effective in prolonging the lives of lethally-irradiated mice does not protect the animals against the development of cataract. 
Table 2

AVERAGE SEVERITY OF CATARACT IN MICE STUDIED

5 MONTHS FOLLOWING IRRADIATION

\begin{tabular}{c|c|c|c|c|c}
\hline $\begin{array}{c}\text { Number of } \\
\text { embryo liver } \\
\text { cells injected } \\
\text { X106 }\end{array}$ & Treatment & $\begin{array}{c}\text { Number } \\
\text { in group }\end{array}$ & $\begin{array}{c}\text { Average } \\
\text { severity } \\
\text { of } \\
\text { cataract }\end{array}$ & $\begin{array}{c}\text { Number } \\
\text { with } \\
\text { cataracts }\end{array}$ & $\begin{array}{c}\text { Number } \\
\text { without } \\
\text { cataracts }\end{array}$ \\
\hline $\begin{array}{l}\text { Control: Body } \\
\text { shielded, Locke's } \\
\text { solution (800 r) } \\
\text { Control: Spleen } \\
\text { shielded, normal } \\
\text { saline (975 r) } \\
\text { Body shielded, } \\
\text { mouse embryo } \\
\text { cells (800 r) } \\
\begin{array}{l}\text { Not irradiated } \\
\text { Spleen shielded, } \\
\text { mouse embryo } \\
\text { cells (975 r) }\end{array}\end{array}$ & 47 & 4.13 & 27 & 10 \\
\hline
\end{tabular}

\section{LITERATURE CITED}

1. Patt, H. M., E. B. Tyree, R. L. Straube, and D. E. Smith. Science, 110:213, 1949.

2. Von Sallman, L. A.M.A. Arch. Opthal., 47:309, 1952.

3. Jacobson, L. O. Cancer Research, 12:315, 1952.

4. Lorenz, E., D. Uphoff, T. R. Reid, and E. Shelton. J. Nat. Cancer Inst., 12:197, 1951.

5. Christenberry, K. W. and J. Furth. Proc. Soc. Exper. Biol. \& Med., 77:559, 1951. 


\section{HORMONES IN HUMAN REPRODUCTION.}

\section{METABOLISM OF PROGESTERONE*}

\section{By}

M. E. Davis, ${ }^{\dagger}$ E. J. Plotz, ${ }^{\dagger}$ G. V. LeRoy, R. G. Gould, ${ }^{\ddagger}$ and H. Werbin

The biosynthesis and metabolism of progesterone during pregnancy were studied by employing radioactive compounds. A study of possible palliways of thc hormonal metahnlites after administration of labeled progesterone was also part of this investigation. The rate of local synthesis of an important precursor of steroid hormones, cholesterol, within maternal and fetal endocrine glands was evaluated by in vivo experiments.

$\mathrm{C}^{14}-1$-acetate, with a specific activity of $1 \mathrm{mc}$ per $\mathrm{ml} ; \mathrm{H}^{3}$-labeled cholesterol, with a specific activity of $7.3 \mu \mathrm{c}$ per $\mathrm{mg}$; and $\mathrm{C}^{14}-4$-progesterone, with a speclfic activity of $7.33 \mu \mathrm{g}$ per $\mathrm{mg}$, were the radiotracers that were given to patients who were scheduled for therapeutic abortions. The content of cholesterol in plasma and tissue was determined and radioassayed by the methods described by Gould et al. ${ }^{1}$ Pure steroids were isolated from the urine by means of a modification of the methods of Dobriner and his associates, Davis and Plotz, ${ }^{3}$ and Axelrod. ${ }^{4}$ : The radioactivity of at least one derivative was examined and compared with that of the free steroid. In some experiments, cholesterol and the steroid samples were counted as infinitely thick samples, using a windowless flow counter; in others, in a liquid scintillation counter. Tissue, feces, and body fluids were combusted to carbon dioxide in a vacuum combustion line and counted in an ionization chamber, using a vibrating reed electrometer.

After the administration of $\mathrm{C}^{14}$-1-acetate, tritium-cholesterol, and $\mathrm{C}^{14}$-4-progesterone, radioactive pregnane-3(a),20(a)-diol was recovered from the urine of pregnant patients. In addition, $\mathrm{C}^{14}$-labeled pregnane-3( $a$ ) ol, 20-one was isolated from the urine after the administration of radioactive progesterone. A diagrammatic representation of the metabolic pathway of progesterone in human pregnancy is shown in Figure 1. The conversion of cholesterol to progesterone has not yet been demonstrated in vivo, however, the perfusion of human placentas with $\mathrm{C}^{14}$-labeled cholesterol from the fetal side resulted in the appearance of radioactive progesterone in the perfusate. ${ }^{5}$ In view of this finding, it seems reasonable to assume that this scheme is correct. A rough calculation revealed that about

* Summary of a paper that appears in the American Journal of Obstetrics and Gynecology, 72:740 (1956). This work was supported in part by the Douglas Smith Foundation for Medical Research and the Joseph Bolivar De Lee Memorial Trust.

$\dagger$ The Department of Obstetrics and Gynecology, The University of Chicago.

‡ Los Alamos Scientific Laboratory, Los Alamos, New Mexico. 

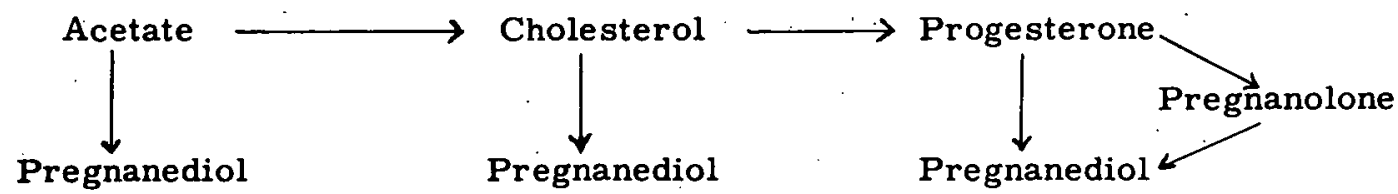

Figure 1. Liagram of the metabolic pathway of progesterone in human pregnancy.

two-thirds of the urinary pregnane-3(a),20(a)-diol was derived from plasma cholesterol.

After the intramuscular administration of labeled progesterone to two pregnant patients, about 25 and 53 per cent, respectively, of the administered radioactivity were excreted into the urine during the respective ensuing 13 and 10 days. The rate of elimination of urinary metabolites was fastest about 24 hours after the injection of the tagged progesterone (Figure 2). About 28.5 per cent of the administered radioactivity was recovered from the feces obtained during 10 days following the administration of progesterone (Table 1). Only negligible amounts of radioactivity were found in the fatty surface film removed during the 48 hours after injection of the hormone.

When tagged progesterone was injected intramuscularly into a woman during the 11 th

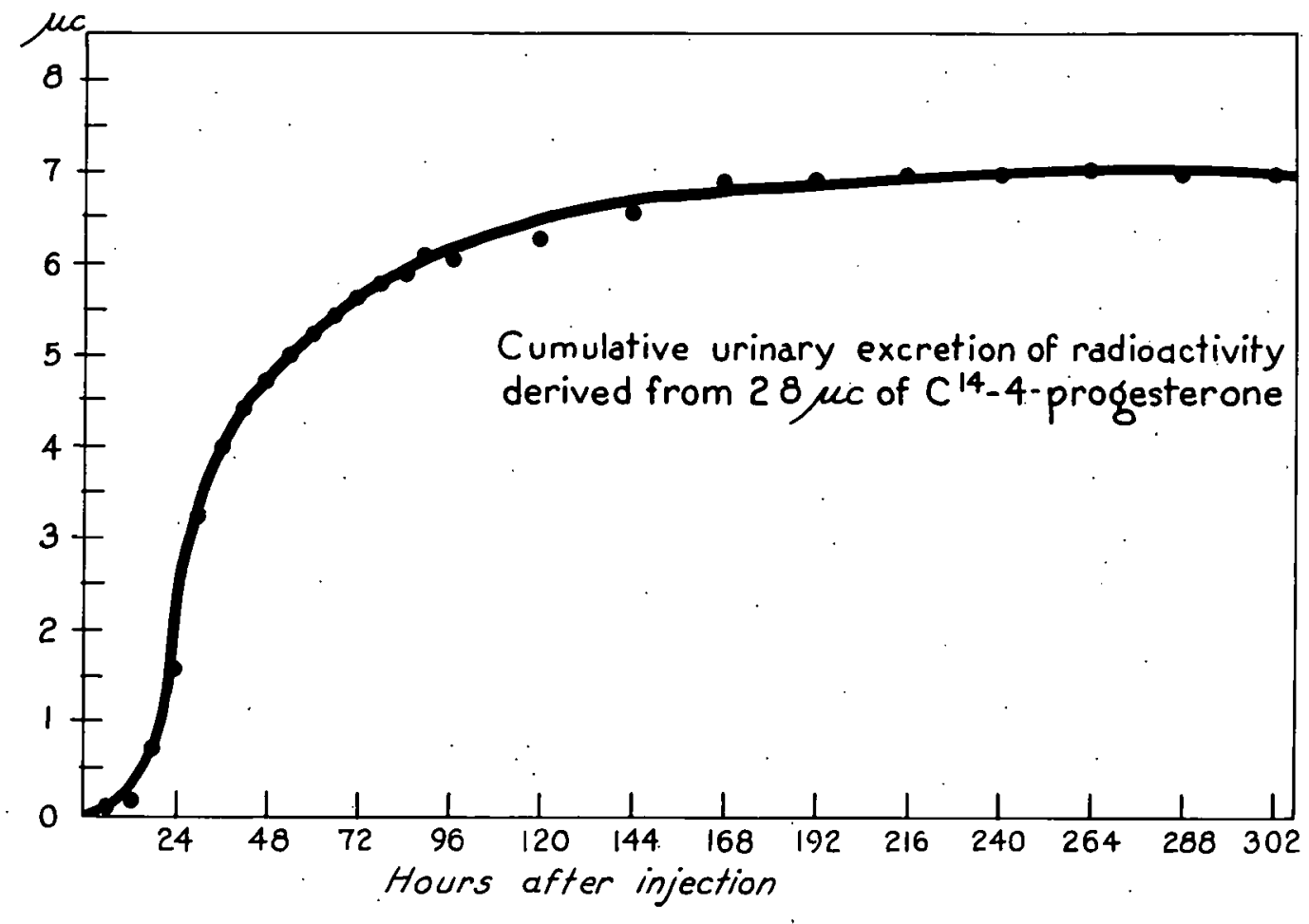

Figure 2. Cumulative urinary excretion of radioactivity derived from $28 \mu c$ of $\mathrm{C}^{14-4-p r o g e s t e r o n e ~ a d m i n i s t e r e d ~ i n t r a m u s c u l a r l y . ~}$ 
Table 1

RADIOACTIVITY FROM $\mathrm{C}^{14}$ FOUND IN THE FECES AFTER INTRAMUSCULAR ADMINISTRATION OF $\mathrm{C}^{14}-4$-PROGESTERONE

\begin{tabular}{|c|c|c|c|}
\hline $\begin{array}{l}\text { Stool specimen } \\
\text { number }\end{array}$ & $\begin{array}{l}\text { Time interval } \\
\text { between injection } \\
\text { and defecation }\end{array}$ & $\begin{array}{l}\text { Radioactivity } \\
(\mu \mathrm{c})\end{array}$ & $\begin{array}{l}\text { Per cent of injected } \\
\text { radioactivity }\end{array}$ \\
\hline 1 & 29 hours & 0.226 & 0.81 \\
\hline 2 & 32 hours & 1.556 & 5.56 \\
\hline 3 (enema) & 36 hours & 2.969 & 10.60 \\
\hline 4 (enema) & 10 days & 3.240 & 11.57 \\
\hline \multicolumn{2}{|l|}{ Total } & 7.991 & 28.54 \\
\hline
\end{tabular}

week of pregnancy, only very small amounts of radioactivity were found in the plasma (Figure 3). The peak activity was reached in the plasma after about 25 hours, and the pattern of the blood curve resembled closely that of the urine, although the absolute amount. of activity found in the plasma and urine differed considerably from each other. These findings suggested that 1) the radioactivity found in the plasma is derived principally from progesterone metabolites, and 2) progesterone entering the blood is eliminated rapidly from the plasma into other compartments.

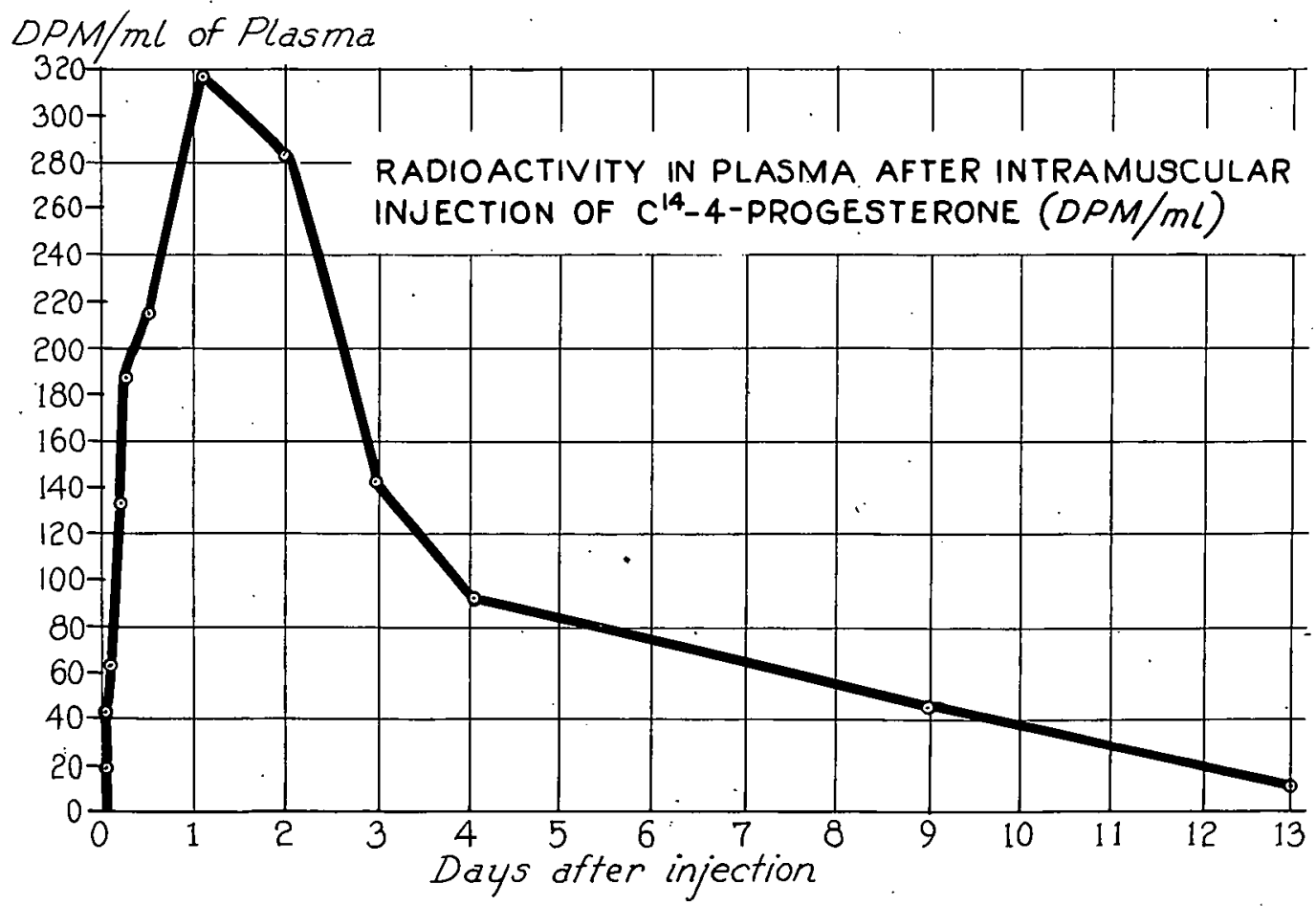

Figure 3 Radioactivity in plasma after intramuscular injection of $\mathrm{C}^{14-4-p r o g e s t e r o n e . ~}$ 
The rate of synthesis: of cholesterol within maternal and fetal glands was studied at various stages of pregnancy by methods that have been described previously by LeRoy et al. ${ }^{6}$ Some of these experiments have already been reported. ${ }^{7}$. The highest rate of local synthesis was found in the corpus luteum of pregnancy, exceeding that of the liver to a considerable extent. It was of great interest that the fast rate of local synthesis of cholesterol in the corpus luteum did not decline with the progress of pregnancy up to the 17 th to 19 th weeks (Table 2). It has generally been assumed that the function of this gland begins to regress at about the 10th week of pregnancy, when the placenta is fully developed. These experiments demonstrate that the corpus luteum is certainly capable of synthesizing cho- lesterol, an important hormonal precursor, at a fast rate during mid-pregnancy.

Table 2

SPECIFIC ACTIVITIES (IN DPM/mg) OF $\mathrm{C}^{14}$-CHOLESTEROL IN

PLASMA AND CORPORA LUTEA AFTER THE INTRAVENOUS ADMINISTRATION OF 200 MICROCURIES OF $\mathrm{C}^{14}-1$-ACETATE

\begin{tabular}{|c|c|c|c|c|}
\hline \multirow[b]{2}{*}{ Patient } & \multirow{2}{*}{$\begin{array}{l}\text { Weeks of } \\
\text { embryonic } \\
\text { life }\end{array}$} & \multirow{2}{*}{$\begin{array}{c}\text { Time } \\
\text { internal } \\
\text { (minutes) }\end{array}$} & \multicolumn{2}{|c|}{ Specific activities } \\
\hline & & & $\begin{array}{c}\text { Maternal } \\
\text { plasma }\end{array}$ & $\begin{array}{l}\text { Corpus } \\
\text { luteum }\end{array}$ \\
\hline 1 & 7 & 167 & 222 & 2,302 \\
\hline 2 & 12 & 147 & 716 & 3,520 \\
\hline 3 & 17 & 133 & 767 & 4.064 \\
\hline 4 & 18. & 131 & 791 & 6,293 \\
\hline 5 & 19 & 180 & 398 & 3,731 \\
\hline
\end{tabular}

There was also evidence of local synthesis of cholesterol in the fetal placenta. On the other hand, both the placenta and the corpus luteum absorbed maternal plasma cholesterol to a large extent as judged from the radioactivity in tissue cholesterol derived from dietary tritium-cholesterol (Table 3). Thus, cholesterol of local as well as of plasma origin is readily available for the synthesis of steroid hormones in these endocrine glands.

These experiments revealed further that the fetal liver and adrenals of young normal fetuses are capable of synthesizing cholesterol from acetate. However, only small amounts of maternal plasma cholesterol crossed the placental barrier as evidenced by the low specific activities of cholesterol derived from dietary tritium-cholesterol in the fetal liver, adrenals, heart, lungs, skin and brain. Apparently, the fetus is able to synthesize its own cholesterol and it does not depend upon the transfer of maternal cholesterol.

In contrast, the liver and adrenals of an anencephalic infant were incapable of synthesizing cholesterol from acetate to an appreciable extent, but absorbed maternal plasma cholesterol at a high rate (Figure 4). This double-label experiment was carried out when 
the mother was in spontaneous labor after 34 weeks of pregnancy. It is well known that the morphology of the adrenal glands of anencephalics differs considerably from that of adrenal glands of the normal fetus.

Table 3

SPECIFIC ACTIVITIES (IN DPM/mg) OF TRITIUM-CHOLES-

TEROL' IN PLASMA, CORPORA LUTEA, AND FETAL

PLACENTAS AFTER THE ORAL ADMINISTRATION

OF TRITIUM-CHOLESTEROL OVER A PROLONGED. PERIOD

\begin{tabular}{c|c|c|c}
\hline \multirow{2}{*}{$\begin{array}{c}\text { Week of } \\
\text { embryonic } \\
\text { life }\end{array}$} & $\begin{array}{c}\mid c \\
\text { Maternal } \\
\text { plasma }\end{array}$ & $\begin{array}{c}\text { Corpus } \\
\text { luteum }\end{array}$ & $\begin{array}{c}\text { Fetal } \\
\text { placenta }\end{array}$ \\
\cline { 2 - 4 } & 3,299 & 3,401 & 4,038 \\
17 & 12,801 & 13,272 & 8,566 \\
19 & 2,980 & 3,230 & 2,678 \\
\hline
\end{tabular}

DOUBLE LABEL EXPERIMENT

ANENCEPHALIC FETUS-34 WEEKS - SPONTANEOUS DEL.

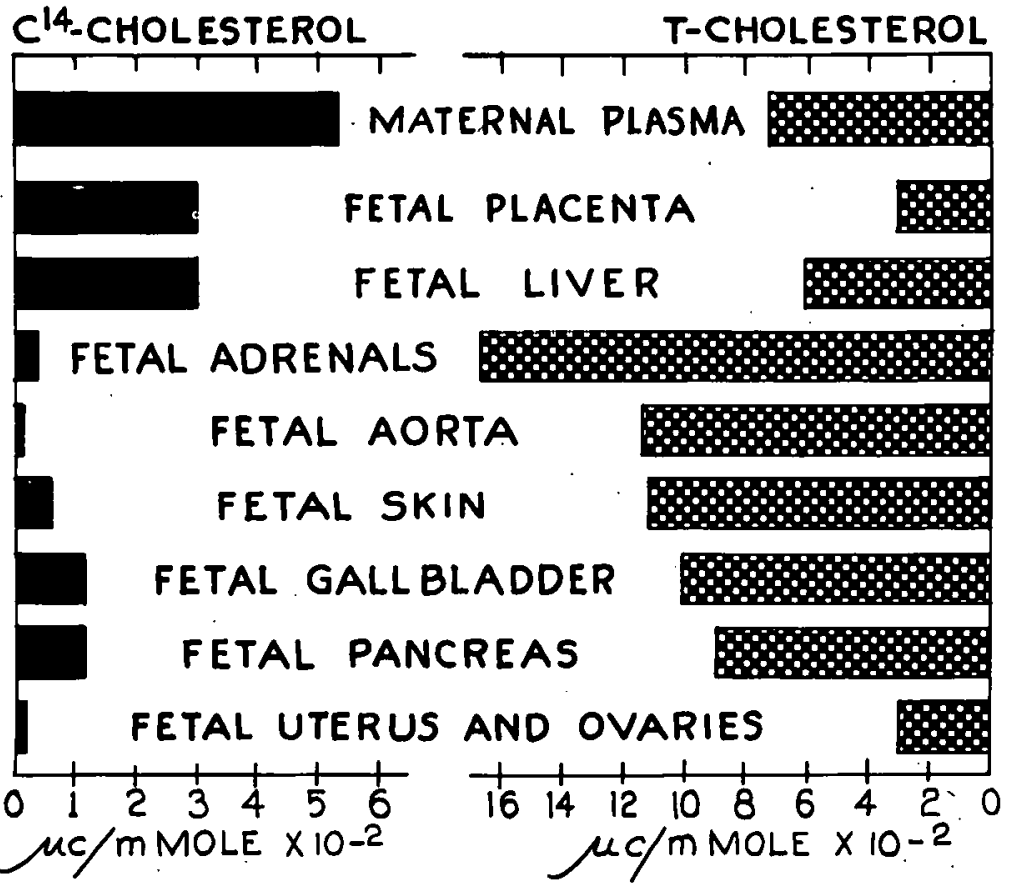

Figure 4. The results of a double-label experiment in which the synthesis of cholesterol from $\mathrm{C}^{14}$-acetate and the absorption of tritium-cholesterol were studied in the tissue of an anencephalic infant. 


\section{LITERATURE CITED}

1. Gould, R. G., G. V. LeRoy, G. T. Okita, J. J. Kabara, P. Keegan, and D. M. Bergenstal. J. Lab. Clin. Med., 46:359, 1955.

2. Dobriner, K., S. Lieberman, and C. P. Rhoads. J. Biol. Chem., 162:241, 1948.

3. Davis, M. E. and E. J. Plotz. Acta Endocrinol., 21:254, 1956.

4. Axelrod, L. R. Report of the University of Rochester Atomic Energy Project, UR-256, April 28, 1956 .

5. Solomon, S., A. L. Lenz, R. VandeWiele, and S. Lieberman, 126 th Meeting Am. Chem. Suc., New York, Sept. 12-17, 1954.

6. LeRoy, G. V., R. G. Gould, G. T. Okita, J. J. Kabara, and D. M. Bergenstal. Manuscript in preparation.

7. Plotz, E. J. Argonne Cancer Research Hospital Semiannual Report to the Atomic Energy Commission, ACRH-4, p. 30, 1955. 
HORMONES IN HUMAN REPRODUCTION. II. RADIOACTIVITY IN MATERNAL

AND FETAL TISSUES FOLLOWING INTRAMUSCULAR ADMINISTRATION OF $\mathrm{C}^{14}-4$-PROGESTERONE*

By

\author{
E. J. Plotz, M. E. Davis, G. T. Okita, and G. V. LeRoy**
}

A rapid increase in the excretion of pregnanediol and pregnanolone is observed during the second trimester of human pregnancy. This reaches a peak of 60 to $90 \mathrm{mg}$ per 24 hours shortly before delivery. Both steroids are regarded as the principal metabolites of progesterone. The plasma concentration of progesterone, however, does not parallel the rapid increase in urinary metabolites. The hormone is found only at very low concentrations in the plasma, ranging from 0.039 to $0.268 \gamma$ per $\mathrm{ml}$ during the 4 th through the 9 th month of pregnancy. ${ }^{1}$ This observation raised some doubt whether pregnanediol and pregnanolone excreted into the urine during pregnancy are actually the metabolic products of progesterone. On the other hand, their appearance could be explained by the assumption that progesterone disappears quite rapidly from the circulating blood in pregnancy. The latter explanation seemed to be more likely since Klein and Ober ${ }^{2}$ were not able to increase the plasma concentration of progesterone (as determined by the HookerForbes test) in the plasma of pregnant women by the intramuscular administration of very large doses of progesterone (1000 to $1200 \mathrm{mg}$ ) although urinary pregnanediol was excreted in relatively large amounts following such an injection.

Our studies ${ }^{3}$ revealed that after the intramuscular administration of $\mathrm{C}^{14}$-4-progesterone during the 11 th and 17 th weeks of pregnancy, the concentration of radioactivity in the plasma rose sharply to a peak value within 24 hours and declined more slowly thereafter over a period of 9 to 12 days. The peak concentration of radioactivity appeared in the urine at the same time. The curve for concentration in the plasma resembled closely that found for urinary samples obtained at frequent intervals after the injection of the labeled hormone. In view of this parallelism and the observation of Klein and Ober, it appeared reasonable to assume that the rise in the concentration of radioactivity in the plasma was due to an increase in the concentration of metabolites rather than to an increase in the hormone itself.

Substantial amounts of radioactivity derived from injected $\mathrm{C}^{14}-4$-progesterone are eliminated via the feces ${ }^{3}$ after having been secreted into the gastrointestinal tract by way

* This study was supported in part by the Douglas Smith Foundation for Medical Research, the Argonne Cancer Research Hospital, and the Joseph Bolivar De Lee Trust of the University of Chicago.

With the technical assistance of G. Struver and F. D. Smith, Jr. 
of the bile. ${ }^{4}$ Approximately 10 per cent of the administered radioactivity was recovered from one of our pregnant patients after an enema was given 36 hours following the administration of the labeled hormone. A total of 28.5 per cent of the injected dose of radioactivity was found in the feces during a 10-day period following injection.

However, a prompt excretion of the inactivation products of progesterone into the urine and feces does not fully account for the fact that large intramuscular doses of progesterone do not raise the plasma level of the hormone during pregnancy. The intravenous administration of progesterone is followed by a rapid decline in the concentration in the plasma within 2 hours. ${ }^{5}$ No progesterone could be detected in the plasma 24 hours after the injection by this route. Despite this, pregnanediol is excreted over a period of several days after intravenous injection. ${ }^{6,7}$ There is no fundamental difference between the excretion pattern of pregnanediol in the urine after the intramuscular or the intravenous injection of progesterone-an indication that the absorption of the hormone from an oily intramuscular depot must be a fast and efficient process. *

Taking these observations into consideration, it was assumed that progesterone secreted into circulating blood from a gland or absorbed from an oily depot in the muscle diffuses rapidly into the tissue from which it is released back into the circulation more slowly, and is subsequently excreted in the form of its metabolites by the kidney and the liver.

The experiments described below were undertaken to study this possibility by determining the distribution of radioactivity in maternal and fetal tissues that were removed at various intervals following the intramuscular injection of $\mathrm{C}^{14}-4$-progesterone.

\section{METHODS AND RESULTS}

$\mathrm{C}^{14}$-4-progesterone was prepared by the method of Thompson et al.$^{9}$ and purified by chromatography on alumina. It was administered intramuscularly to three pregnant women. Therapeutic abortions were performed at various time intervals after the injection. Maternal and fetal tissue obtained at surgery were combusted to carbon dioxide in a vacuum combustion line and counted in an ionization chamber, using a vibrating reed electrometer according to the method of Brownell and Lockhart. ${ }^{10}$ All measurements were done for periods long enough to give a standard error of less than \pm 5 per cent.

Patient C.C.

This patient (gravida III, para II) was 37 years old and had a severe bronchial asthma that required almost constant medical care. Seven months before she became pregnant she was found to have hyperthyroidism. Treatment with $\mathrm{I}^{131}$ and propylthiouracil resulted in a good therapeutic response, but did not alter the asthmatic condition. The patient was 11 weeks pregnant when $28.1 \mu \mathrm{c}$ of $\mathrm{C}^{14}-4$-progesterone was injected intramuscularly,

This is likewise true for estrogens since there is no difference between the daily amounts of radioactivity excreted into the urine after intramuscular and intravenous injection of $\mathrm{C}^{14-\text { labeled-estrogens. }}$ 
48 hours before the abortion was performed. The distribution of radioactivity found in maternal and fetal tissue is shown in Table 1. The results are expressed in microcuries per gram of tissue. Table 1 also gives the percentage of the administered dose of radioactivity found in the various organs.

Table 1

RADIOACTIVITY IN MATERNAL AND FETAL TISSUE

Dose of $\mathrm{C}^{14}-4$-progesterone $\quad 28.1 \mu \mathrm{C}$

Method of administration Intramuscular injection

Interval between injection
and therapeutic abortion

Length of pregnancy 11 weeks

\begin{tabular}{|c|c|c|c|c|}
\hline Tissue & $\begin{array}{l}\text { Weight } \\
\text { (g) }\end{array}$ & $\begin{array}{r}\mu \mathrm{c} / g \\
\times 10\end{array}$ & $\begin{array}{l}\mu c / \text { organ } \\
\times 10^{-6}\end{array}$ & $\begin{array}{l}\text { Per cent of administered } \\
\text { radioactivity in organ }\end{array}$ \\
\hline $\begin{array}{l}\text { Corpus luteum } \\
\text { Rest of ovary } \\
\text { Decidua } \\
\text { Myometrium } \\
\text { Fat } \\
\text { Skin }\end{array}$ & $\begin{array}{l}3.67 \\
2.58 \\
- \\
- \\
- \\
-\end{array}$ & $\begin{array}{r}153 \\
45 \\
170 \\
368 \\
845 \\
72\end{array}$ & $\begin{array}{c}562 \\
116 \\
- \\
- \\
- \\
-\end{array}$ & $\begin{array}{c}0.002 \\
<0.001 \\
- \\
- \\
19.6 * \\
-\end{array}$ \\
\hline $\begin{array}{l}\text { Placenta } \\
\text { Liver } \\
\text { Lungs } \\
\text { Heart } \\
\text { Intestine } \\
\text { Brain }\end{array}$ & $\begin{array}{l}46 \\
0.62 \\
0.25 \\
0.12 \\
0.46 \\
1.85\end{array}$ & $\begin{array}{r}52 \\
26 \\
10 \\
14 \\
11 \\
0\end{array}$ & $\begin{array}{r}2392 \\
16 \\
3 \\
2 \\
5 \\
-\end{array}$ & $\begin{array}{r}0.008 \\
<0.001 \\
<0.001 \\
<0.001 \\
<0.001 \\
-\end{array}$ \\
\hline
\end{tabular}

* Calculated from total-body weight of patient (assuming 18 per cent fat).

The myometrium, decidua, and corpus luteum had relatively high concentrations of radioactivity, whereas only moderate amounts were detected in the rest of the ovary, the maternal skin, and the fetal placenta. Relatively small amounts of radioactivity derived from labeled progesterone were found in all fetal tissues with the exception of the brain, where no radioactivity was detected by the method used. However, by far the highest concentration of radioactivity was found in a sample of maternal fat obtained from the subcutaneous tissue of the abdominal wall. Assuming that 18 per cent of the total-body weight of this patient consisted of fat, approximately 19.6 per cent of the administered dose of . radioactivity was present in the fat compartment 48 hours after the administration of the tagged hormone. (This assumes that the radioactivity was distributed evenly in the fat.)

Patient J.O.

This patient (gravida VIII, para V) was 37 years old and had a huge goiter for many years. which enlarged quite rapidly during a 5-month period preceding the date of admission to the hospital, At that time she was 11 weeks pregnant. There were no symptoms of 
thyrotoxicosis. The growth of the goiter continued during the ensuing weeks, and the pregnancy was terminated during the 17 th week because of possible carcinoma of the thyroid. The patient received $12 \mu \mathrm{c}$ of $\mathrm{C}^{14}$-4-progesterone intramuscularly 24 hours before surgery. The values of radioactivity found in the various tissues are shown in. Table 2 .

Table 2

KADIOACTTIVITY IN MA'I'EKINAL AND F'E'I'AL 'I'ISSUE'

Dose of $\mathrm{C}^{14}-4$-progesterone $\quad 12 \mu \mathrm{c}$

Method of administration . Intramuscular injection

Interval between injection
and therapeutic abortion

Length of pregnancy 17 weeks

\begin{tabular}{l|c|c|c|c}
\hline \multicolumn{1}{c|}{ Tissue } & $\begin{array}{c}\text { Weight } \\
(\mathrm{g})\end{array}$ & $\begin{array}{c}\mu \mathrm{c} / \mathrm{g} \\
\times 10^{-6}\end{array}$ & $\begin{array}{c}\mu \mathrm{c} / \text { organ } \\
\times 10^{-6}\end{array}$ & $\begin{array}{c}\text { Per cent of administered } \\
\text { radioactivity in organ }\end{array}$ \\
\hline Corpus luteum & 2.45 & 71 & 175 & 0.001 \\
Rest of ovary & 4.60 & 18 & -83 & $<0.001$ \\
Decidua & - & 62 & - & - \\
Myometrium & $531 *$ & 41 & 21,771 & 0.181 \\
Fat & - & 368 & - & $33.7 * *$ \\
Skin & - & 85 & - & - \\
\hline Placenta & 120. & 74 & 8,880 & - \\
Liver & 8.25 & 0 & - & - \\
Adrenals & 0.70 & 61 & 43 & - \\
Testes & 0.20 & 0 & - & 0.001 \\
Lungs & 3.70 & 35 & 128 & $<0.001$ \\
Heart & 0.65 & 18 & 12 & - \\
Brain & 12.00 & 0 & - & \\
\hline
\end{tabular}

* Total weight of the emptied uterus.

* Calculated from total-body weight of patient.

Again, the highest concentration of radioactivity was found in a sample of maternal fat. Only moderate amounts of radioactivity were present in the myometrium, decidua, corpus luteum, maternal skin, and fetal placenta. The concentration of radioactivity in the fetal organs was lower than that found in the maternal tissues. No radioactivity was detected in the fetal liver, the testes, or the brain. A relatively high concentration was present in the fetal adrenals as compared with that found in other fetal organs.

Patient M.P.

This patient (gravida II, para 0) was 27 years old and had lupus erythematosus. The patient's condition had become progressively worse during the first half of pregnancy. A therapeutic abortion was performed during the 18th week of gestation, which could not prevent the fatal outcome. The patient received $15.5 \mu \mathrm{c}$ of $\mathrm{C}^{14}-4$-progesterone intramuscularly 12 hours before the hysterotomy was performed. 
As seen in Table 3 , considerable amounts of radioactivity were found in maternal fat and skin obtained from the abdominal wall during the operation. Comparatively small amounts of activity were present in the myometrium, decidua, and corpus luteum. The largest amounts of radioactivity in fetal organs were found in the placenta and the adrenals, whereas no. activity could be detected in the fetal brain.

Table 3

RADIOACTIVITY IN MATERNAL AND FETAL TISSUE

Dose of $\mathrm{C}^{14}-4$-progesterone $\quad 15.5 \mu \mathrm{c}$

Method of administration Intramuscular injection

Interval between injection $\quad 12$ hours and therapeutic abortion

18 weeks

\begin{tabular}{l|c|c|c|c}
\hline \multicolumn{1}{c|}{ Tissue } & $\begin{array}{c}\text { Weight } \\
(\mathrm{g})\end{array}$ & $\begin{array}{c}\mu \mathrm{c} / \mathrm{g} \\
\times 10^{-6}\end{array}$ & $\begin{array}{c}\mu \mathrm{c} / \text { organ } \\
\times 10^{-6}\end{array}$ & $\begin{array}{c}\text { Per cent of administered } \\
\text { radioactivity in order }\end{array}$ \\
\hline Corpus luteum & 1.10 & 55 & 61 & $<0.001$ \\
Decidus & - & 46 & - & - \\
Myometrium & $490 *$ & 89 & 43,610 & 0.281 \\
Fat & - & 228 & - & $17.7 * *$ \\
Skin & - & 168 & - & 0.082 \\
\hline Placenta & 111 & 115 & 12,765 & $<0.001$ \\
Liver. & 5.39 & 41 & 221 & $<0.001$ \\
Adrenals & 0.54 & 112 & 61 & $<0.001$ \\
Lungs & 5.51 & 14 & 77 & \\
Heart & 1.02 & 7 & 7 & -001 \\
Brain & 18.4 & 0 & - & \\
\hline
\end{tabular}

* Weight of the emptied uterus.

** Calculated from total-body weight of patient.

\section{DISCUSSION}

Following the intramuscular administration of $\mathrm{C}^{14}-4$-progesterone to three pregnant patients, the highest concentration of radioactivity was found in maternal fatty tissue. Assuming an even distribution of radioactivity in the fat compartment of the body, about 17.7 per cent of the administered dose was present 12 hours after injection, 33.7 per cent after 24 hours, and 19.6 per cent after 48 hours. These calculations are based on the assumption that 18 per cent of the total-body weight consisted of fat.

The se findings indicate that when progesterone and/or its metabolites are administered intramuscularly, they diffuse promptly from the circulating blood into the fat compartment. We have not determined whether the radioactivity found in the fat was derived from the hormone or from its metabolites. However, it appears very likely that the radioactivity is due principally to the presence of the unchanged hormone because Kaufmann and Zander ${ }^{11}$ found a relatively high concentration of progesterone in fatty tissue of pregnant 
women. The amount was 6 times higher than that found in the fat of nonpregnant women during the luteal phase.

Our results explain the following phenomena: 1) the failure of large doses of progesterone injected intramuscularly to raise the blood level of progesterone and the rapid disappearance of progesterone from the blood after intravenous injection; 2) the delayed excretion of progesterone metabolites after intravenous injection; 3) our previous finding 3,12 that the specific activity of urinary $\mathrm{C}^{14}$-pregnanediol, derived from injected $\mathrm{C}^{14}$-acetate, declines during a 48 to 72 hour period after removal of the chief sources of progesterone, the placenta, and the corpus luteum. At that time we explained that this phenomenon resulted from a dilution of the radioactive pregnanediol with inert steroid molecules derived from the maternal adrenals. In view of the findings of this study it is more likely that urinary $\mathrm{C}^{14}$-pregnanediol was diluted by molecules derived from progesterone stored in the maternal fat.

These data further demonstrate that erroneous conclusions regarding progesterone production may be drawn from values obtained for urinary pregnanediol. Pregnanediol may continue to be excreted into the urine in appreciable amounts even though its production has ceased. This has been demonstrated in one of our patients who was in spontaneous labor. 3,12

It is of interest that only moderate amounts of radioactivity from tagged progesterone were found in the myometrium and the decidua in two pateitns with advanced pregnancy (17th and 18 th week of gestation), whereas a relatively higher concentration was found for both tissues in a patient who was 11 weeks pregnant. The decidua as well as the myometrium is considered to be the most important target organ for progestational activity. In mice and rats, a low level of radioactivity derived from $\mathrm{C}^{14}-21$-progesterone was found in the uterus. ${ }^{3}$ Progesterone could not be isolated from the myometrium and the decidua of pregnant women even though a very sensitive method of assay was used. ${ }^{14}$ At present, we have no knowledge about the actual mechanism by which a hormone exerts its biologic effect on the target organ. Recent experiments by Hisaw and Velardo ${ }^{15}$ suggest strongly that interactions of progesterone with its so-called "inactive" metabolites are important for the production of its physiologic effect in the cell. The chemical nature of this interaction is not known.

Low to moderate concentrations of radioactivity derived from $\mathrm{C}^{14}-4$-progesterone were found in the corpus luteum and the placenta. It is to be expected that these endocrine glands are unfavorable sites for the absorption and storage of the hormone that they elaborate.

Radioactivity was found in all fetal tissues in relatively small amounts with the exception of the brain (negative radioassay in all three cases), and testes (negative assay in one case), and the liver (negative assay in one of two cases). The comparatively highest concentration of radioactivity in fetal organs was found in the adrenal glands of two fetuses which were, respectively, 17 and 18 weeks old. Progesterone is regarded as an important intermediate of adrenal cortical steroids. However, only small amounts of corticoids 
can be detected in fetal adrenal glands at that stage of embryonic life. On the other hand, the relatively high concentration of progesterone may be due to the accumulation of lipids in the fetal cortex. Histochemical studies indicate that lipoid material is only present in relatively small amounts in the fetal cortex, but these amounts may be still higher than those found in other fetal organs. In view of this finding, it is of interest that Riegel et al. ${ }^{13}$ found a relatively high concentration of radioactivity in the adrenals of mice after they had been given $\mathrm{C}^{14}-21$-progesterone.

\section{SUMMARY}

$\mathrm{C}^{14}$-4-progesterone was administered intramuscularly to pregnant women who were scheduled for therapeutic abortion. The distribution of radioactivity was determined in maternal and fetal tissues that were removed at various intervals following the injection. The highest concentration of radioactivity was found in the maternal fat. A rough calculation revealed that about 17.7 per cent of the administered radioactivity was present at 12 hours, 33.7 per cent at 24 hours, and 19.6 per cent at 48 hours after the administration of the labeled hormone. These findings indicate that progesterone and/or its metabolites diffuse rapidly from the circulating blood into the fat compartment of the body.

Only moderate amounts of radioactivity were found in the myometrium and the decidua, the two principal target organs of progesterone. Low to moderate concentrations of radioactivity were detected in the principal sources of the hormone, the corpus luteum and the placenta. Radioactivity was found in all the fetal tissues in relatively small amounts with the exception of the fetal brain, testes, and liver, where the radioassay gave negative results. In two cases, slight radioactivity was detected in the liver.

\section{LITERATURE CITED}

1. Zander, J. Klin. Wochschr., 33:697, 1955.

2. Klein, I. and K. G. Ober. Klin. Wochschr., 32:464, 1954.

3. Davis, M. E., E. J. Plotz, G. V. LeRoy, G. R. Gould, and H. Werbin. Amer. J. Obștet. \& Gynecol., 72:740, 1956 .

4. Sandburg, A. A. and W. R. Slaunwhite. The Endocrine Society Meeting, June 7-9, 1956. Chicago, Illinois.

5. Zander, J. Geburtsh. \& Frauenheilk., 14:402, 1954.

6. Zander, J. Nature, 174:406, 1954.

7. Rothschild, I. J. Clin. Endocrinol. \& Metabolism, 13:1213, 1953.

8. Beer, C. T. and T. F. Gallagher. J. Biol. Chem., 214:335, 1955.

9. Thompson, L. M., C. H. Yates, and A. D. Odell. J. Am. Chem. Soc., 76:1196, 1954.

10. Brownell, G. L. and H. S. Lockhart. Nucleonics, 10:26, 1952.

11. Kaufmann, C. and J. Zander. Klin. Wochschr., 34:7, 1956. 
12. Plotz; E. J. Argonne Cancer Research Hospital Semiannual Report to the Atomic Energy Commission, ACRH-4, p. 30, 1955.

13. Riegel, B., W. L. Hartop, Jr., and G. W. Kittinger. Endocrinology, 47:331, 1950.

14. Zander, J. and A. M. von Munstermann. Klin. Wochschr., 34:944, 1956.

15. Hisaw, F. L. and J. T. Velardo. Endocrinology, 49:732, 1951. 


\section{CHOLESTEROL-A PRECURSOR OF EXTRONE IN VIVO*}

H. Werbin, E. J. Plotz, ${ }^{\dagger}$ G. V. LeRoy, and M. E. Davis ${ }^{\dagger}$

On the basis of the report by Heard and $\mathrm{O}^{\prime}$ Donnell ${ }^{1}$ that the pregnant mare is unable to synthesize estrone from $\mathrm{C}^{14}$-labeled cholesterol, it was assumed that this sterol was not a precursor of the estrogen hormones. ${ }^{2}$ However, evidence to the contrary has been obtained. The conversion of $\mathrm{C}^{14}$-labeled testosterone ${ }^{3-5}$ and 19 -hydroxy- $\Delta^{4}$-androstene3,17 -dione ${ }^{6}$ to the estrogens strongly implicates cholesterol as a precursor. We have demonstrated this conversion.

A pregnant woman $\dagger^{\dagger}$ was given $87.4 \mu \mathrm{c}$ of cholesterol-4- $\mathrm{C}^{14}(2.35 \mu \mathrm{c} / \mathrm{mg})$ over a 6 day period during which time urine samples were collected daily and assayed for radioactivity $(0.6 \%$ found). The urinary steroid conjugates were hydrolyzed with $\beta$-glucuronidase and extracted with ether at $\mathrm{pH}$ 5. The crude phenolic fraction, weighing $338 \mathrm{mg}$ and with 0.012 per cent of the administered radioactivity, was obtained by using the procedure of Engel ${ }^{7}$ Carrier estrone, $3.875 \mathrm{mg}$, was added to the toluene before extraction of the estrogens. ${ }^{7}$ The ketonic residue from a Girard separation was chromatographed for 3 hours on 15 sheets of Whatman \#1 paper in a methanol-water-benzene-petroleum ether system. ${ }^{8}$.The area with an $R_{f}$ corresponding to estrone was cut out and eluted with methanol. Using the Kober assay, $4.5 \mathrm{mg}$ were found. The material did not separate from authentic estrone in mixed paper chromatugraphy in two solvent systems. ${ }^{*}$ Estrone, 110.9 $\mathrm{mg}$, was added as carrier, and the acetate was prepared in the usual manner. The acetate was purified over charcoal and crystallized twice from aqueous methanol. The crystals were dissolved in $15 \mathrm{ml}$ of toluene which contained $30 \mathrm{mg}$ of 2,5-diphenyloxazole (DPO), and the solution was counted in a Packard Tri-Carb Liquid Scintillation Counter. ${ }^{\dagger \dagger}$ The toluene was removed in vacuo, and the acetate was freed from DPO by washing twice with $0.5 \mathrm{ml}$ of petroleum ether. After two crystallizations from aqueous methanol, the acetate was recounted. The toluene was then removed, the acetate hydrolyzed with 5 per cent methanolic potassium hydroxide, and the estrone converted to the benzoate derivative. ${ }^{3}$ The benzoate was crystallized from 95 per cent ethanol twice $(15 \mathrm{ml}$ each time) and was counted as described above for the acetate. After the toluene was removed and the crys-

* Based on a Letter to the Editor that appears in the Journal of the American Chemical Society, 79:1012, 1957.

+ Department of Obstetrics and Gynecology, The University of Chicago.

\# Six days before a scheduled therapeutic abortion.

* Toluene-propylene glycol ${ }^{6}$ and that described by. Migeon et al. ${ }^{8}$

t† Commercially available from Packard Instrument Corp., LaGrange, Illinois. 
tallization steps were repeated, the counting was repeated. The counting data are shown in Table 1. It is unlikely that the estrone was synthesized from a degradation product of cholesterol-4-C $\mathrm{C}^{14}$ since this sterol does not appear to be degraded in vivo to any appreciable extent. 9

Table 1

SPECIFIC AC'IIVITY UF ESTRONE ISOLATĒD BY CARRIER TECHNIQUE

\begin{tabular}{l|c|c|c|c|c}
\hline Derivative & $\begin{array}{c}\text { No. of times } \\
\text { crystallized }\end{array}$ & m.p. & mg. counted & DPM $^{\dagger}$ & $\begin{array}{c}\text { DPM/mg. } \\
\text { free estrone }\end{array}$ \\
\hline Acetate & 2 & $125.5-127.0$ & 117.4 & 1615 & 15.9 \\
Acetate & 4 & $120.5-121.5$ & 96.1 & 1335 & 16.0 \\
& 2 & $217.0-219.5$ & 84.7 & 899 & 14.7 \\
Benzoate & 4 & $216.5-218.5$ & 77.0 & 806 & 14.5 \\
Benzoate & 6 & $216.0-218.0$ & 68.9 & 761 & 15.3 \\
Benzoate & &
\end{tabular}

* Taken on a Fisher-Johns apparatus; uncorrected.

+ Corrected for quenching effects $(23-30 \%)$ on the counting. The counting efficiency was 61.5 per cent and the background was $35 \mathrm{cpm}$.

Since cholesterol can serve as a precursor for estrone, it is no longer necessary to assume a pathway of estrogen biosynthesis independent of cholesterol in vivo, although such a pathway may exist. The data lend support to the pattern of estrogen biosynthesis from cholesterol that was proposed recently by Solomon and his co-workers. ${ }^{10}$

\section{LITERATURE CITED}

1. Heard, R. D. H. and V. J. O'Donnell. Endocrinology, 54:209, 1954 .

2. Roberts, S. and C. M. Szego. Ann. Rev. Biochem., 24:557, 1955.

3. Heard, R. D. H., P. H. Jellnick, and V. J. O'Donnell. Endocrinology, 57:200, 1955.

4. Wotiz, H. W., J. W. Davis, H. M. Lemon, and M. Gut. J. Biol. Chem., 222:487, 1956.

5. Baggett, B., L. L. Engel, K. Savard, and R. I. Dorfman. J. Biol. Chem., 222:931, 1956, Fed. Proc. 14:175, 1955.

6. Meyer, A. S. Biochem. Biophys. Acta, 17:441, 1955.

7. Engel, L. L. Recent Progress Hormone Research, 5:343, 1950.

8. Migeon, C. J., W. R. Slaunwhite, Jr., R. Aldous, R. Fox, R. Hardy, D. Johnson, and W. Perkins. J. Clin. Endocrinol. \& Metabolism, 15:775, 1955.

9. Werbin, H., D. M. Bergenstal, R. G. Gould, and G. V. LeRoy. J. Clin. Endocrinol. \& Metabolism, in press.

10. Solomon, S., R. V. Wiele, and S. Lieberman. J. Am. Chem. Soc., 78:5453, 1956. 
In 1952 our group at the Argonne Cancer Research Hospital began a study of steroidogenesis in human subjects using radioisotope-labeled cholesterol. Our objectives were to determine the extent to which cholesterol served as a precursor for steroid hormones and to develop clinical research procedures to exploit this particular precursor-product relationship. At that time (1952) it was known from Bloch's ${ }^{1}$ experiment with deuteriocholesterol that the free sterol was a precursor of pregnanediol-hence of progesteronein the pregnant woman. Hellman's ${ }^{2}$ group had found comparable values for radioactivity in plasma cholesterol and urinary dehydroisoandrosterone following the administration of $\mathrm{C}^{14}$-acetate. Furthermore, Zaffaroni and his associates ${ }^{3}$ had just reported that beef adrenals perfused with $\mathrm{C}^{14}$-cholesterol produced radioactive compounds $\mathrm{B}$ and $\mathrm{F}$. It was evident that inferences regarding the biogenesis of some steroid hormones, based on similarities of molecular.structure, were gaining experimental support.

Initially, we devoted our attention to the isolation of 17-ketosteroids; but at the suggestion of Dr. E. A. Doisy, methods were adopted that permitted us to concentrate on the recovery of the metabolites of compounds $E$ and F: tetrahydrocortisone (THE) and tetrahydrohydrocortisone (THF), respectively. The procedures employed for the isolation and identification of urinary steroids have been described in several reports by our group. ${ }^{4}$ In summary, they consisted of mild hydrolysis, with $\beta$-glucuronidase, extraction with ether, and separation of steroids by paper chromatography. Steroids eluted from the chromatograms were crystallized repeatedly, often with the addition of carrier, until radiochemical purity was achieved. The decision as to purity was based upon a combination of the following criteria: melting point, constant specific activity of derivatives, ultraviolet and infrared spectrographic analysis, and comparison with authentic samples of steroids. Radioassay of steroid samples was greatly facilitated by the use of the fast-coincidence liquid scintillation counter. An instrument for this purpose was designed for us ${ }^{* *}$ that is similar in principle to the research counters developed by Hiebert and Watts. ${ }^{5}$ In addition to the great sensitivity of liquid scintillation counters, it is possible to assay a sample of steroid

* This is a report of a collaborative project that Dr. LeRoy presented at the meetings of the Association of American Physicians, May 7, 1957; Atlantic City, on behalf of his colleagues: Harold Werbin, now at the University of California; R. Gordon Gould, Los Alamos Scientific Laboratory; Delbert M. Bergenstal, now at National Cancer Institute; and the following members of the staff of the Argonne Cancer Research Hospital: E. Jurgen Plotz,.Jon J. Kabara, George T. Okita, and M. Edward Davis.

* By Mr. Lyle E. Packard of the Packard Instrument Company. The commercial version of this unit is known as the Tri-Carb Counter. 
without combusting it. Following assay, the steroid can be recovered from the scintillator solvent system for further purification, the preparation of derivatives, and the like. Whenever possible (i.e., unless the activity of the sample was a small fraction of background), samples were counted sufficiently long to give a standard error of counting of 5 per cent or less. Radioassay of cholesterol in plasma, urine, and tissues was performed by methods that have been described in our previous reports. 6

Since we were concerned primarily with the precursor-product relationship of cholesterol and steroid hormones, all data are expressed in units of radioactivity per millimole. This is referred to as specific activity (SA). "The ratio:

Specific activity of metabolite (or hormone)

Specific activity of free cholesterol in an organ, or in the plasma

is an index of the extent to which cholesterol serves as a precursor for a particular hormone or its metabolite. If the ratio is unity, it means (within determinable limits of confidence) that free cholesterol is the only precursor. When the ratio is less than one, two interpretations are possible: first, there may be some other precursor than cholesterol; and second, equilibration of the tracer cholesterol in the organ or tissue is not complete.

Two forms of tracer cholesterol were used in these studies: $4-\mathrm{C}^{14}$-cholesterol obtained from commercial sources; and cholesterol- $\mathrm{H}^{3}$ (referred to customarily as tritiumcholesterol), which was prepared by Dr. Gould according to the method of Fukushima and Gallagher. ${ }^{7}$ In this material, the tritium label is distributed as shown in Figure 1 . Chemical degradation studies reported by our group ${ }^{8}$ demonstrated that 53.4 per cent of the tritium was attached to the tetracyclic ring of cholesterol. Intercomparison in the same individual, using cholesterol- $\mathrm{H}^{3}$ and $4-\mathrm{C}^{14}$-cholesterol, established that the labeling was stable, in vivo, for at least two weeks. There was no evidence that the side-chain, when split off, was reutilized for steroidogenesis. When tritium-cholesterol was used in a tracer experiment, the value for SA of free cholesterol was multiplied by 0.53 to provide the denominator of the ratio. There is good evidence for the stability of the $\mathrm{C}^{14}$ label at the carbon-4 position; namely, the fact that no radioactive carbon dioxide can be detected in expired air, using the most sensitive methods. ${ }^{9,10}$ Most students of the subject agree that the free cholesterol of the diet, of plasma, and of tissue, is indistinguishable physiologically and biochemically, except if labeled with ran isotope of carbon or hydrogen.

When labeled cholesterol is used in a tracer experiment, the interpretation of the data is complicated by three factors:

1) Virtually every organ and tissue except the nervous system can synthesize cholesterol from acetate. The actual rates of synthesis are not known and, in the case of intact human subjects, they are probably not knowable, but their rank

* We debated expressing all data in terms of microcuries per milliatom of C; but this would introduce an inconsistency when the tracer substance was labeled with tritium $\left(\mathrm{H}^{3}\right)$. In such material the isotope is distributed to several positions (see Figure 1) and is described more accurately on a per cent basis than on milliatom basis. 


\section{CHOLESTEROL}

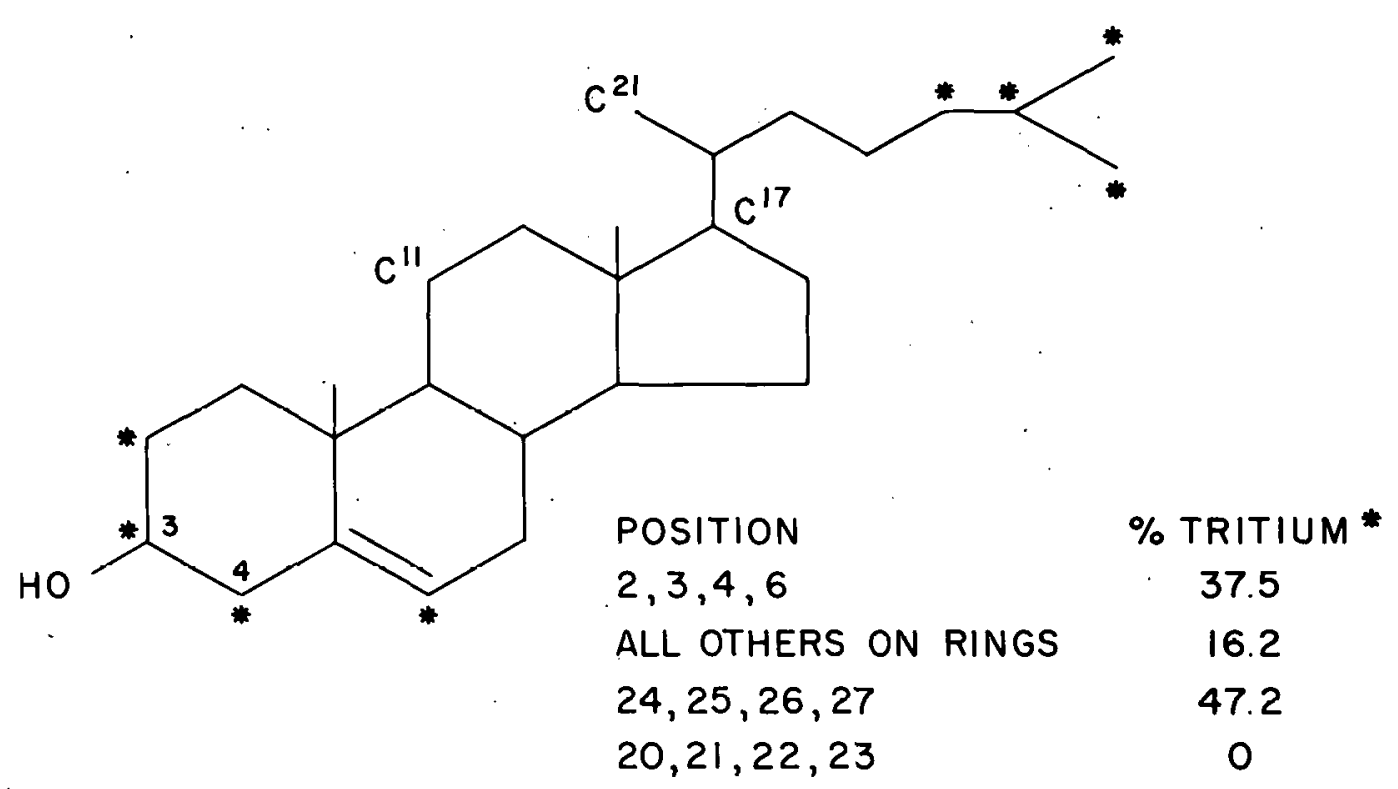

Figure 1. Molecular structure of cholesterol. Carbon-14 labeling of the rings is accomplished at the 3 or 4 position. Asterisks indicate the predominate sites of exchange of hydrogen isotopes.

order is approximately as shown in Table 1:

2) The rate of equilibration of free cholesterol between plasma and various tissues, also, is not known. The rank order of these processes is approximately that given in Table 1.

3) The size of the "miscible pool" of cholesterol is uncertain, so that estimates of the rate of turnover can only be considered as first approximations at the best.

To minimize these uncertainties, most of our studies were performed on subjects who received labeled cholesterol daily by mouth for 6 to 20 days, during which time we hoped that the blood level would become constant, and equilibration would be established between the blood and the endocrine organs. * To obtain a nearly constant blood level rapidly, the first oral dose was 5 to 10 times the daily dose, thus serving as a primer.

The subjects of our studies were patients in the Argonne Cancer Research Hospital and the Chicago Lying-in Hospital of the University of Chicago. To date we have performed 31 clinical experiments to investigate various aspects of steroidogenesis. The several types of study are summarized in Table 2. For the purpose of this report, selected examples are presented that illustrate the broad features of our work, and demonstrate the utilization of cholesterol in steroidogenesis in man.

* Accurate radioassay of plasma cholesterol is time-consuming, and in most experiments the actual values for cholesterol SA were not known until the study was finished. Uncertainty of this sort is unavoidable under most circumstances. 
Table 1

APPROXIMATE RANK ORDERS*

\begin{tabular}{l|c}
\hline Cholesterol synthesis & $\begin{array}{c}\text { Equilibration with } \\
\text { plasma free cholesterol }\end{array}$ \\
\hline Corpus luteum & Liver \\
Liver & Corpus luteum \\
Adrenals & Fetal placenta \\
Gonads & Adrenals \\
Fetal placenta & Gonads \\
* These are educated guesses based on two series of hu- \\
man studies at the Argonne Cancer Research Hospital, \\
and on studies of the dog by Gould and his associates.
\end{tabular}

Table 2

TRACER STUDIES OF STEROIDOGENESIS

\begin{tabular}{|c|c|c|}
\hline Type of study & $\begin{array}{c}\text { İsotopic } \\
\text { cholesterol }\end{array}$ & $\begin{array}{l}\text { Number of } \\
\text { studies }\end{array}$ \\
\hline Pre- and post-adrenalectomy & T. $\mathrm{C}^{14}$ & 4 \\
\hline $\begin{array}{l}\text { Equilibration of cholesterol and } \\
\text { corticoids }\end{array}$ & $\mathbf{T}$ & 1 \\
\hline $\begin{array}{l}\text { Equilibration of acetyl groups, } \\
\text { cholesterol and corticoids }\end{array}$ & (Acetate- $\mathrm{C}^{14}$ ) & 1 \\
\hline Post-hypophysectomy + ACTH & $\mathrm{T}$ & 3 \\
\hline Post-adrenalectomy & (Acetate-C $\mathrm{C}^{14}$ ) & 2 \\
\hline Evaluation of pituitary function & $\mathrm{T}$ & 1 \\
\hline Evaluation of $\mathrm{T}$-cholesterol & T. $C^{14}$ & 1 \\
\hline Isolation of 11 -keto-etiocholanolone & $\mathbf{T}$ & 1 \\
\hline Progesterone metabolism in pregnancy & (Progesterone- $\mathrm{C}^{14}$ ) & 4 \\
\hline Progesterone-corticoids & (Progesterone $-\mathrm{C}^{14}$ ) & 1 \\
\hline Cholesterol-pregnanediol & T. $C^{14}$ & 3 \\
\hline Estrogen biosynthesis & $\begin{array}{c}\text { T. } C^{14} \\
\text { (Acetate-C }\end{array}$ & 9 \\
\hline & Total & 31 \\
\hline
\end{tabular}

Experiment 1: This study was performed to evaluate the use of tritium-cholesterol as a tracer in man. A single intravenous dose containing both $\mathrm{C}^{14}$ cholesterol $(4.24 \mu \mathrm{c})$ and cholesterol- $\mathrm{H}^{3}(33.8 \mu \mathrm{c}$ ) was given to a 60 -year old white man (Unit \#47-76-62) with mild chronic arthritis. Blood and urine samples were collected over a period of 10 days. The time-course of the $\mathrm{C}^{14}$ and $\mathrm{H}^{3}$ free cholesterol of the plasma is shown in Figure 2 . 


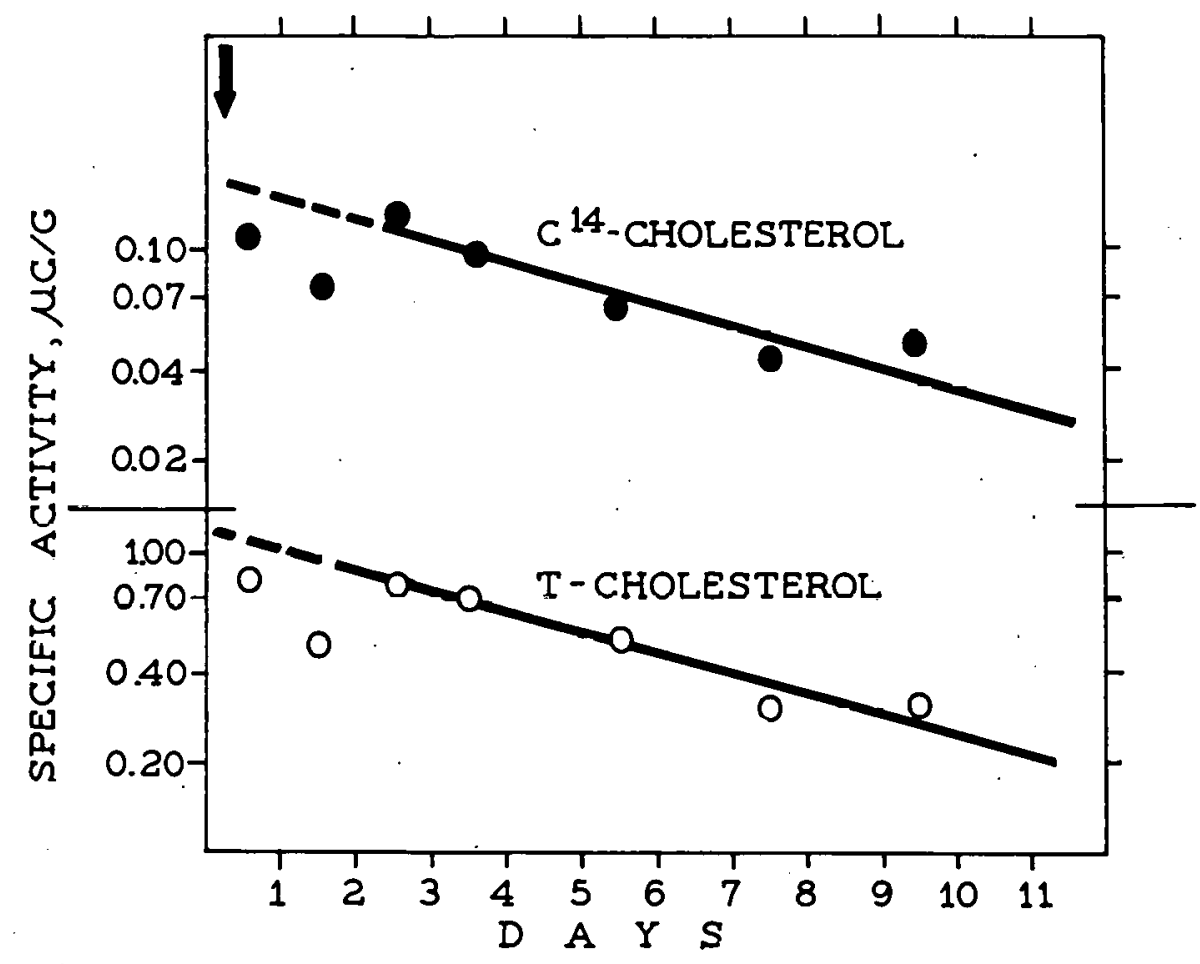

Figure 2. Experiment I: Parallel die-away curves, plotted semilogarithmically, for $\mathrm{C}^{14}$ and $\mathrm{T}$ specific activity of plasma free cholesterol, following a single intravenous dose of cholesterol labeled with both isotopes.

The curves are parallel, indicating no loss of the tritium label. Five crystalline steroid metabolites were isolated from the urine, each with substantially the same specific activity (Table 3 ). In Figure 3 is shown the time-course of the SA of plasma free

Table 3

SPECIFIC ACTIVITIES OF CRYSTALLINE STEROIDS ISOLATED FROM URINE BY CARRIER TECHNIQUE

\begin{tabular}{c|l|c|c}
\hline Day & \multicolumn{1}{|c|}{ Steroid } & $\begin{array}{c}\text { Amount } \\
\text { isolated } \\
(\mathrm{mg})\end{array}$ & $\begin{array}{c}\mathrm{C}^{14} \\
(\mu \mathrm{c} / \mathrm{mM})\end{array}$ \\
\hline 4 & Androsterone & 1.24 & 0.035 \\
4 & $\begin{array}{l}\text { Etiocholanolone } \\
1-8\end{array}$ & 1.90 & 0.027 \\
4. & $\begin{array}{c}\text { 11-Keto-etiocholanolone } \\
\text { (Acetate) }\end{array}$ & 1.67 & 0.028 \\
$2-6$ & $\begin{array}{c}\text { Tetrahydrocortisone } \\
\text { (Diacetate) } \\
\text { (Diacetate) }\end{array}$ & 2.39 & 0.024 \\
\hline
\end{tabular}

$47-76-62$ 
cholesterol and of the SA of two of the metabolites: tetrahydrocortisone and androsterone: This was the first case ${ }^{*}$ in which we recovered crystalline metabolites of 11-oxy-corticoids. Within experimental error (i.e., of the radioassay), the ratio of $\mathrm{H}^{3}$ to $\mathrm{C}^{14}$ in plasma cholesterol and in the metabolites was the same as the ratio in the tracer dose given intravenously. From the urine collected over a period of 8 days, a total of $37.64 \mathrm{mg}$ of crystalline steroids was recovered. The radioactivity of this amount was 0.7 per cent of the tracer dose. Since there was no reason to suspect adrenal insufficiency, the recovery of crystalline material was probably not more than one-fourth of the actual amount excreted.

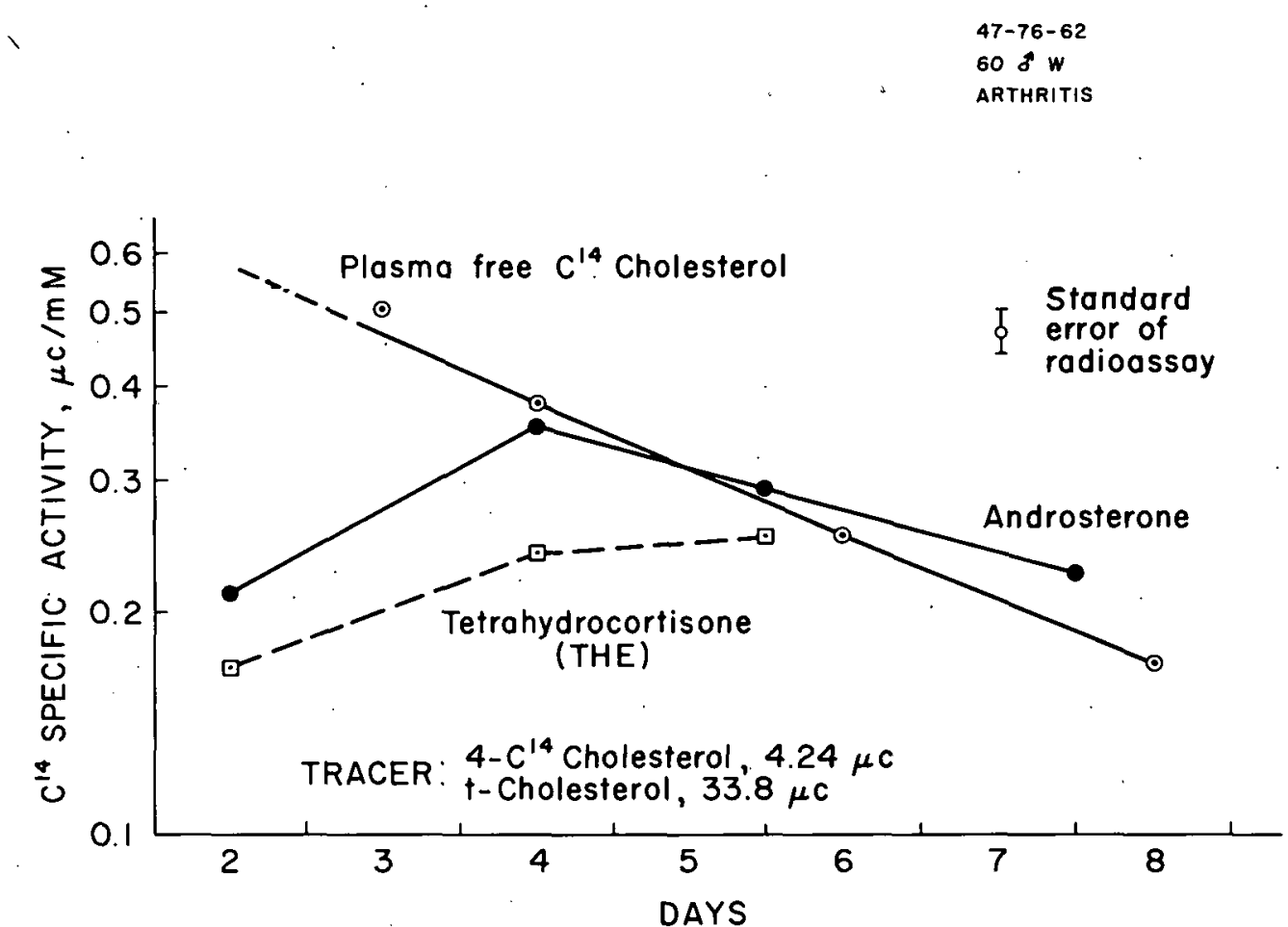

Figure 3. Experiment I: Relationship between $\mathrm{C}^{14}$ specific activities of plasma free cholesterol and two steroid metabolites in a male subject with presumably normal function.

Referring to Figure 3, it will be noted that the curve for SA of androsterone intersects the curve for SA of cholesterol at a point where the former is approximately maximal. Subsequent to this intersection, the die-away of specific activity in free cholesterol and steroid metabolite should be parallel. This type of relationship is regularly noted when the time-course of a precursor and its product is followed. A pattern similar to this has been described by Hellman and his associates, ${ }^{2}$ and by other workers. In an experiment

The data for this experiment are given in detail in reference 8. 
of this type, using a single dose of precursor, it is not feasible to attempt to estimate the quantitative relationship. One can only say that the results are strong evidence that preformed cholesterol is a precursor of the steroids recovered in the urine.

Experiment II. This study was performed to obtain information on the timè required for the specific activity of tetrahydrocortisone to become constant when the tracer cholesterol was fed.continuously. The patient was a 26-year-old-white woman (Unit \#61-60-99) with early untreated acromegaly. She was given an oral priming dose of $100 \mu \mathrm{c}$ of tritiumcholesterol, followed by $20 \mu \mathrm{c}$ orally per day for 14 days. The priming dose was inadequate (see Figure 4) since the SA of plasma free cholesterol increased throughout the period of

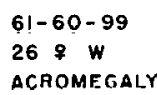

RATIO: $\quad .37$

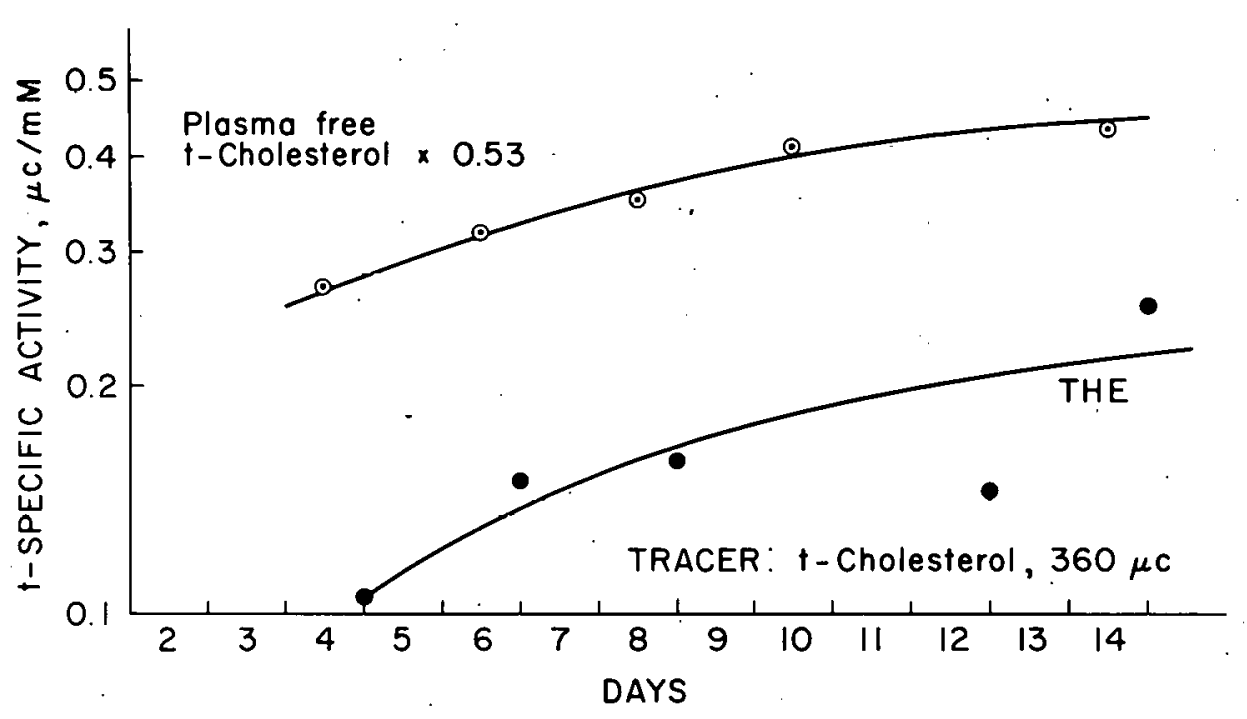

Figure 4. Experiment II: Tritium specific activity of plasma free cholesterol and tetrahydrocortisone over a 2-week period when tracer cholesterol was fed daily.

study. Likewise, the SA of THE was evidently still rising when the last sample was collected. We do not know how to evaluate the influence of the pituitary disorder on this case. We could only conclude that a metabolite (THE) of an 11-oxy-corticoid was derived from the tritium cholesterol that was fed to her; and that equilibration was not yet complete at 14 days.

Experiment III. Using patients scheduled for bilateral adrenalectomy for metastatic breast cancer, four attempts were made to estimate the ratio of SA of corticoid metabolites and adrenal free cholesterol, as well as the ratio of SA of the metabolites and plasma free cholesterol. In the first three cases, published elsewhere, ${ }^{11}$ a double-labeling ex- 
periment was performed: tritium-cholesterol was fed for several days, and $1-\mathrm{C}^{14}$ acetate was given during the sur'gery to evaluate cholesterol synthesis by the adrenal glands.

Such synthesis was demonstrated, but the data for the ratio of specific activities were not satisfactory because of inadequate doses of tracer. A satisfactory experiment was performed on a 49-year-old white woman (Unit \#62-16-34) who received $26.7 \mu \mathrm{c}$ of $\mathrm{C}^{1.4}$-cholesterol as the priming dose, and $6.7 \mu \mathrm{c}$ on each of the five subsequent days. Urine was collected for isolation of THE on the 4th and 5th days of the experiment. At surgery, on the 6 th day, $95 \mathrm{ml}$ of adrenal vein blood was obtained. One entire adrenal gland was available to us for assay. The SA of plasma free cholesterol was approximately constant on the 4 th, 5 th, and 6 th days of the study. The block diagrams in Figure 5 indicate the rela-

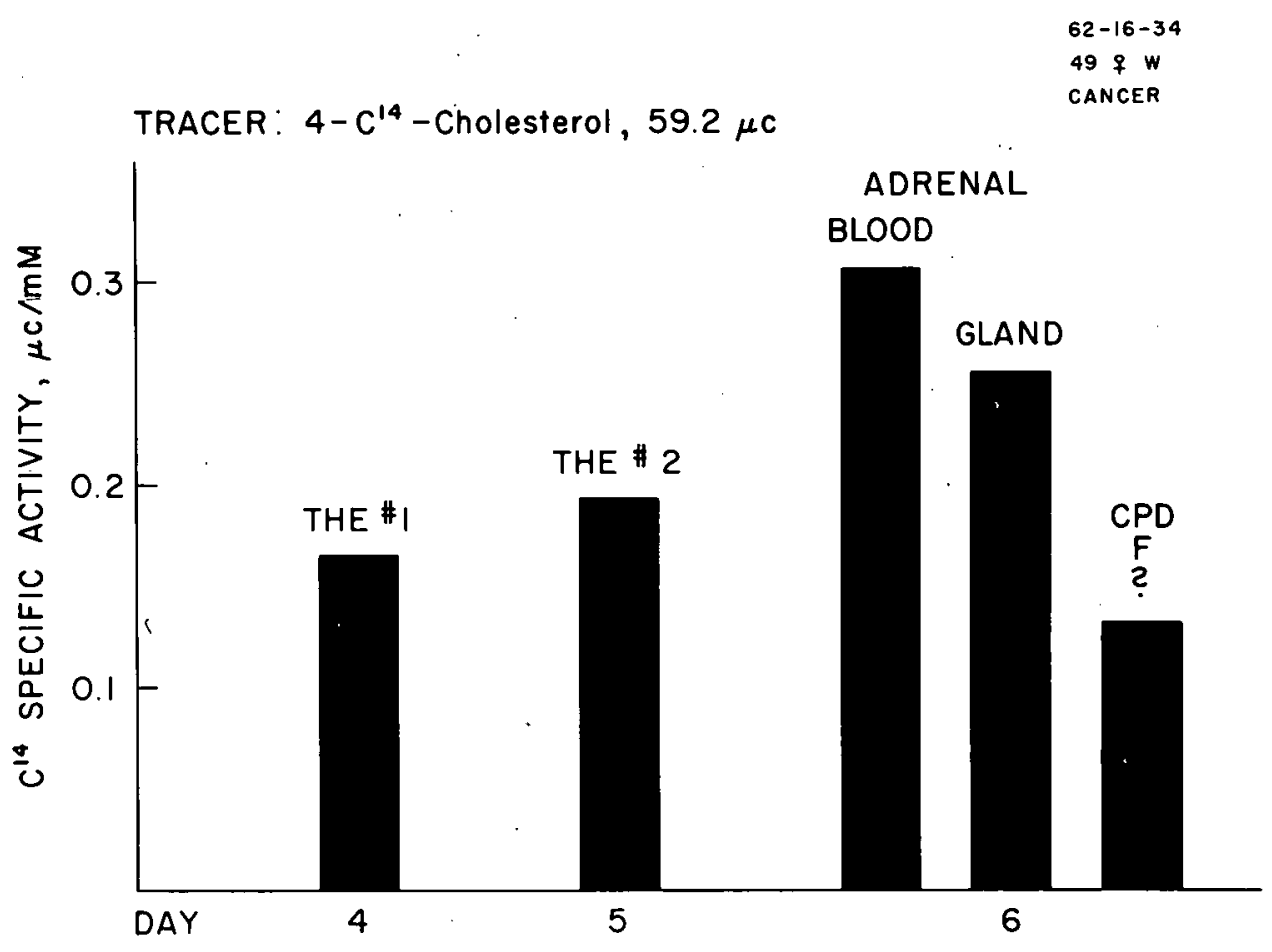

Figure 5. Experiment III: Comparison of $\mathrm{C}^{14}$ specific activities in corticoid metabolites, adrenal free cholesterol, and the plasma free cholesterol of blood from an adrenal vein. The labeled cholesterol was fed for 6 days, and adrenalectomy was performed on the last day of feeding.

tions between the SA of adrenal free cholesterol, the plasma free cholesterol of adrenal vein blood, the THE, and $28 \mu \mathrm{g}$ of a steroid from the adrenal vein blood that was certainly cortisol. Radiochemical purity could not be established because of the small amount, so the SA assigned to it is tentative and probably low. We really do not know whether equilibration had been achieved in this case, or not.

Experiment IV: This experiment was performed to examine one aspect of the prevalent (1955) scheme of adrenal steroidogenesis. Hechter ${ }^{12}$ and others postulated that pro- 
gesterone was an intermediate between cholesterol and compounds B and F: This was the hypothesis that we hoped to test. The subject was a 45-year-old woman (Unit \#60-29-12) with Cushing's syndrome due to adrenal carcinoma with extensive metastases. * Prior to our study, her treatment included large doses of progesterone, but these were discontinued for two weeks. A single dose of $14 \mu \mathrm{c}$ of $4-\mathrm{C}^{14}$ progesterone in sesame oil was given intramuscularly. Urine collected for the following 4 days contained a total of approximately $130 \mathrm{mg}$ of corticoids, and $130 \mathrm{mg}$ of 17 -ketosteroids. The following radioactive crystalline steroids were recovered from the 4-day pool (in addition to pregnanediol, which was expected): etiocholanolone, THE, THF, and cortisol. ${ }^{*}$ The specific activities of the steroids are shown in Table 4. The SA of pregnanediol was about 15 per cent of that of the progesterone administered, which is a reasonable value considering the probable dilution by progesterone administered therapeutically. The SA of the corticoids was approximately 0.1 per cent of that of the pregnanediol. The experiment demonstrated that adrenal cortical tissue (neoplastic, in this case) can utilize progesterone for the biosynthesis of corticoids. The small fraction of the progesterone administered that appeared in the corticoids, as determined by the ratio: SA cortisol/SA pregnanediol, is not unreasonable when the following factors are considered: Blood levels of progesterone in pregnancy, for example,

Table 4

BIOSYNTHESIS OF 11-OXY-CORTICOIDS FROM $4-\mathrm{C}^{14}$-PROGESTERONE, $14 \mu \mathrm{C}$

\begin{tabular}{l|c|c}
\hline \multicolumn{1}{c|}{ Steroid } & $\begin{array}{c}\mathrm{C}^{14} \text { specific } \\
\text { activity } \\
(\mu \mathrm{c} / \mathrm{mM})\end{array}$ & $\begin{array}{c}\text { Amount } \\
\text { isolated } \\
(\mathrm{mg})\end{array}$ \\
\hline $\begin{array}{l}\text { Progesterone administered } \\
\text { Pregnanediol }\end{array}$ & 948.0 & 76.20 \\
$\begin{array}{l}\text { Cortisol } \\
\text { Tetrahydrohydrocortisone } \\
\quad \text { (THF) }\end{array}$ & 0.128 & 1.00 \\
$\begin{array}{l}\text { Tetrahydrocortisone } \\
\quad \text { (THE) }\end{array}$ & 0.149 & 0.83 \\
$\begin{array}{l}\text { Etiocholanolone } \\
\text { 64-56-67 }\end{array}$ & 0.149 & 1.36 \\
Adrenal carcinoma & 0.131 & 0.70 \\
\hline
\end{tabular}

* This patient was under the care of Dr. Richard L. Landau, who kindly permitted us to perform this study.

* A series of control studies in vitro demonstrated that our steroid isolation procedure readily separated "hot" pregnanediol from "cold" cortisol, and vice versa. This is what one would expect in theory, but because of the low activity of the corticoids, it was desirable to confirm theory by experiment. For the same reason, derivatives of cortisol were prepared without reduction of specific activity. 
range from 0.02 to $0.38 \gamma / \mathrm{ml}^{13}$ while blood levels of free cholesterol are of the order of $500 \gamma / \mathrm{ml}$. On the basis of other experiments, we would expect a single intramuscular dose of $100 \mathrm{mg}$ of progesterone to give a peak blood.level of $0.5 \mathrm{\gamma} / \mathrm{ml}$. The expected dilution of progesterone by cholesterol is thus by a factor of 1000 , which is the ratio of the specific activities of pregnanediol and cortisol.

Experiment V: Four studies have been performed using patients who had been submitted to bilateral adrenalectomy, or hypophysectomy, for the palliation of metastatic breast cancer. The objective of these studies after hypophysectomy was to determine the extent to which adrenal steroidogenesis was interrupted by the surgical procedure.

A 45-year-old woman (Unit \#52-15-62), whose hypophysis had been ablated by the implantation of pellets of yttrium-90 oxide 6 months previously, was fed tritium-cholesterol in large doses for a period of 10 days, following the usual priming dose. She continued to take her regular substitution therapy: cortisone, $50 \mathrm{mg}$ per day; and 1 -thyroxine, $0.2 \mathrm{mg}$ per day, throughout the experiment. Urine was collected on the 5 th and 6 th days, and crystalline THF recovered using carrier. A very low order of radioactivity was detected: 0.018 $\mu \mathrm{c} / \mathrm{mM}$. Which was 0,4 per cent of the SA of the plasma free cholesterol. This indicated slight, but definite, steroidogenesis by the adrenal glands. On the 8th, 9th, and 10th day of the study she was given ACTH, 20 units per day, intramuscularly. Another urine pool was collected on the 9 th and 10 th days. The radioactivity of the THF recovered from this sample was substantial, and the SA was 53 per cent of that of the plasma free cholesterol. It was obvious that her adrenal glands could respond normally to stimulation by the corticotrophin. In one other hypophysectomized patient, the results were comparable; and in two adrenalectomized patients, no radioactive THE could be detected.

Experiment VI: Over the past three years we have made 8 unsuccessful attempts to recover labeled estrogens from the urine of pregnant women scheduled for termination of pregnancy. Since radioactive estrogens have been produced in vitro using derivatives of cholesterol, and acetate, as the precursor, we concluded that our failures were due to inadequate doses of the tracer cholesterol and/or insufficient quantities of carrier in the isolation procedure. For the ninth trial, $87.4 \mu \mathrm{c}$ of $4-\mathrm{C}^{14}$-cholesterol was fed to a $26-y e a r-$ old woman (Unit \#66-51-62) in the second trimester of pregnancy. The priming dose was 5 times the daily dose, and feeding was continued for 6 days, during which time all the urine was collected and processed as a single pool. The crude estrogen extract weighed $338 \mathrm{mg}$ and contained 0.012 per cent of the dose of radiocarbon. Using large amounts of carrier, radiochemically-pure estrone was recovered. The radioassay data are shown in Table 5. The free estrone recovered had been diluted in the isolation process by approximately 75 parts of carrier. The SA of the final product remained constant when derivatives were formed. The approximate SA of the patient's estrone was $0.190 \mu \mathrm{c} / \mathrm{mM}$ and the SA of plasma free cholesterol at the time of delivery was $0.330 \mu \mathrm{c} / \mathrm{mM}$. The ratio of the se SA values is 59 per cent. The quantitative yield, however, was very small, and only about 0.0001 per cent of the labeled cholesterol administered was recovered as estrone. The reasons for our previous failues were apparent. 
Table 5

SPECIFIC ACTIVITY OF. ESTRONE-C ${ }^{14}$

ISOLATED BY CARRIER METHOD

\begin{tabular}{l|c|c|c}
\hline Derivative & Mg & DPM & $\begin{array}{c}\text { Free estrone } \\
\text { (DPM } / \mathrm{mg})\end{array}$ \\
\hline Acetate & 117.4 & 1615 & 15.9 \\
Acetate & 96.1 & 1335 & 16.0 \\
Benzoate & 84.7 & 899 & 14.7 \\
Benzoate & 77.0 & 806 & 14.5 \\
Benzoate & 68.9 & 761 & 15.3 \\
& (15 DPM x 75 $=0.190 \mu \mathrm{c} / \mathrm{mM})$ \\
\hline
\end{tabular}

$66-51-62$

Tracer $87.4 \mu \mathrm{c} \quad 4$-C 14 -Cholesterol

The classic experiment of Konrad Bloch ${ }^{*}$ has been repeated three times, using either $\mathrm{C}^{14}$ - or $\mathrm{H}^{3}$-labeled cholesterol. In his case, the fraction of pregnanediol derived from preformed cholesterol was 68 per cent; in our three cases the values were 59, 60, and 73 per cent, respectively. ${ }^{14}$

In summary, then, using cholesterol labeled with radiocarbon or tritium as a tracer; we have demonstrated in vivo that it is a precursor for the adrenal corticoids whose principal metabolites are tetrahydrocortisone, tetrahydrohydrocortisone, and 11-keto-etiocholanolone, as well as for steroid hormones whose principal metabolites are androsterone and etiocholanolone. In one case of adrenal carcinoma, some of these metabolites and radioactive cortisol were isolated from the urine following the administration of $\mathrm{C}^{14}$ progesterone. Finally, we have recovered radioactive estrone from urine during the second trimester of pregnancy when $\mathrm{C}^{14}$-cholesterol was fed to the patient.

Rather consistently, in all our experiments, the SA of the crystalline steroids isolated from the urine ranged from 60 to 80 per cent of the SA of the plasma free cholesterol when the tracer had been administered for a week or more. We cannot tell from our data whether this represents an equilibrium value for the cholesterol extracted from blood by the endocrine organ and that produced in situ, or whether it indicates the existence of a precursor other than cholesterol from which the balance is derived. We prefer the simpler explanation, i.e., it represents the equilibrium value. Using several assumptions, it is possible to estimate conditions for cholesterol synthesis and interchange in an endocrine organ that would result in the ratios formed. Such estimates are reasonable and are compatible with the scant information we have about these functions in the human subject.

Feeding of labeled cholesterol to a pregnant woman, and recovering crystalline pregnanediol for isotopic analysis. ${ }^{1}$ 


\section{SUMMARY}

The intact human endocrine system appears to be capable of performing the principal biosynthetic reactions responsible for steroidogenesis from cholesterol that have been demonstrated in vitro using perfused organs, tissue slices, and breis. The key reactions demonstrated by our study are:

1) Removal of the side-chain of cholesterol to give $\mathrm{C} 21, \mathrm{C} 19$, and $\mathrm{C} 18$ steroids.

2) Hydroxylation by the adrenal cortex at $\mathrm{C} 11, \mathrm{C} 17$, and $\mathrm{C} 21$ of the tetracyclic nucleus.

3) Rearrangement of the A-ring (by the placenta) to yield estrone, a C-18 steroid.

Finally, as a first approximation, our data demonstrate that 0.5 to 1.0 per cent of the plasma free cholesterol that is utilized daily goes into the biosynthesis of corticoids. ${ }^{*}$ In pregnancy, about 0.001 per cent of the daily cholesterol turnover goes into the production of estrone.

\section{LITERATURE CITED}

1. Bloch, IS. J. Diol. Chem., 157:661, 1045.

2. Hellman, L., W. Peacock, M. L. Eidinoff, Rr S. Rosenfeld, and K. Dobriner. Radioisotope Techniques, Volume I (Proceedings of the Isotope Techniques Conference) Oxford, 1951, H. M. Stationery Office.

3. Zaffaroni, A., O. Hechter, and G. Pincus. J. Am. Chem. Soc., 73:1930, 1951.

4. Werbin, H. and G. V. LeRoy. J. Am. Chem. Soc., 76:5260, 1954; Federation Proc., 14:303, 1955; J. Am. Chem. Soc., 79:1012, 1957.

5. Hiebert, R. D. and R. J. Watts. Nucleonics, $11: 38,1953$.

6. Gould, R. G., G. V. LeRoy, G. T. Okita, J. J. Kabara, P. Keegan, and D. M. Bergenstal. J. Lab. Clin. Med., 46:372, 1955; and Kabạra, J. J., Ibid., in press.

7. Fukushima, D. K. and T. F. Gallagher. J. Biol. Chem., 198:861, 1952.

8. Werbin, H., D. M. Bergenstal, R. G. Gould, and G. V. LeRoy. J. Clin. Endocrin. \& Metabolism, 17:337; 1957 .

9. Hellman, L., R. S. Rosenfeld, M. L. Eidinoff, D. K. Fukushima, and T. F. Gallagher. J. Clin. Invest., $34: 48,1955$.

10. Unpublished data.

11. LeRoy, G. V., R. G. Gould, D. M. Bergenstal, H. Werbin, and J. J. Kabara. J. Lab. and Clin. Med., in press.

12. Hechter, O. and G. Pincus. Physiol. Rev. 34:459, 1954.

13. Davis, M. E., E. J. Plotz, G. V. LeRoy, R. G. Gould, and H. Werbin. Am. J. Obstet. Gynecol., 72:740, 1956. Summary appears on p. 14 of this report.

Assume the average turnover rate of plasma free cholesterol to be $4.0 \mathrm{~g}$ per day; assume the daily production of corticoids to be $20 \mathrm{mg}$ per day, 60-80 per cent of which is produced from preformed cholesterol $=0.5$ per cent. 


\section{A TEST FOR THE DETERMINATION OF TAURINE IN THE URINE*}

\section{By}

E. I. Pentz, C. H. Davenport, W. Glover, and D. D. Smith

A description of a simple method for the determination of taurine in urine, which permits multiple analyses in a relatively short period of time, is the subject of this paper. The technique provides the opportunity for extending the recent observation that the excretion of taurine is increased in both the human being ${ }^{1}$ and the rat $^{2}$ following irradiation.

The sodium salt of dinitrophenol taurine (DPN-taurine) was synthesized and purified, and appropriate dilutions were made with $\mathrm{HCl}-\mathrm{KCl}$ buffer. Samples were read in a Beckman spectrophotometer, Model $\mathrm{B}$, at $355 \mathrm{~m} \mu$ to establish the validity of the standard curve. The reagents and procedure were as follows:

\section{REAGENTS FOR TAURINE DETERMINATION}

Dowex 50. 200-400 mesh, 8 per cent cross linked. (Nalcite HCR-8, $\mathrm{H}^{+}$form). ${ }^{* *}$

Used without further treatment

Potassium acid phthalate - sodium hydroxide buffer, $\mathrm{pH} 4.5$.

$50 \mathrm{ml} 0.2 \mathrm{M}$ potassium acid phthalate

$10 \mathrm{ml} 0.2 \mathrm{M} \mathrm{NaOH}$

$0.40 \mathrm{~g}$ sodium benzoate

make to $200 \mathrm{ml}$ with water

Sodium bicarbonate, 8 per cent

* Summary of a paper that has been accepted for publication in the Journal of Biological Chemistry.

* Two different lots of Nalcite HCR-8, 200-400 mesh, $\mathrm{H}^{+}$form, were used to carry out this work. Subsequently, small differences have been found between various lots of the product. The se chiefly affect the optical density readings of the blanks, some lots yielding much lower blank readings than others. It is suggested that having obtained a lot that yields a low blank, sufficient amounts of this material be obtained to last for a considerable number of analyses. It has been observed also that the 12 per cent cross-linked material is equally satisfactory for the performance of this test. A correction for dilution caused by the water content of the Dowex 50 must be applied. It is necessary to determine the value of this factor for each lot of Dowex used. This is done by developing a standard curve without using the resin; that is, by starting at Step 5 of the procedure and using appropriate dilutions of the standard solution direct1y. The difference between the slope of this curve and that of the standard curve obtained using Dowex is the correction factor. It may either be applied directly in the equation, or, as has been done here, as a percentage of the final figure. Inspection of Figure 1 shows that the standard curve obtained with Dowex cuts the origin and there is, therefore, no question of taurine loss by virtue of its adherence to the resin. For the determination reported here this correction factor has been found to be 0.90 . 
Dinitrofluorobenzene

Hydrochloric acid, $6 \mathrm{~N}$

Potassium chloride - hydrochloric acid buffer, pH 1.25

$50 \mathrm{ml} 0.4 \mathrm{M}$ potassium chloride

$41.5 \mathrm{ml} \mathrm{0.4} \mathrm{M}$ hydrochloric acid

make to $200 \mathrm{ml}$ with water

Chloroform. Reagent grade.

Taurine standard: $120.0 \mathrm{mg}$ taurine in $100 \mathrm{ml}$ of phthalate buffer. Dilute 1 to $100 \mathrm{ml}$ with buffer. Use $10 \mathrm{ml}$ in step 2 below. 1-, 2-, and 3-ml aliquots of filtrate (see 5 below) provide final taurine values of $3.2,6: 4$, and $9.6 \gamma / 4 \mathrm{ml}$, respectively.

Specimens for analyses:

a. Human urine was usually diluted 2 to $10 \mathrm{ml}$ with phthalate buffer before treatment with Dowex and $1 \mathrm{ml}$ of filtrate from step 4 used in step 5 below.

b. Rat urine was diluted 1 to 20 with phthalate buffer and $10 \mathrm{ml}$ treated with Dowex. $1 \mathrm{ml}$ of filtrate was used for analysis in step 5 .

\section{PROCEDURE}

1. Introduce $5.0 \mathrm{~g}$ Dowex 50 into a 50-ml Erlenmeyer flask

2. Add $10.0 \mathrm{ml}$ of the sample or the standard solution that is to be analyzed

3. Mix and let stand at room temperature for $5 \mathrm{~min}$. with occasional agitation

4. Filter through Whatman \# 40 filter paper

5. Introduce 1.0 to $3.0 \mathrm{ml}$ of filtrate into a $25-\mathrm{ml}$ volumetric flask

6. Add $5 \mathrm{ml}$ of 8 per cent sodium bicarbonate

7. Add $0.28 \mathrm{ml} \mathrm{DNFB}$

8. Shake overnight (16 hrs) at 180 oscillations per min. on a machine that is protected from light

9. Remove from shaking machine and add $1.0 \mathrm{ml}$ of $6 \mathrm{~N} \mathrm{HCl}$

10. Add $2.0 \mathrm{ml} \mathrm{KCl-HCl}$ buffer, $\mathrm{pH} 1.25$

11. Add $10 \mathrm{ml}$ chloroform. Stopper and extract by shaking vigorously for $1 \mathrm{~min}$.

12. Add water to $25 \mathrm{ml}$

13. Mix and transfer to a straight-sided 25-ml graduate

14. Transfer $10.0 \mathrm{ml}$ of the top layer to a $50-\mathrm{ml}$ straight-sided, stoppered graduate

15. Add $15 \mathrm{ml}$ chloroform. Extract by shaking $1 \mathrm{~min}$.

16. Transfer $4.0 \mathrm{ml}$ of the top layer to matched colorimeter tubes and read at $355 \mathrm{~m} \mu$.

The line of regression obtained from 50 analyses of standard solutions is expressed by the equation:

* Eastman Organic Chemicals or Eastern Chemical Corp. dinitrofluorobenzene (DNFB) have both been found to yield uniform results. The products of some other manufacturers have not been equally consistent. 


$$
\mathrm{Y}=0.0073 \pm 0.0383 \mathrm{X} \text {, }
$$

where $\mathrm{Y}$ represents the optical density and $\mathrm{X}, \mu \mathrm{g}$ of taurine per $4 \mathrm{ml}$ (Figure 1). The calculated standard error was \pm 0.5 per cent.

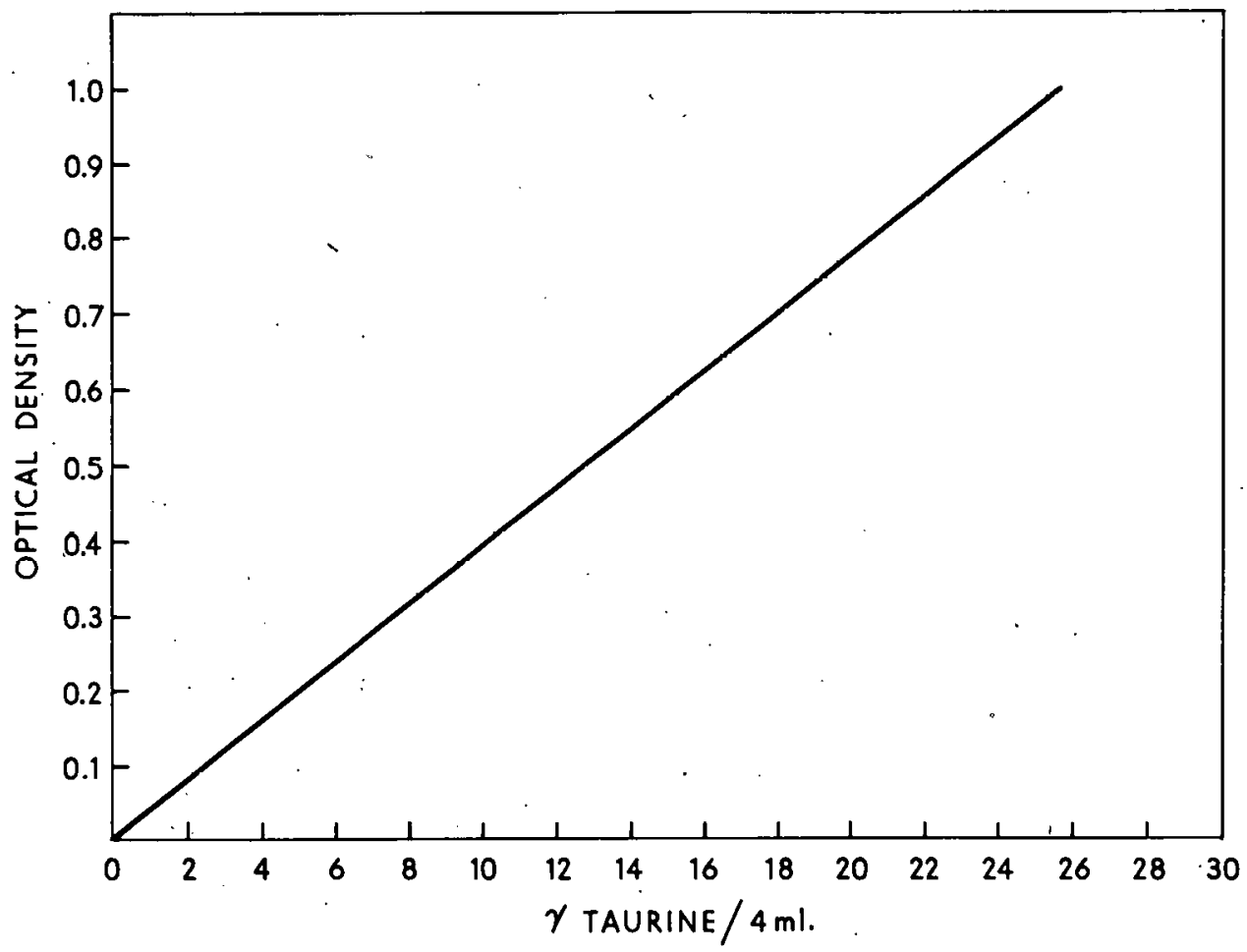

Figure 1. The relationship of optical density of the dinitrophenol derivative to the concentration of taurine as determined by the method outlined in the procedure.

Solutions of taurine were added quantitatively to urine that had been analyzed previously for its taurine content; and analyses were made for recovery of the added taurine. The results are given in Table 1.

Table 1

RECOVERY OF ADDED TAURINE FROM URINE THAT HAD BEEN PREVIOUSLY ANALYZED FOR TAURINE CONTENT

\begin{tabular}{c|c|c}
\hline $\begin{array}{c}\text { Taurine content } \\
\text { of urine } \\
(\dot{\gamma} / 4 \mathrm{ml})\end{array}$ & $\begin{array}{c}\text { Taurine added } \\
(\gamma / 4 \mathrm{ml})\end{array}$ & $\begin{array}{c}\text { Recovery } \\
(\%)\end{array}$ \\
\hline 5.2 & 3.8 & 100 \\
4.2 & 3.8 & 98 \\
5.5 & 7.8 & 102 \\
5.5 & 6.2 & 102 \\
12.4 & 5.3 & 102 \\
4.7 & 16.0 & 99 \\
5.6 & 13.2 & 98 \\
4.0 & 5.1 & 103 \\
8.0 & 5.1 & 102 \\
4.9 & 5.0 & 104 \\
\hline
\end{tabular}


A large number of amines and related compounds were tested for interference in the tests for taurine, and only two, cysteic acid and tyrosine-o-sulfate, were found to give positive results. Since these are normally present in urine in small amounts, the test is reasonably specific for taurine.

The importance of both the ionic strength and the $\mathrm{pH}$ of the diluent solution for completeness of recovery of taurine and for the exclusion of other amino acids is revealed by the data given in Tahle 2.

Table 2

\section{RECOVERY OF TAURINE FROM AMINO ACID MIXTURES OF VARIOUS HYDROGEN ION CONCENTRATION WITH AND WITHOUT ADDED BUFFER SOLUTIONS}

\begin{tabular}{|c|c|c|c|c|}
\hline Test solution & Diluent & $\mathrm{pH}$ & $\begin{array}{c}\gamma_{\text {(found) }} \\
\text { Taurine } / 4 \mathrm{ml}\end{array}$ & $\underset{(\%)}{\operatorname{Recovery} *}$ \\
\hline $\begin{array}{l}\text { Amino acids }(125 \gamma / 4 \mathrm{ml}) \\
\text { Amino acids }+8 \gamma \text { taurine } \\
\text { Amino acids }+16 \gamma \text { taurine }\end{array}$ & $\begin{array}{l}0.2 \mathrm{M} \text { potassium } \\
\text { phthalate, } \mathrm{HCl} \\
\text { buffer }\end{array}$ & $\begin{array}{l}2.6 \\
2.6 \\
2.6\end{array}$ & $\begin{array}{r}0.93 \\
8.62 \\
16.39\end{array}$ & $\begin{array}{l}96.2 \\
96.6\end{array}$ \\
\hline $\begin{array}{l}\text { Amino acids }(125 \gamma / 4 \mathrm{ml}) \\
\text { Amino acids }+8 \gamma \text { taurine } \\
\text { Amino acids }+16 \gamma \text { taurine }\end{array}$ & $\begin{array}{l}0.2 \mathrm{M} \text { potassium } \\
\text { acid phosphate } \\
\text { buffer }\end{array}$ & $\begin{array}{l}6.9 \\
6.9 \\
6.9\end{array}$ & $\begin{array}{r}0.38 \\
7.62 \\
15.56\end{array}$ & $\begin{array}{l}95.2 \\
95.9\end{array}$ \\
\hline $\begin{array}{l}\text { Amino acids }(125 \gamma / 4 \mathrm{ml}) \\
\text { Amino acids }+8 \gamma \text { taurine } \\
\text { Amino acids }+16 \gamma \text { taurine }\end{array}$ & $\begin{array}{l}0.2 \mathrm{M} \text { boric acid } \\
\text { potassium chloride } \\
\text { sodium hydroxide } \\
\text { buffer }\end{array}$ & $\begin{array}{l}10.0 \\
10.0 \\
10.0\end{array}$ & $\begin{array}{r}1.22 \\
9.27 \\
16.84\end{array}$ & $\begin{array}{r}100.5 \\
97.6\end{array}$ \\
\hline $\begin{array}{l}\text { Amino acids }(125 \gamma / 4 \mathrm{ml}) \\
\text { Amino acids }+8 \gamma \text { taurine } \\
\text { Amino acids }+16 \gamma \text { taurine }\end{array}$ & $\begin{array}{l}0.2 \mathrm{M} \text { potassium } \\
\text { phthalate, } \mathrm{HCl} \\
\text { buffer }\end{array}$ & $\begin{array}{l}4.5 \\
4.5 \\
4.5\end{array}$ & $\begin{array}{l}0.0 \\
8.06 \\
15.86\end{array}$ & $\begin{array}{c}100.75 \\
99.0\end{array}$ \\
\hline $\begin{array}{l}\text { Amino acids }(125 \gamma / 4 \mathrm{ml}) \\
\text { Amino acids }+8 \gamma \text { taurine } \\
\text { Amino acids }+16 \gamma \text { taurine }\end{array}$ & water & $\begin{array}{l}2.05 \\
2.05 \\
2.05\end{array}$ & $\begin{array}{r}0.0 \\
8.12 \\
16.39\end{array}$ & $\begin{array}{l}101.4 \\
101.8\end{array}$ \\
\hline $\begin{array}{l}\text { Amino acids } \\
\text { Total content } 251 \gamma / 4 \mathrm{ml}\end{array}$ & $\begin{array}{l}0.2 \mathrm{M} \text { potassium } \\
\text { phthalate, } \mathrm{HCl} \\
\text { buffer }\end{array}$ & 4.5 & 1.84 & $\therefore$ \\
\hline $\begin{array}{l}\text { Amino acids } \\
\text { Total content } 251 \gamma / 4 \mathrm{ml}\end{array}$ & water & 4.5 & 2.03 & \\
\hline $\begin{array}{l}\text { Amino acids } \\
\text { Total content } 333 \gamma / 4 \mathrm{ml}\end{array}$ & $\begin{array}{l}0.2 \mathrm{M} \text { potassium } \\
\text { phthalate, } \mathrm{HCl} \\
\text { buffer }\end{array}$ & 4.5 & 3.20 & r. \\
\hline $\begin{array}{l}\text { Amino acids } \\
\text { Total content } 313 \gamma / 4 \mathrm{ml}\end{array}$ & water & 4.5 & 3.17 & \\
\hline
\end{tabular}

* Where color was obtained from the solution of amino acids containing no taurine, the value has been subtracted from the color obtained from the solutions containing taurine to calculate the per cent recovery. 
Twenty-four-hour specimens were collected for 19 normal healthy male subjects between the ages of 20 and 40 years. They were analyzed for taurine before and after hydrolysis, and the results are shown in Table 3.

Some clinical applications for a test of this kind may well develop in view of the recent studics of Mann and his associatcs ${ }^{3-6}$ on taurine metabolism and on the relationship of the sulfur-containing amino acids to hypercholesterolemia.

Table 3

THE TAURINE V VALUES FOUND FOR UNHYDROLYZED AND HYDROLYZED URINE OBTAINED FROM

10 MALE BUEJEC'T'S

\begin{tabular}{l|c|c}
\hline Subjest & $\begin{array}{c}\text { Unhydrolyzed } \\
\text { (mg/ } 4 \text { hrs.) }\end{array}$ & $\begin{array}{c}\text { (mg/24 hrs.) } \\
\text { Hydrolyzed }\end{array}$ \\
\hline J.K. & 194.76 & 241.47 \\
J.S. & 287.28 & 310.95 \\
W.G. & 131.22 & 131.13 \\
L.S. & 253.35 & 287.19 \\
J.N. & 178.38 & 173.52 \\
E.S. & 119.88 & 136.17 \\
A.L. & 211.14 & 239.58 \\
C.H. & 191.25 & 229.41 \\
C.J. & 165.15 & 216.99 \\
R.H. & 513.90 & 512.10 \\
S.P. & 230.40 & 216.90 \\
R.H. & 269.73 & 343.35 \\
P.H. & 210.42 & 226.62 \\
F.S. & 139.77 & 165.60 \\
R.Z. & 43.83 & 52.92 \\
J.S. & 268.20 & 256.05 \\
V.W. & 260.37 & 319.68 \\
G.B. & 213.57 & 232.29 \\
F.S. & 140.04 & 145.35 \\
& & \\
Average & 211.6 & 233.5 \\
\hline
\end{tabular}

ACKNOWLEDGMENTS

The authors take pleasure in acknowledging the interest and encouragement of $\mathrm{Dr}$. Robert J. Hasterlik and the helpful suggestions of Dr. Leif Sorenson. Mr. Rodney Sung also contributed to the early phases of the work.

\section{LITERATURE CITED}

1. Katz, E. J. and R. J. Hasterlik. J. Nat. Cancer Inst., 15:1085, 1955.

2. Kay, R. E. and C. Entenman. Abstracts of the Radiation Research Society, May 1956.

3. Portman, O. W. and G. V. Mann. J. Biol. Chem., 213:733, 1955.

4. Mann, G. V., S. B. Andrus, A. McNally, and F. J. Stare. J. Exp. Med., 98:195, 1953.

5. Fillios, L. C. and G. V. Mann. Metabolism, Clin. and Exptl., 3:16, 1954.

6. Portman, O. W. and G. V. Mann. J. Biol. Chem., 220:105, 1956. 


\title{
IN VIVO RADIOTRACER STABILITY OF A TRITIUM "SELF-RADIATION" LABELED COMPOUND*
}

By

\author{
.James L. Spratt. ${ }^{\dagger}$ George T, Okita, and E. M. K. Geiling ${ }^{\ddagger}$
}

Radioisotopic labeling of biochemical tracer compounds has been accomplished by diverse chemical reaction techniques and biosynthetic procedures. The recently announced "self-radiation" method of tritium labeling ${ }^{1}$ appears to offer numerous advantages over other labeling techniques. This is true for all compounds but particularly so for those that are difficult or impossible to synthesize as well as those having unknown structures. A rigorous test for the applicability of this labeling method to biochemical tracer research is digitoxin, a very labile cardiac glycoside that cannot withstand many of the laboratory techniques usually employed in removing "exchangeable" tritium atoms. With the cooperation of Drs. Wilzbach and Brown, Chemistry Division, Argonne National Laboratory, we were able to obtain self-radiation labeled $\mathrm{H}^{3}$-digitoxin and demonstrate the feasibility of using this labeling procedure in biochemical tracer investigations.

\section{MATERIALS AND METHODS}

Approximately $450 \mathrm{mg}$ of nonradioactive digitoxin (Nutritional Biochemical Co.) was sealed with 7.5 curies of tritium gas and allowed to react for one week. Exchangeable tritium was removed by ethanol washing, and the compound was purified by means of Decalso chromatography, ${ }^{2}$ charcoal decolorization, and recrystallization to constant melting point and specific activity using ethanol-water and chloroform-ether as solvents for crystallization. Chromatographic strip analyses were made using various solvent systems. $2,3,4$ Continuous radiograms of the paper strips were also taken using a Forro chromatogram scanner, a Nuclear-Chicago count rate meter (model 1620), and an Esterline-Angus graphic ammeter.

The question of in vivo stability of the radioactive label was answered by use of a double-labeling experiment utilizing biosynthetically labeled $\mathrm{C}^{14}$-digitoxin and the $\mathrm{H}^{3}$ digitoxin. A mixture of the $\mathrm{C}^{14}$ - and $\mathrm{H}^{3}$-labeled drug was injected intravenously into two rats, and the unchanged glycoside was recovered from the first 24-hour samples of urine and feces. The radioactivity in the individual $\mathrm{H}^{3}$ and $\mathrm{C}^{14}$ solutions and the radioassay of

* Based on a paper that has been accepted for publication in the International Journal of Applied Radiation and Isotopes. The work was aided in part by a grant from the Life Insurance Medical Research Fund and the Dr. Wallace C. and Clara A. Abbott Memorial Fund.

† Predoctoral Research Fellow of the National Heart Institute.

‡ Department of Pharmacology, The University of Chicago. 
the double-labeled injected mixture and the glycoside recovered from the urine and feces were determined by a double-label counting method ${ }^{5}$ using a Packard Tri-Carb liquid scintillation spectrometer. ${ }^{*}$

\section{RESULTS}

The original sample from Argonne National Laboratory was found to have numerous radioactive contaminants and had to be subjected to extensive purification including 6 Decalso columns and numerous crystallizations before radiochemical purity was obtained. The specific activity of the compound decreased from $513 \mu \mathrm{c}$ per mg to a constant $75 \mu \mathrm{c}$ per $\mathrm{mg}$ in the final product. The product had a melting point of $254-257^{\circ} \mathrm{C}$, and crystalline structure was similar to that reported by Windaus and Freese. ${ }^{6}$ It gave the same Rf values on paper strips as that of digitoxin obtained from three different laboratories. In addition, paper chromatography, using three different solvent systems, ${ }^{2,3,4}$ gave the same $\mathrm{Rf}$ as nonradioactive digitoxin. Each system yielded a single radioactivity peak coinciding with the alkaline picrate color band when the radioactive drug was run alone (Figure 1). and when mixed with nonradioactive digitoxin: Distribution of the isotope within the molecule is as yet undetermined.

Cardiotonic activity of the purified compound was verified by Langendorf perfusion of isolated guinea pig hearts.

Within the limits of experimental error, the double-label ratios (Figure 2) indicate in vivo radiostability of the compound and commend self-radiation labeling to biochemical tracer studies if meticulous care is taken regarding radiochemical purity and the in vivo stability of the product.

\section{DISCUSSION}

Self-radiation labeling offers numerous advantages to biochemical tracer technology. Among these are 1) ease of labeling, 2) availability of high specific activities (detection of $0.0002 \mu \mathrm{g}$ of digitoxin is possible), 3) unlimited quantities of tracer compound, 4) low cost (the cost of tritium used was $\$ 15.00)$, and 5) ability to label compounds difficult or impossible to label by other means.

The only limitation on this method (as on other methods) is that the burden of proof concerning its efficacy as a biochemical tracer is in the particular compound in use. In biochemical tracer work, the various physical criteria of purity considered absolute in the analytical chemistry laboratory are a minimum requirement and represent only the first step in ascertaining radiochemical purity (i.e., 0.01 per cent gravimetric impurity may account for all the radioactivity). Removal of radioactive contaminants as well as "scrubbing" the molecule by diverse procedures to remove all labile radioactive atoms is fundamental. This is well demonstrated where self-radiation-labeled 3-amino-1,2,4triazole recrystallized to fairly constant specific activity in water was found to yield

Packard Instrument Company, LaGrange, Illinois. 


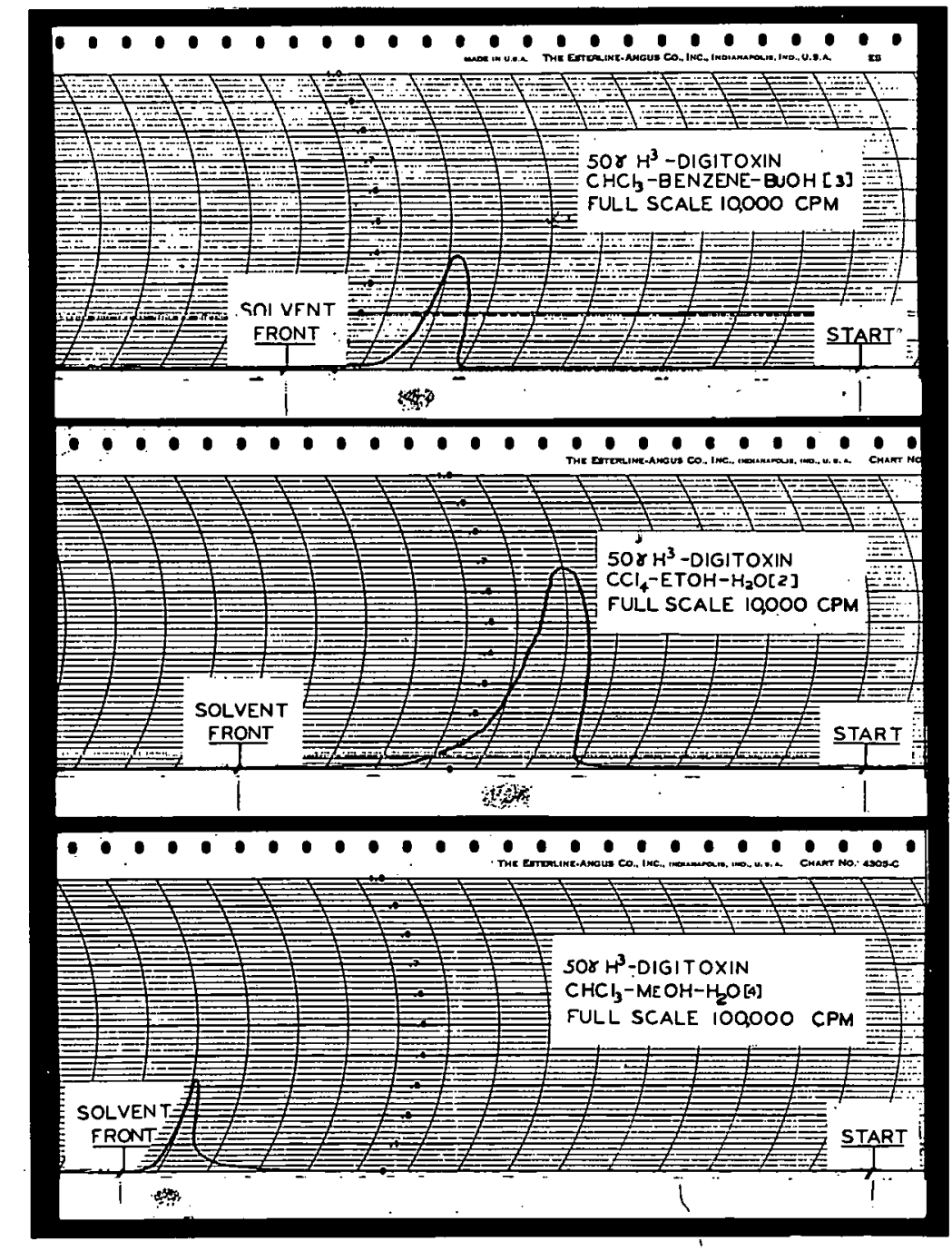

Figure 1. Chromatograms and radiograms of $\mathrm{H}^{3}$-digitoxin. Chromatograms simulated from original alkaline picrate color reaction. Solvent reference is designated in brackets.

\begin{tabular}{|c|c|c|c|}
\hline SAMPLE & DPM $\mathrm{H}^{3}$ & DPM $C^{14}$ & $\mathrm{H}^{3} / \mathrm{C}^{14}$ \\
\hline Individual assays & 971,362 & 216,745 & 4. 48 \\
\hline Injected mixture & 217,324 & 46,480 & 4.68 \\
\hline Uri ne & 11,986 & 2,912 & 4. 12 \\
\hline Feces & 5,152 & 1,097 & 4.70 \\
\hline
\end{tabular}

Figure 2. $\mathrm{H}^{3}$-digitoxin: $\mathrm{C}^{14}$-digitoxin ratios. 
evenly dispersed radioactivity throughout a paper chromatographic strip thereby showing that contaminants or labile atoms were still present. ${ }^{7}$

We recommend that thorough "scrubbing" of self-radiation labeled compounds be accomplished by 1) washing with water, alkali, or hydrogenated organic solvents; 2) crystallizing from hydrogen-containing systems; or 3) employing chromatographic procedures using adsorbent and/or hydrogen-containing solvents as. "exchangers." The preparative use of multi-fraction chromatographic analyses correlating quantitative assay and radioassay can be an extremely valuable technique in the resolution of radiochemical contaminants. In addition, the analytical use of different chromatographic systems with varying resolution characteristics may be very important in checking the radiochemical purity of a "chemically pure" compound.

We believe that we have established the validity of using tritium self-radiation labeling in biochemical tracer studies employing digitoxin and that the method is applicable to other tracer compounds if purity and in vivo radiotracer stability are established.

\section{LITERATURE CITED}

1. Wilzbach, K. Fall Meeting of the American Chemical Society, New York, New York, 1956.

2. Okita, G. T., F. E. Kelsey, E. J. Walaszek, and E. M. K. Geiling. J. Pharm. and Exp. Ther., 110:244, 1954 .

3. Brown, B. T., D. Ranger, and S. B. Wright. J. Pharm. and Exp. Ther., 113:353, 1955.

4. Jensen, K. B. Acta Pharm. Tox., 9:99, 1953.

5. Okita, G. T., J. J. Kabara, F. Richardson, and G. V. LeRoy. Nucleonics, 15:No. 6, $111,1957$.

6. Windaus, A. and S. Freese. Ber. deut, chem. Ges., 58:2503, 1925.

7. Feinstein, R. N. (Argonne National Laboratory, Lemont, Illinois), Personal communication. 


\section{STUDIES WITH RADIOACTIVE DIGITALIS*+}

By

G. T. Okita

The purpose of this paper is to summarize our findings on the blood level; tissue distribution, excretion, and placental transfer of radioactive digitoxin in human beings.

Radioactive digitoxin was isolated from Digitalis purpurea L. plants grown in an atmosphere of $\mathrm{C}^{14} \mathrm{O}_{2}$. The method has been reported previously.

Eight patients with congestive heart failure were divided into two groups for studies of blood levels and excretion. Each of those in one group was given a single intravenous injection of $0.5 \mathrm{mg}$ of radioactive digitoxin, and each in the other, from 1.2 to $1.5 \mathrm{mg}$. Prior to this time, digitalis had been withheld from 14 to 34 days; afterwards it was withheld for 14 days. After injection of the labeled drug, 10- to $20-\mathrm{ml}$ samples of blood were withdrawn at various intervals up to 96 hours. Each sample was quickly transferred after withdrawal into a heparinized tube and stored at $-17^{\circ} \mathrm{C}$. Urine samples were collected daily for as long as 80 days after injection and were lyophilized and stored as the dehydrated powder.

Blood level determinations indicated that both the unchanged labeled drug and its metabolic products can be detected in the blood as long as 96 hours after the introduction of radioactive digitoxin. Approximately 42 per cent of the injected dose was found in the vascular system as unchanged digitoxin within 2 minutes after the administration of 0.5 or 1.2 to $1.5 \mathrm{mg}$ of the labeled glycoside (Figure 1). At the end of 15 minutes, the value dropped to 12 per cent, at 6 hours to 3 , and at 96 hours from trace amounts to 1 per cent. There was a higher percentage of metabolic products in the blood than the unchanged drug as can be seen from the curves in Figure 1 representing total $\mathrm{C}^{14}$.

The concentration of unchanged digitoxin in the blood is plotted semi-logarithmically in Figure 2. The curve can be resolved into two straight line components from which it is possible to determine the half-life of each component. ${ }^{2,3}$ The biological half-life of the first component is 15 to 30 minutes, and that of the second component is 48 to 54 hours. Comparison of these half-lives between the two dosage levels employed suggests that the rate of disappearance from the vascular system is not dose dependent.

The average daily excretion rates of the patients who received $0.5 \mathrm{mg}$ of radioactive

* Summary of a paper that appears in the Journal of the American Geriatrics Society 5:163 (1957).

+ Presented at the Annual Meeting of the American Therapeutic Society, Chicago, Ill., June $7-10,1956$. 


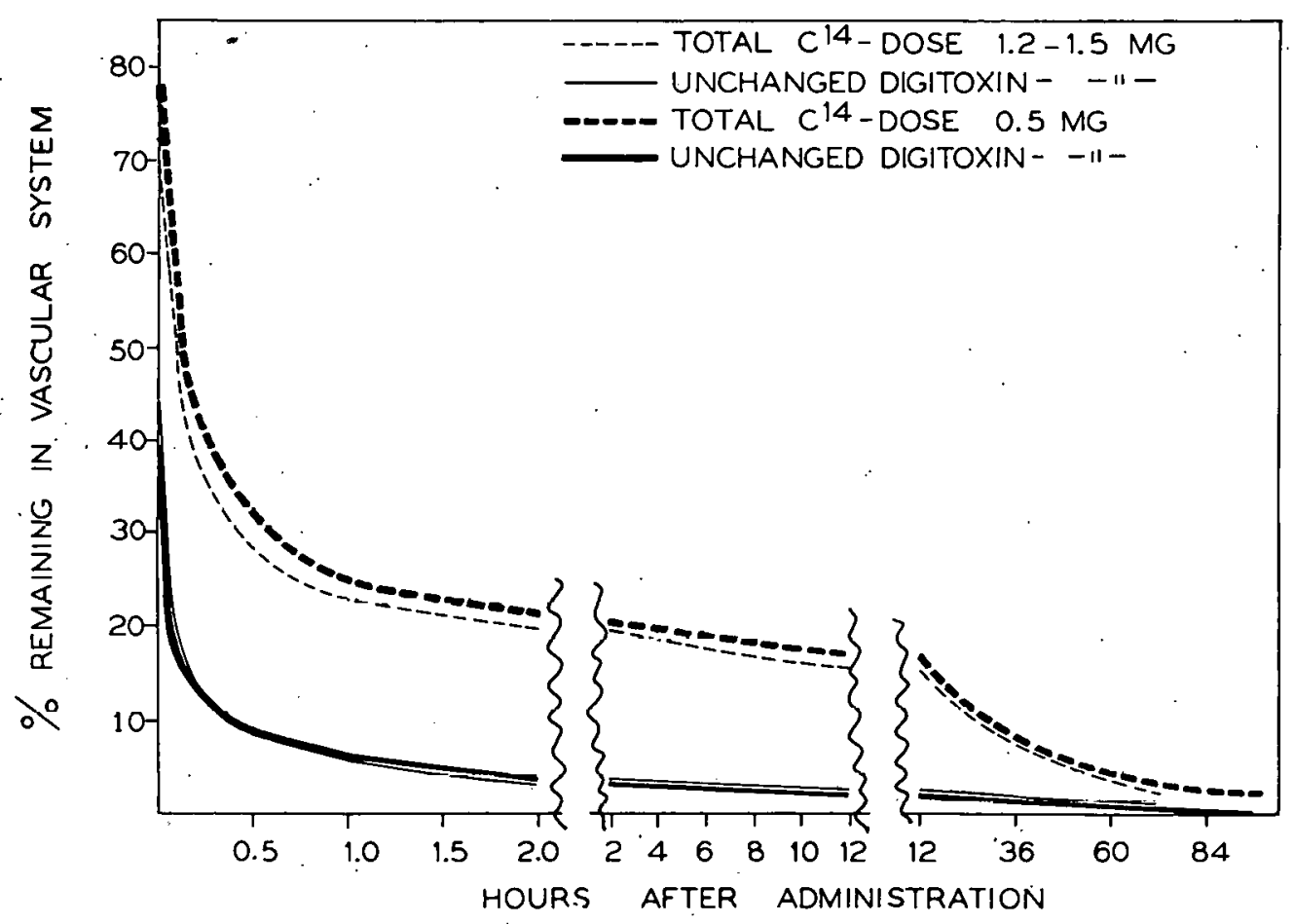

Figure 1. Blood level curves showing per cent of dose remaining in vascular system as unchanged digitoxin and total $\mathrm{C}^{14}$ after a single intravenous administration of radioactive digitoxin.

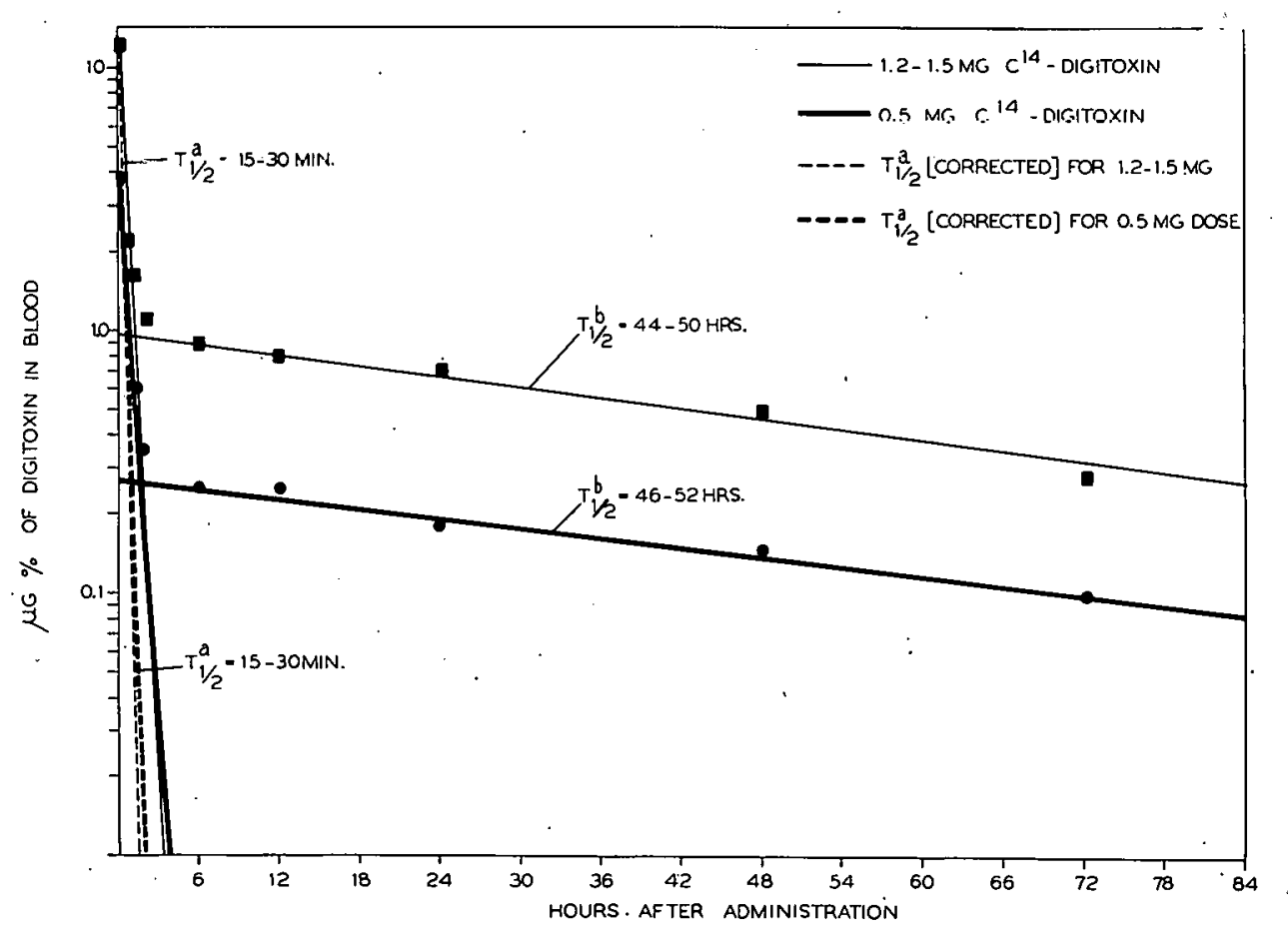

Figure 2. Semi-logarithmic plot showing disappearance rate of . unchanged digitoxin in blood after intravenous administration of $\mathrm{C}^{14}$-digitoxin. 
digitoxin are shown in Figure 3 and those for the patients who were given 1.2 to $1.5 \mathrm{mg}$ in Figure 4. During the initial three-day period of rapid decline, 20 per cent of the administered dose was eliminated as total $C^{14}$, with about half of this amount during the first 24 hours. It is evident that the rate of excretion is dependent upon the amount that is in the

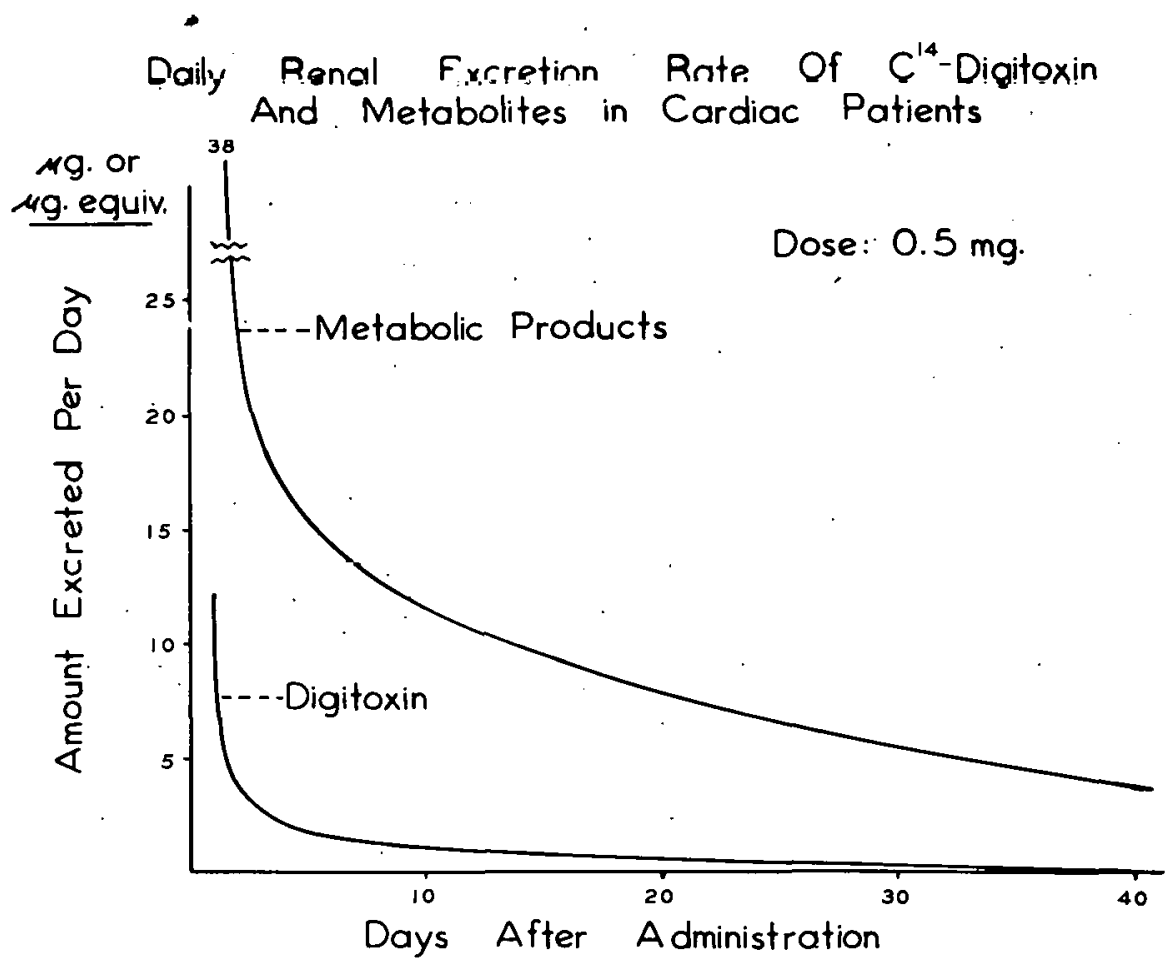

Figure 3. Average daily renal excretion rate of unchanged digitoxin and its metabolic products for four cardiac patients receiving $\mathrm{C}^{14}$-digitoxin. Dose $-0.5 \mathrm{mg} \mathrm{I} . \mathrm{V}$.

body. The results also indicate that the glycoside is excreted over a considerable period of time. Minute amounts of the unchanged drug can be detected in the urine up to as long as 50 days after the drug has been administered, and its metabolic products have been assayed up to 80 days.

The disappearance curve for unchanged digitoxin in urine (Figure 5) indicates a biological half-life of about 9 days, which is in good agreement.with the clinical evidence for the long cumulative action of digitoxin.

It was significant that most of the administered drug was converted to metabolic products. Approximately 71 per cent of the original dose was excreted in the urine as metabolites of digitoxin, whereas only 8 per cent of the parent compound was detected. A comparison of renal excretion with fecal excretion reveals that digitoxin and its metabolic products ( 60 to 80 per cent) are eliminated primarily by the kidneys. However, there was 
no real difference in the amount of unchanged drug that was excreted via the urine or feces.

Tissue distribution was studied in three terminal patients. Multiple doses of radioactive digitoxin were given intravenously at varying intervals until a short time before death in order to maintain adequate tissue concentrations.

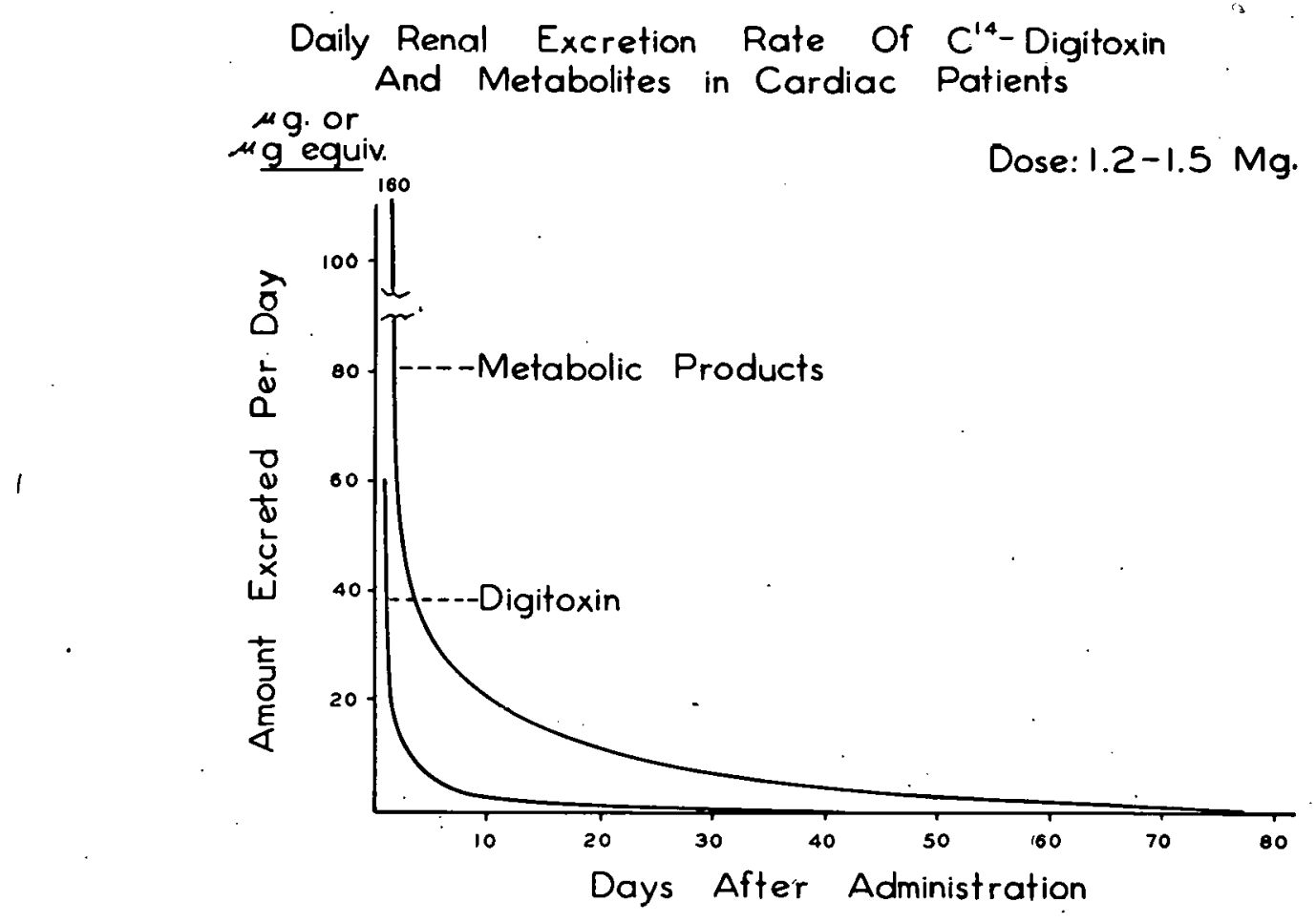

Figure 4. Average daily renal excretion rate of unchanged digitoxin and its metabolic products for four cardiac patients receiving $\mathrm{C}^{14}$-digitoxin. Dose -1.2 to $1.5 \mathrm{mg}$ IV.

It is of particular interest that the myocardium has no greater selectivity for digitoxin than any of the other organs that were studied (Figures 6 and 7). The site of highest concentration of unchanged digitoxin on a tissue-weight basis was the colonic content. This may reflect the concentration of substances through reabsorption of water by the colonic mucosa. The liver was found to have the highest concentration when the concentration of the drug is expressed as per cent of the administered dose.

In almost all of the organs that were assayed, the concentration of metabolic products was higher than that of the unchanged drug. By calculating the metabolite:digitoxin ratio for each organ, it was possible to obtain information regarding the site of conversion of digitoxin. The spleen had the highest ratio averaging 16; the liver, 9; contents of the gall bladder and the jejunum, 7 ; ileal contents, 5 ; colonic contents, 1 ; kidney, 3 ; lung and ventricle, 2; and blood, 4.

The high ratio in the spleen may be due to the accumulation of metabolite-protein 
complexes by the reticulo-endothelial cells. As to be expected, the high ratio obtained for the liver in all probability is indicative that this organ is the principal site for detoxification.

The entero-hepatic cycling of digitoxin and its metabolites is shown by the passage of labeled compounds into the small intestine by way of the biliary tract and their reabsorption by the intestinal mucosa. There is a greater rate of reabsorption of metabolites by the small intestine as compared with unchanged digitoxin, which is suggested by the decrease in the metabolite:digitoxin ratio during passage of labeled products from the small to the large intestine.

Semi-Logarithmic Plot Of Disappearance

Rate of $\mathrm{C}^{14}$-Digitoxin in Urine of

Cardiac Patients

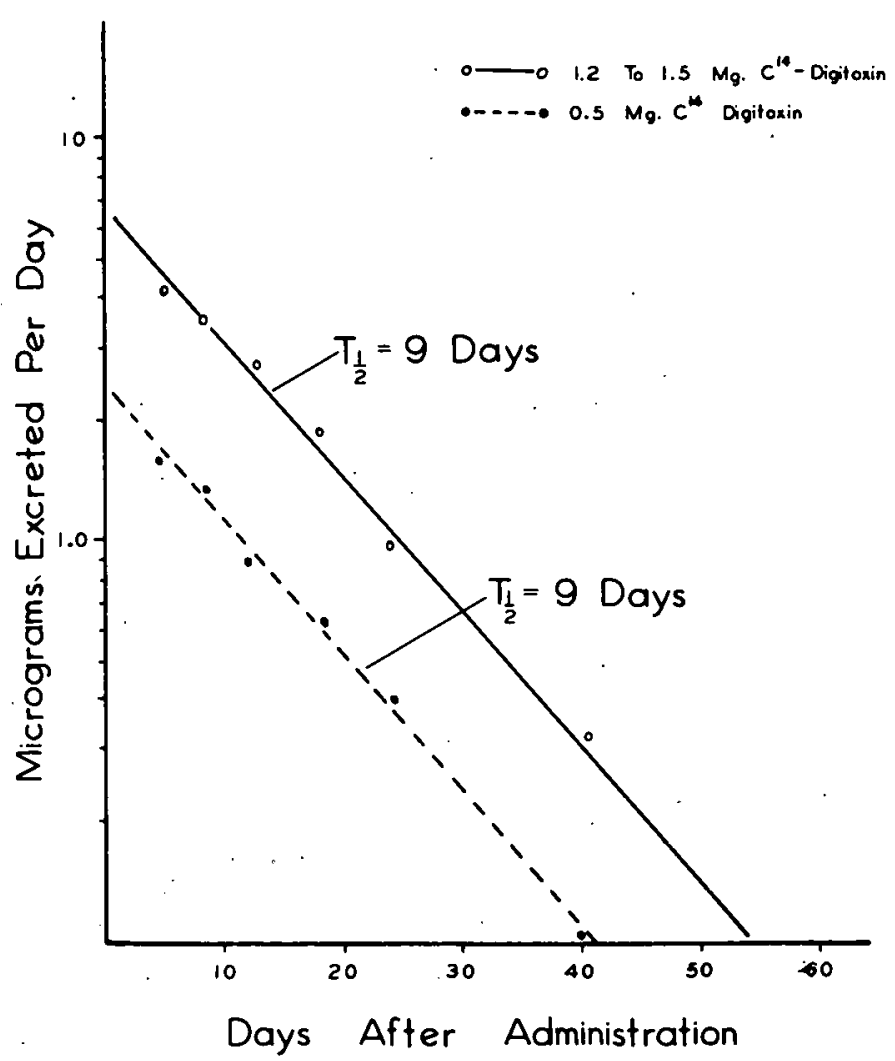

Figure 5. Semi-logarithmic plot showing disappearance rate of unchanged digitoxin in urine after intravenous administration of $\mathrm{C}^{14}$-digitoxin.

Placental transfer studies were made on four pregnant women who were scheduled for therapeutic abortion. Three of the patients who were from 11 to 12 weeks pregnant were 
given 0.25 to $0.50 \mathrm{mg}$ of the labeled drug at 2.7 to 5.0 hours before removal of the fetus. The fourth woman, in the 34 th week of gestation, was given $0.5 \mathrm{mg}$ of $\mathrm{C}^{14}$-digitoxin about 2 to 3 hours prior to the expected time of delivery of an anencephalic infant. The fetal heart beat stopped during delivery 2 hours after the drug had been administered.

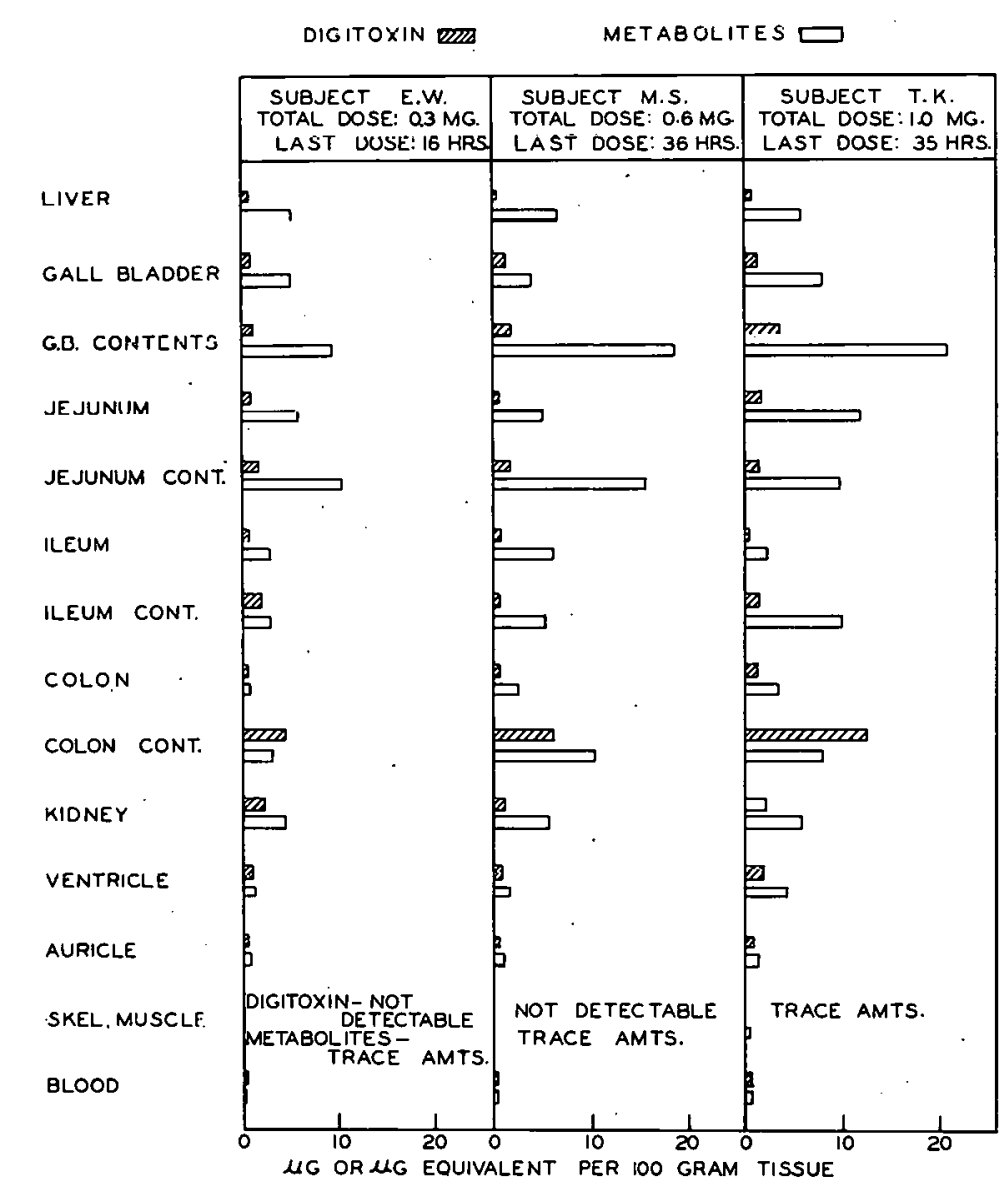

Figure 6. Tissue distribution of radioactive digitoxin in human organs. Amount per $100 \mathrm{~g}$ of tissue.

Our.results indicate that a small amount of cardiac glycoside crosses the placental barrier. Less than 0.1 per cent of the injected dose was found as unchanged digitoxin and less than 0.33 per cent as its metabolic product in the 11 - to 12 -week-old fetuses. In the 34-week fetus, 0.84 per cent appeared as the unchanged drug and 3.49 per cent as metabolic products. This difference may be due to body size since there is no significant difference in concentration when it is expressed on a tissue-weight basis.

The distribution of radioactive digitoxin and its metabolic products in the organs of the 11 - to 12-week fetuses is shown in Figure 8, and that for the 34-week infant in Figure 9 . 
A direct comparison of the concentration of digitoxin in the maternal heart with that in the fetal heart was not possible. However, a sample of auricular appendage was obtained from a patient undergoing cardiac surgery who had been given $0.5 \mathrm{mg}$ of the labeled

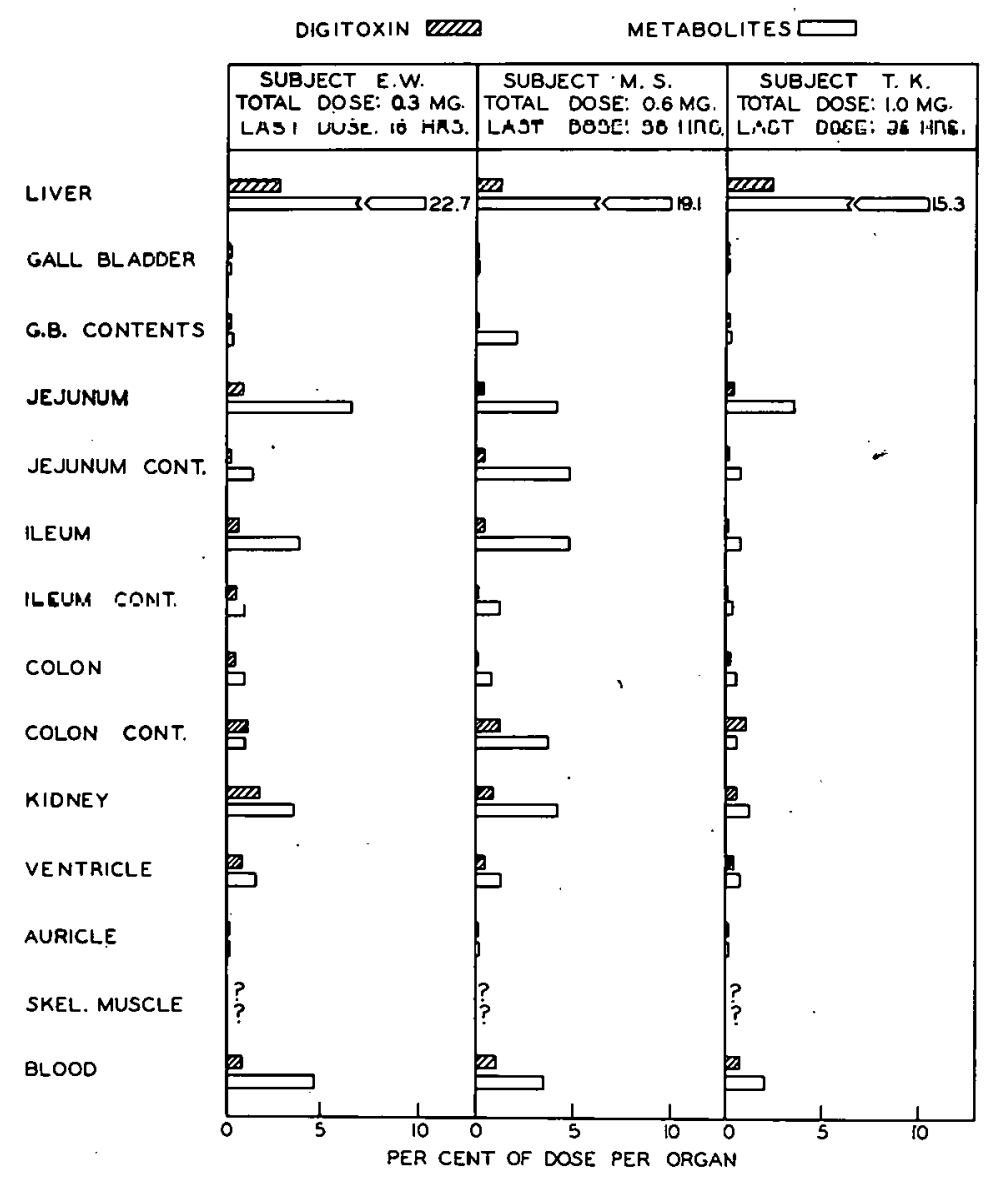

Figure 7. Tissue distribution of radioactive digitoxin in human organs. Per cent of dose per organ.

glycoside 3 hours before removal of the tissue. The tissue from the adult was found to have approximately twice the concentration as that of the near-term infant, but the concentration in the hearts of the 11 - and 12 -week fetuses was ten times greater than that of the adult tissue. This may possibly be attributed to differences in cell sizes. Wollenberger ${ }^{4}$ has postulated that mature and immature cells may have roughly the same number of drug molecules per cell, although they differ on a tissue-weight basis. This would account for his finding that the heart of immature experimental animals is able to tolerate a larger dose of ouabain on a milligram-per-kilogram basis than the heart of mature animals. If the findings of Wollenberger ${ }^{4}$ can be extrapolated to human beings, it seems likely that the minute amount of digitoxin (less than 1 per cent) that crosses the 
placental barrier may be considered to be nontoxic to the unborn child.

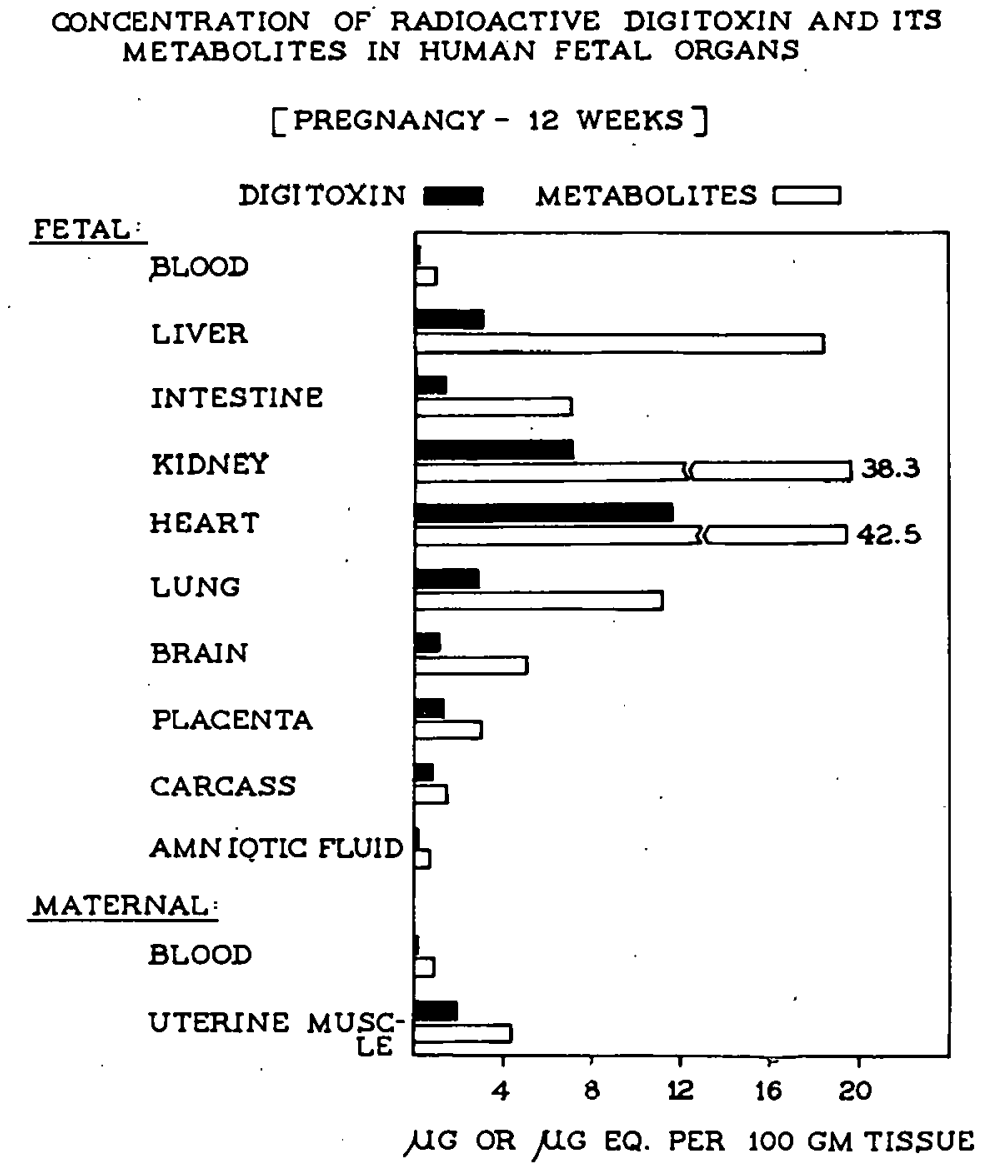

Figure 8 . Concentration of radioactive digitoxin and its metabolites in human fetal organs at 11 to 12 weeks of gestation. One-half $\mathrm{mg}$ of labeled digitoxin was administered intravenously 2.8 to 5 hours before therapeutic abortion. Fetal tissues obtained from the patient receiving $0.25 \mathrm{mg}$ were corrected for $0.5 \mathrm{mg}$ dose. All figures represent the average value from tissues of three fetuses.

\section{ACKNOWLEDGMENT}

This communications includes data that were obtained earlier by joint efforts of other colleagues. These include Drs. E. M. K. Geiling, P. J. Talso, F. E. Kelsey, E. J. Plotz, M. E. Davis, and Messrs. J. H. Curry, Jr. and F. D. Smith, Jr., to whom the author wishes to express his indebtedness and gratitude. The author also wishes to express his appreciation to Drs. W. H. Adams and E. B. Bay for their cooperation in providing cardiac patients for this study, to Dr. R. W. Wissler for conducting the autopsies, and to Dr. E. Mika for raising the radioactive Digitalis purpurea L. plants from which the labeled $\underline{C}^{14}$-digitoxin was obtained. 


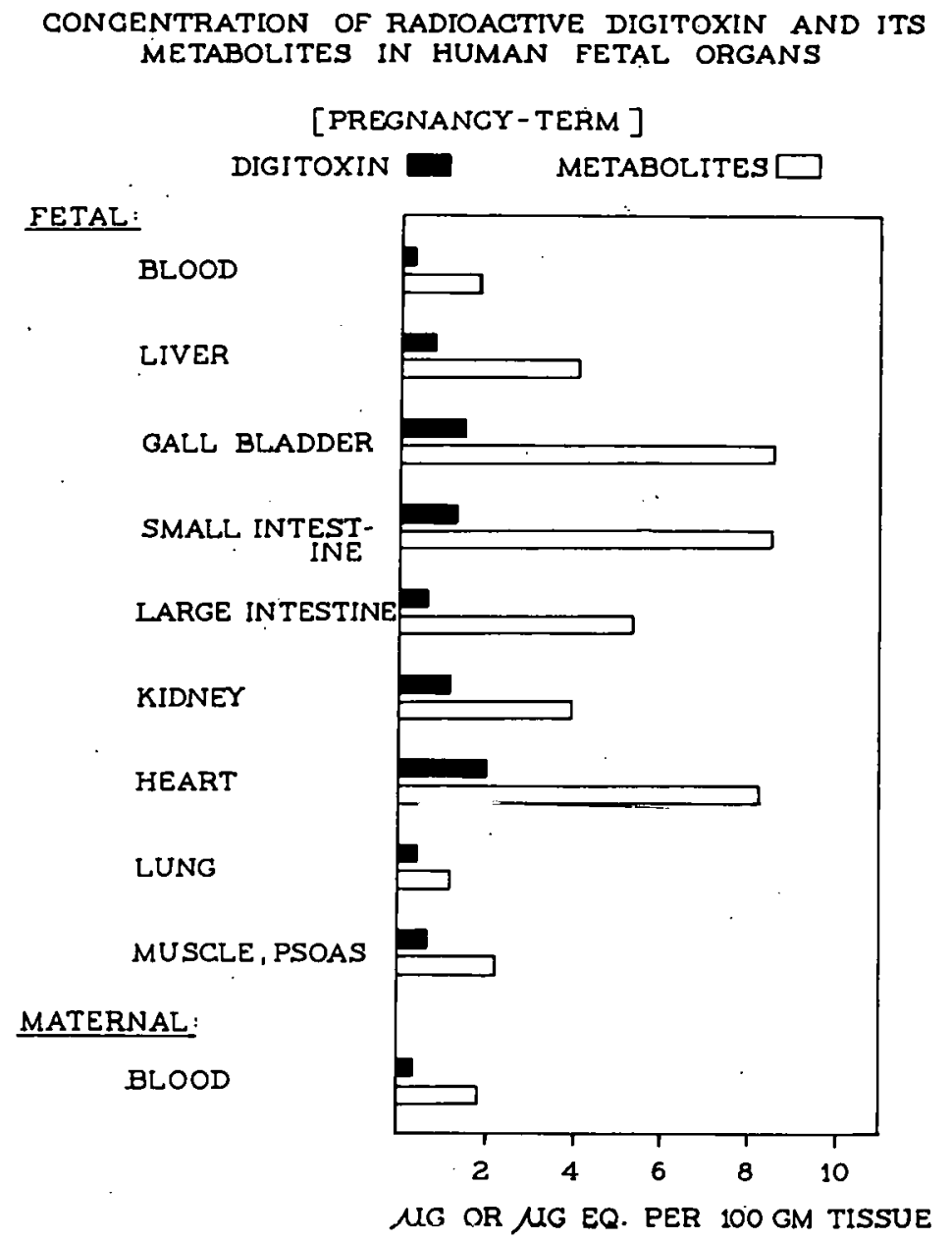

Figure 9. Concentration of radioactive digitoxin and its metabolites in human fetal organs at 34 weeks of gestation. One-half $\mathrm{mg}$ of labeled $\mathrm{C}^{14}$-digitoxin was administered intravenously 2 hours before death occurred during delivery.

\section{LITERATURE CITED}

1. Okita, G. T., F. E. Kelsey, E. J. Walaszek, and E. M. K. Geiling. J. Pharmacol. Exper. Therap., $110: 244,1954$.

2. Zilversmit, D. B., C. Entenman, C. and M. C. Fishler. J. Gen. Physiol., 26:325 (1943).

3. Comar, C. L. Radioisotopes in Biology and Agriculture, McGraw-Hill Book Company, New York, p. 18, 1955.

4. Wollenberger, A., J. Jehl, and M. L. Karsh. J. Pharmacol. Exper. Therap., 108:52, 1953. 


\section{SIMULTANEOUS RADIOASSAY OF COMPOUNDS CONTAINING TRITIUM AND CARBON-14 USING A LIQUID SCINTILLATION COUNTER*}

By

G. T. Okita, J. J. Kabara, F. Richardson, and G. V. LeRoy

The use of tritium and carbon-14 in double-labeling isotope experiments offers an additional dimension that greatly increases the versatility of tracer studies in biological research. Tritium and carbon-14 are especially important in such studies because the stable forms of these two isotopes are found in all organic compounds. The lack of convenient methods for determining the two weak $\beta$-emitting isotopes simultaneously has limited the use of this type of tracer experiment.

The method employed currently for assaying double-labeled compounds of tritium $\left(\mathrm{H}^{3}\right)$ and $\mathrm{C}^{14}$ involves separation of the two isotopes by combustion techniques; ${ }^{1,2}$ the $\mathrm{H}^{3}$ being converted to either tritium gas or tritium methane, the $C^{14}$ to $C^{14}$-carbon dioxide. The gases are then assayed separately in a suitable gas-phase counter.

Liquid scintillation assay permits simple and rapid determinations, ${ }^{3-5}$ both from the standpoint of sample preparation and counting. Therefore, the feasibility of counting doublelabeled isotopes by this means was investigated. This was accomplished by taking advantage of the difference in the energies of the $\beta$ particles of $\mathrm{H}^{3}$ and $\mathrm{C}^{14}$. The maximum $\beta$ energy for tritium is $0.018 \mathrm{Mev}$ and for carbon-14 $0.155 \mathrm{Mev}$. The instruments generally used are fast-coincidence circuits with one or more pulse-height discriminators. In some cases, the discriminator circuit is arranged so that one scaler monitors one portion of the energy spectrum for which upper and lower discriminators may be set, and a second scaler monitors another portion. In Figure 1 are shown the spectral energy curves for tritium and carbon-14 and the discriminator settings of a liquid scintillation counter. The instrument used in this study was the Tri-Carb liquid scintillation spectrometer with a twochannel pulse-height analyzer. ${ }^{\dagger}$ Two channels for pulse-height discrimination are obtained by means of three discriminator controls: A, B, and C. The output of each channel is fed into its respective scaler. All pulses of energy greater than $A$, and less than $B$, are monitored by the scaler connected with channel 1 . Pulses with energies greater than $B$, and less than $C$, are registered by the scaler of channel 2. This channel can also be set to monitor pulses with energies greater than $A$ and less than $C$.

\section{SELECTION OF DISCRIMINATOR AND VOLTAGE SETTINGS}

To differentiate between the two isotopes, as well as to obtain maximum reproducibil-

Based on a paper that appears in Nucleonics, 15:No. 6, 111, 1957.

+ Tri-Carb Counter, Model 314, Packard Instrument Co., LaGrange, Illinois. 


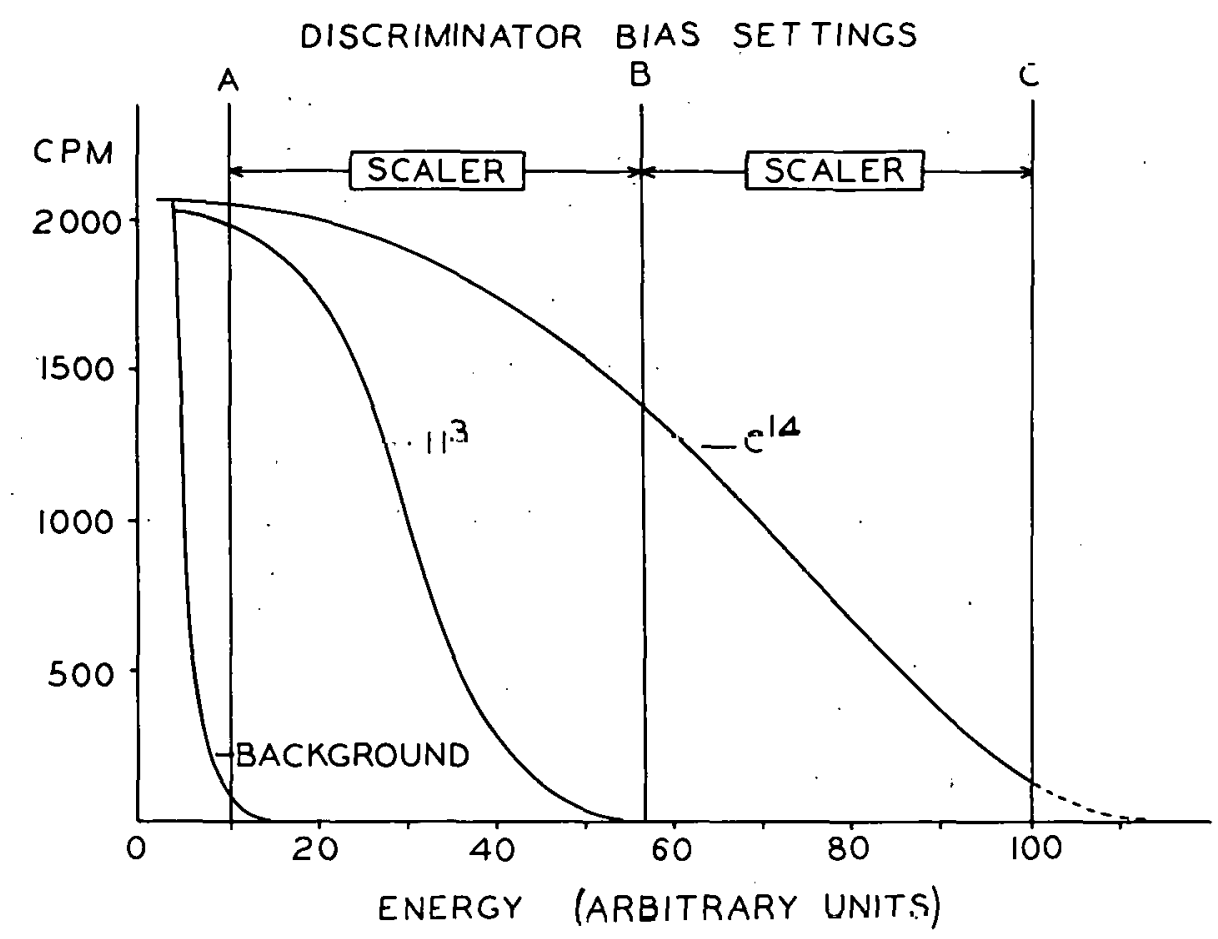

Figure 1. Spectral energy curves for tritium and carbon-14 and discriminator bias settings of liquid scintillation counter. Photomultiplier voltage was 1130 volts. Differential curves were plotted using "window" width of 5 volts.

ity, it is necessary to select critically the proper pulse-height discriminator and photomultiplier voltage settings. To obtain the optimum settings, integral bias curves first were plotted for both isotopes. In Figure 2 is shown the graphical plot of such curves. The criterion used to estimate the optimum settings was the point on the graph at which the highest "contrast" ratio (ratio of counts occurring in the second to the first channel) was obtained for both isotopes without an appreciable loss in counting efficiency in the first channel.

Discriminator control $A$ for both channels was set at a pulse height of 10 volts, the point at which a good signal-to-noise ratio was obtained for the two isotopes. For the second channel, the "upper-gate" discriminator at $\mathrm{C}$ was set at the maximum pulse height setting of 100 volts to eliminate large background pulses caused by local $\gamma$ radiation and cosmic rays. Therefore, the discriminator control requiring critical selection for the best "contrast" ratio is control B of the first channel. By examination of Figure 2, it can be seen that the most desirable position for discriminator $B$ is between pulse amplitudes of 20 to 30 volts. The 20 -volt region may be less desirable because of appreciable sacrifice in counting efficiency in the first channel.

For selection of the photomultiplier voltage, it will be noted that any voltage lower than 1000 will not be suitable for double-label counting since a "contrast" ratio of unity is obtained for tritium pulses below this value. Also, any voltage setting greater than 1250 
volts is undesirable because of the marked drop in carbon-14 efficiency. Therefore, the voltage range to be selected should be between 1100 and 1200 volts. The drop in carbon14 efficiency can be attributed to over pulsing of carbon-14 pulses beyond the "uppergate" discriminator with an increase in photomultiplier voltage.

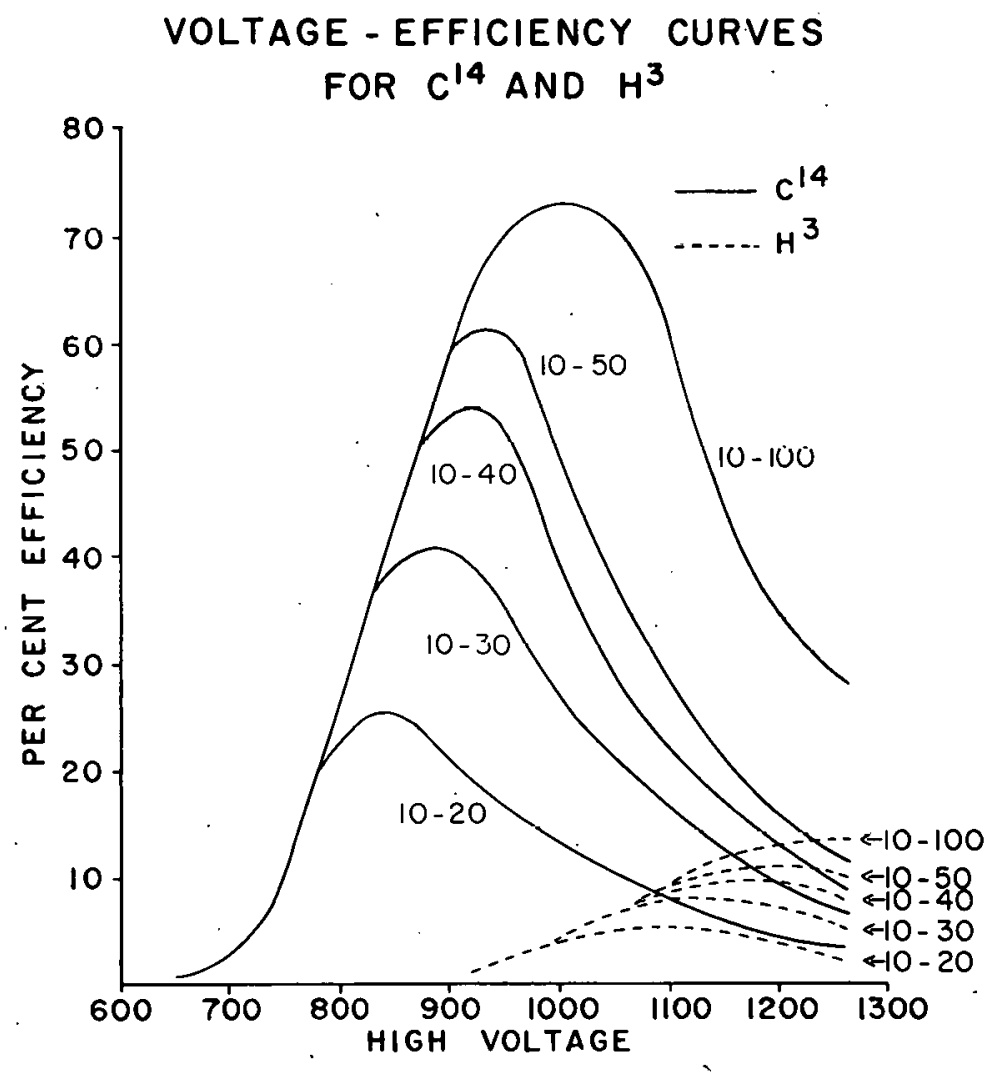

Figure ${ }^{-2}$. Integral discriminator bias curves for tritium and carbon-14. Per cent dounting efficiency is plotted against photomultiplier voltage.

For final selection of the optimum discriminator and photomultiplier voltage settings, a combination of voltage ranges between 1100 and 1250 volts and variation in discriminator bias control $\mathrm{B}$ from 20 to 30 were investigated using a mixed sample containing a known amount of both tritium and carbon-14. The results of such determinations are shown in Table 1. It can be seen from the data that the greatest accuracy was obtained with a voltage setting of 1130 volts and a discriminator range of 10 to 30 for channel 1 and 10 to 100 for channel 2.

The photomultiplier voltage and discriminator settings will vary from instrument to instrument depending upon the condition of the phototube, electronic circuitry, type of solvent system employed, etc. It should be emphasized that it will be necessary to check the integral bias curves from time to time to note any shift. 
Table 1

EFFECT OF VOLTAGE AND DISCRIMINATOR SETTINGS

ON ACCURACY OF ASSAY

\begin{tabular}{|c|c|c|c|c|c|c|c|}
\hline \multirow{2}{*}{\multicolumn{2}{|c|}{$\begin{array}{l}\text { Discriminator } \\
\text { settings }\end{array}$}} & \multicolumn{6}{|c|}{ Per cent standard error ${ }^{*}$} \\
\hline & & \multirow{2}{*}{\multicolumn{2}{|c|}{$\begin{array}{l}\text { Voltage } \\
1130\end{array}$}} & \multirow{2}{*}{\multicolumn{2}{|c|}{$\begin{array}{l}\text { Voltage } \\
1200\end{array}$}} & \multirow{2}{*}{\multicolumn{2}{|c|}{$\begin{array}{l}\text { Voltage } \\
1260\end{array}$}} \\
\hline \multirow{2}{*}{$\begin{array}{l}\text { First } \\
\text { channel }\end{array}$} & \multirow{2}{*}{$\begin{array}{l}\text { Second } \\
\text { channel }\end{array}$} & & & & & & \\
\hline & & $\mathrm{H}^{3}$ & $\mathrm{C}^{14}$ & $\mathrm{H}^{3}$ & $\mathrm{C}^{14}$ & $\mathrm{H}^{3}$ & $\mathrm{C}^{14}$ \\
\hline $10-20$ & $10-100$ & 7.6 & 4.7 & 6.5 & 10.5 & 7.2 & 16.5 \\
\hline $10-25$ & $10-100$ & 6.1 & 3.4 & 5.9 & 8.0 & 18.8 & 6.9 \\
\hline $10-30$ & $10-100$ & 1.5 & 3.5 & 4.1 & 7.4 & 9.8 & 7.0 \\
\hline
\end{tabular}

* Each figure represents standard error of 4 experiments.

\section{METHOD OF ASSAY}

In the course of our work, we have used three methods for counting the two isntopes in the salne sampie in order to determine which gives the highest degree of accuracy. The three are the screening, the simultaneous equation, and the discriminator-ratio method. As applied to an instrument of the Tri-Carb type, descriptions of the three procedures follow:

Screening method. This procedure requires counting both isotopes simultaneously at a given discriminator and photomultiplier voltage and then counting the pulses due to carbon-14 alone at a lower photomultiplier voltage in order to screen out all tritium pulses. Initially, an attempt was made to screen out all tritium pulses by holding the voltage constant and setting the discriminator control $\mathrm{B}$ high enough to eliminate all tritium pulses as illustrated in Figure 1. However, this method was not satisfactory since it was not possible to eliminate all tritium pulses.

The radioactivity for each isotope can be calculated by applying the following formulas where $\mathrm{dpm}=$ disintegrations per minute, $\mathrm{cpm}=$ counts per minute, $\mathrm{C}=\mathrm{dpm}$ of $\mathrm{C}^{14}$, $\mathrm{H}=$ dpm of $\mathrm{H}^{3}, \mathrm{~N}_{1}=$ net cpm at low voltage, $\mathrm{N}_{2}=$ net cpm at higher voltage, $\mathrm{h}_{1}=\mathrm{H}^{3}$ efficiency at low voltage, $\mathrm{h}_{2}=\mathrm{H}^{3}$ efficiency at higher voltage, $\mathrm{c}_{1}=\mathrm{C}^{14}$ efficiency at low voltage, and $c_{2}=C^{14}$ efficiency at higher voltage:

Set

$$
\begin{aligned}
\mathrm{h}_{1} & =0 \text { and } \mathrm{c}_{1}>0 \\
\mathrm{~N}_{1} & =\mathrm{Hh_{1 }}+\mathrm{Cc}_{1} \\
\mathrm{~N}_{1} & =\mathrm{Cc_{1 }} \\
\mathrm{C} & =\frac{\mathrm{N}_{1}}{\mathrm{C}_{1}}=\mathrm{C}^{14} \mathrm{dpm}
\end{aligned}
$$

therefore, 
therefore,

$$
\begin{aligned}
& \mathrm{N}_{2}=\mathrm{Hh}_{2}+\mathrm{Cc}_{2} \\
& \mathrm{Hh}_{2}=\mathrm{N}_{2}-\mathrm{Cc}_{2} \\
& \mathrm{H}=\frac{\mathrm{N}_{2}-\mathrm{Cc}_{2}}{\mathrm{~h}_{2}}=\mathrm{H}^{3} \mathrm{dpm}
\end{aligned}
$$

Simultaneous equation method. In this method the photomultiplier voltage was held constant. The discriminator control $\mathrm{B}$ was set so that an appreciable amount of both tritium and carbon-14 pulses could be detected in both channels. The discriminator range for the first channel was from $A$ to $B$ and for the second channel from $A$ to $C$.

The radioactivity for each isotope was calculaled by applying the following formulas that were derived by setting up a simultaneous equation to solve for the two unknowns. $\mathrm{N}_{1}=$ net cpm of channel $1, \mathrm{~N}_{2}=$ net cpm of channel 2, $\mathrm{h}_{1}=\mathrm{H}^{3}$ efficiency channel $1, \mathrm{~h}_{2}=$ $\mathrm{H}_{3}$ efficiency of channel 2, $\mathrm{c}_{1}=\mathrm{C}^{14}$ efficiency of channel 1 , and $\mathrm{c}_{2}=\mathrm{C}^{14}$ efficiency of channel 2.

$$
\begin{aligned}
& C^{14} \text { dpm }=\frac{N_{1} h_{2}-N_{2} h_{1}}{c_{1} h_{2}-c_{2} h_{1}} \\
& H^{3} d p m=\frac{N_{1} c_{2}-N_{2} c_{1}}{h_{1} c_{2}-h_{2} c_{1}}
\end{aligned}
$$

Discriminator-ratio method. In the discriminator-ratio method, ${ }^{*}$ the photomultipliervoltage and discriminator control settings were similar to those used in the simultaneous equation method. The discriminator-ratio procedure was employed to circumvent the use of efficiency factors, which are only as accurate as the original assidy of the tritium ${ }^{\dagger}$ and carbon- $14^{\ddagger}$ standards.

This mêthod uses the ratio of counts per minute occurring in the second channel to those occurring in the first channel, which are obtained from standard samples of each of the isotopes.

An equation is then derived which utilizes the discriminator ratio for each isotope instead of the counting efficiency as used in the two previous methods. The equations for calculating the activities for each of the isotopes were derived as follows: $N_{1}=$ net $\mathrm{cpm}$ of

\footnotetext{
We are indebted to $\mathrm{Mr}$. Leo Slatery of the Packard Instrument Co. for suggesting this method.

$+\quad$ Tritium-labeled cholesterol used as the tritium standard was assayed by the method of Wilzbach et al. 1

\# Cholesterol-r-C 14 , used as the carbon-14 standard, was assayed against $\mathrm{Na}_{2} \mathrm{CO}_{3}-\mathrm{C}^{14}$ obtained from the National Bureau of Standards. The method of assay was the wet-combustion and ion-chamber vibrating-reed electrometer method of Brownell and Lockhart. ${ }^{2}$
} 
channel 1, $\mathrm{N}_{2}=$ net cpm of channel $2, \mathrm{H}_{1}=$ net $\mathrm{cpm}$ of $\mathrm{H}^{3}$ in channel $1, \mathrm{H}_{2}=$ net cpm of $\mathrm{H}^{3}$ in channel 2, $\mathrm{C}_{1}=$ net $\mathrm{cpm}$ of $\mathrm{C}^{14}$ in channel 1 , and $\mathrm{C}_{2}=$ net cpm of $\mathrm{C}^{14}$ in channel 2 .

Set

$$
\begin{aligned}
& \frac{\mathrm{H}_{2}}{\mathrm{H}_{1}}=\mathrm{a}, \mathrm{H}_{2}=a \mathrm{H}_{1} \text { and } \\
& \frac{\mathrm{C}_{2}}{\mathrm{C}_{1}}=\mathrm{b}, \mathrm{C}_{2}=\mathrm{bC}_{1}
\end{aligned}
$$

Calculation for $\mathrm{H}^{3}$ :

$$
\begin{aligned}
& \mathrm{N}_{2}=\mathrm{H}_{2}+\mathrm{C}_{2} \\
& \mathrm{C}_{2}=\mathrm{N}_{2}-\mathrm{H}_{2} \\
& \mathrm{bC}_{1}=\mathrm{N}_{2}-\mathrm{H}_{2}=\mathrm{N}_{2}-\mathrm{aH}_{1} \\
& \mathrm{C}_{1}=\frac{\mathrm{N}_{2}}{\mathrm{~b}}-\frac{\mathrm{aH}}{\mathrm{b}}
\end{aligned}
$$

also,

$$
\begin{aligned}
& \mathrm{N}_{1}=\mathrm{H}_{1}+\mathrm{C}_{1} \\
& \mathrm{H}_{1}=\mathrm{N}_{1}-\mathrm{C}_{1}
\end{aligned}
$$$$
\mathrm{H}_{1}=\mathrm{N}_{1}-\frac{\mathrm{N}_{2}}{\mathrm{~b}}+\frac{\mathrm{aH}}{\mathrm{b}}
$$$$
\mathrm{H}_{1}-\frac{\mathrm{aH}}{\mathrm{b}}=\mathrm{N}_{1}-\frac{\mathrm{N}_{2}}{\mathrm{~b}}
$$$$
\mathrm{H}_{1} \frac{(1-\mathrm{a})}{\mathrm{b}}=\mathrm{N}_{1}-\frac{\mathrm{N}_{2}}{\mathrm{~b}}
$$$$
\mathrm{H}_{1}=\left[\mathrm{N}_{1}-\frac{\mathrm{N}_{2}}{\mathrm{~b}}\right]\left[\frac{\mathrm{b}}{(\mathrm{b}-\mathrm{a})}\right]=\frac{\mathrm{bN}_{1}}{(\mathrm{~b}-\mathrm{a})}-\frac{\mathrm{N}_{2}}{(\mathrm{~b}-\mathrm{a})}
$$

therefore,

$$
\mathrm{H}_{1}=\frac{\mathrm{bN}_{1}-\mathrm{N}_{2}}{\mathrm{~b}-\mathrm{a}}=\mathrm{H}^{3} \mathrm{cpm}
$$

also,

$$
\mathrm{H}^{3} \mathrm{dpm}=\frac{\mathrm{H}_{1}}{\text { channel 1 } \mathrm{H}^{3} \text { efficiency factor }}
$$

Calculation for $\mathrm{C}^{14}$ :

Since

$\dot{H}_{2}=a H_{1}$, and $\mathrm{H}_{1}=\frac{\mathrm{bN}_{1}-\mathrm{N}_{2}}{\mathrm{~b}-\mathrm{a}}$

then,

$\mathrm{H}_{2}=\frac{\mathrm{abN}_{1}-\mathrm{aN}_{2}}{\mathrm{~b}-\mathrm{a}}$

also,

$$
\begin{aligned}
& \mathrm{N}_{2}=\mathrm{H}_{2}+\mathrm{C}_{2} \\
& \mathrm{C}_{2}=\mathrm{N}_{2}-\mathrm{H}_{2}
\end{aligned}
$$




$$
\begin{aligned}
& \mathrm{C}_{2}=\mathrm{N}_{2}-\frac{a b N_{1}}{(\mathrm{~b}-\mathrm{a})}+\frac{a N_{2}}{(\mathrm{~b}-\mathrm{a})} \\
& \mathrm{C}_{2}=\left[1+\frac{a}{(\mathrm{~b}-\mathrm{a})}\right] \mathrm{N}_{2}-\frac{a b N_{1}}{(\mathrm{~b}-\mathrm{a})} \\
& \mathrm{C}_{2}=\left[\frac{\mathrm{b}-\mathrm{a}+\mathrm{a}}{(\mathrm{b}-\mathrm{a})}\right] \mathrm{N}_{2}-\frac{a b N_{1}}{(\mathrm{~b}-\mathrm{a})} \\
& \mathrm{C}_{2}=\frac{\mathrm{bN_{2 }}-\mathrm{abN} \mathrm{N}_{1}}{\mathrm{~b}-\mathrm{a}} \\
& \mathrm{C}_{2}=\frac{\mathrm{b}\left(\mathrm{N}_{2}-\mathrm{aN} \mathrm{N}_{1}\right)}{\mathrm{b}-\mathrm{a}}=\mathrm{C}^{14} \mathrm{cpm} \\
& \mathrm{C}^{14} \mathrm{dpm}=\frac{\mathrm{C}_{2}}{\text { channel } 2 \mathrm{C}^{14} \text { efficiency factor }}
\end{aligned}
$$$$
\text { therefore. }
$$$$
\text { also, }
$$

The following is a sample calculation of a double-labeled compound using the discriminator ratio method. The sample contained a known activity of $10,800 \mathrm{dpm}$ of $\mathrm{H}^{3}$ and $2928 \mathrm{dpm}$ of $\mathrm{C}^{14}$. Setting the photomultiplier voltage at 1130 volts and the discriminator at 10 to 30 volts for the first channel and 10 to 100 volts for the second channel, the following figures were obtained: $\mathrm{N}_{1}=561 \mathrm{cpm}, \mathrm{N}_{2}=3759 \mathrm{cpm}, \mathrm{a}=3.30, \mathrm{~b}=16.8$, channel 1 tritium efficiency factor $=0.0382$, and channel $2 \mathrm{C}^{14}$ efficiency factor $=0.816$. Therefore, using equations 5 and 6 , the calculated tritium activity is given by:

$$
\begin{aligned}
& \frac{\mathrm{bN}_{1}-\mathrm{N}_{2}}{\mathrm{~b}-\mathrm{a}}=\frac{16.8 \times 561-3759}{16.8-3.30}=418 \mathrm{cpm} \text { of } \mathrm{H}^{3} \\
& \mathrm{H}^{3} \mathrm{dpm}=\frac{418}{0.0382}=10,942
\end{aligned}
$$

Similarly by means of equations 7 and 8 , the calculated $\mathrm{C}^{14}$ activity is given by

$$
\begin{aligned}
& \frac{\mathrm{b}\left(\mathrm{N}_{2}-\mathrm{aN} \mathrm{N}_{1}\right)}{\mathrm{b}-\mathrm{a}}=\frac{16.8(3759-3.30 \times 561)}{16.8 \times 3.30}=2355 \mathrm{cpm} \text { of } \mathrm{C}^{14} \\
& \mathrm{C}^{14} \mathrm{dpm}=\frac{2355}{0.816}=2886
\end{aligned}
$$

\section{EFFECT OF METHOD OF ASSAY ON ACCURACY}

To determine which method was the most reliable, twelve samples containing varying amounts and ratios $\left(\mathrm{H}^{3} \mathrm{dpm} / \mathrm{C}^{14} \mathrm{dpm}\right.$ was 1 to 10$)$ were assayed by the three methods described. The standard error of the assay was used as a criterion of accuracy (S.E. = $\sqrt{\Sigma d^{2} / n(n-1)}$, where $d=$ per cent deviation from theoretical). The data are given in Table 2 . Of the three methods investigated, the discriminator-ratio proved to be the most reliable. The standard error for the tritium assay was 3.7 per cent and for carbon-14, 4.6 per cent. The larger error obtained by the screening method may be attributed to the difficulty in eliminating all tritium pulses when the discriminator bias and photomultiplier 
Table 2

ACCURACY OF METHODS

\begin{tabular}{l|l|l}
\hline \multirow{2}{*}{ Method of assay } & \multicolumn{2}{|c}{ Standard error $(\%)^{*}$} \\
\cline { 2 - 3 } & $\mathrm{H}^{3}$ & $\mathrm{C}^{14}$ \\
\hline Screening & 7.6 & 6.7 \\
Simultaneous equation & 4.7 & 8.4 \\
Discriminator -ratio & 3.7 & 4.6 \\
\hline
\end{tabular}

* Each figure represents standard error of 12 samples containing varying amounts of tritium and carbon-14 activity.

voltage were set to assay only carbon-14 pulses.

The lower reliability of the simultaneous-equation method may be attributed to the fact that it requires using the counting efficiencies for both isotopes six times. Since the counting efficiencies are only as accurate as the assay of the original isotope standard, this may introduce an appreciable error if there was a slight error in the original assay.

\section{OTHER FACTORS AFFECTING RESULTS}

For the most reliable results in counting double-labeled compounds, it is necessary to consider the scintillator-solvent system, the isotope ratio, and the radioactivity level of the sample.

Change in scintillator solvent system. Each scintillator solvent system has its own characteristic integral discriminator bias curves for tritium and carbon-14. It is therefore essential that the discriminator and photomultiplier voltage settings be redetermined whenever the composition of a scintillator solvent system is to be changed.

Isotope ratio in sample. Effect of variation in the ratio of the two isotopes on reliability of assay was also determined. As can be seen from the curve in Figure 3, for both very large and very small values of this ratio, the determination is inaccurate. For accurate assays, the isotope ratio $\left(\mathrm{H}^{3} \mathrm{dpm} / \mathrm{C}^{14} \mathrm{dpm}\right)$ should be between 1 and 15.

Minimum level of radioactivity. It is, of course, essential that all sample activity be sufficiently greater than that of the background. The minimum level of the counting rate of the sample will depend upon the background rate, the length of counting time, and the accuracy desired. For routine radioassay, it was found that for a background counting rate of 40 and $60 \mathrm{cpm}$ for channel 1 and channel 2 discriminators, respectively, and for a counting period of less than 30 minutes, the sample-to-background counting rate ratio should be no less than three.

\section{SUMMARY .}

The feasibility of counting double-labeled compounds of tritium and carbon-14 using a liquid scintillation counter with a two channel pulse height analyzer was investigated. 


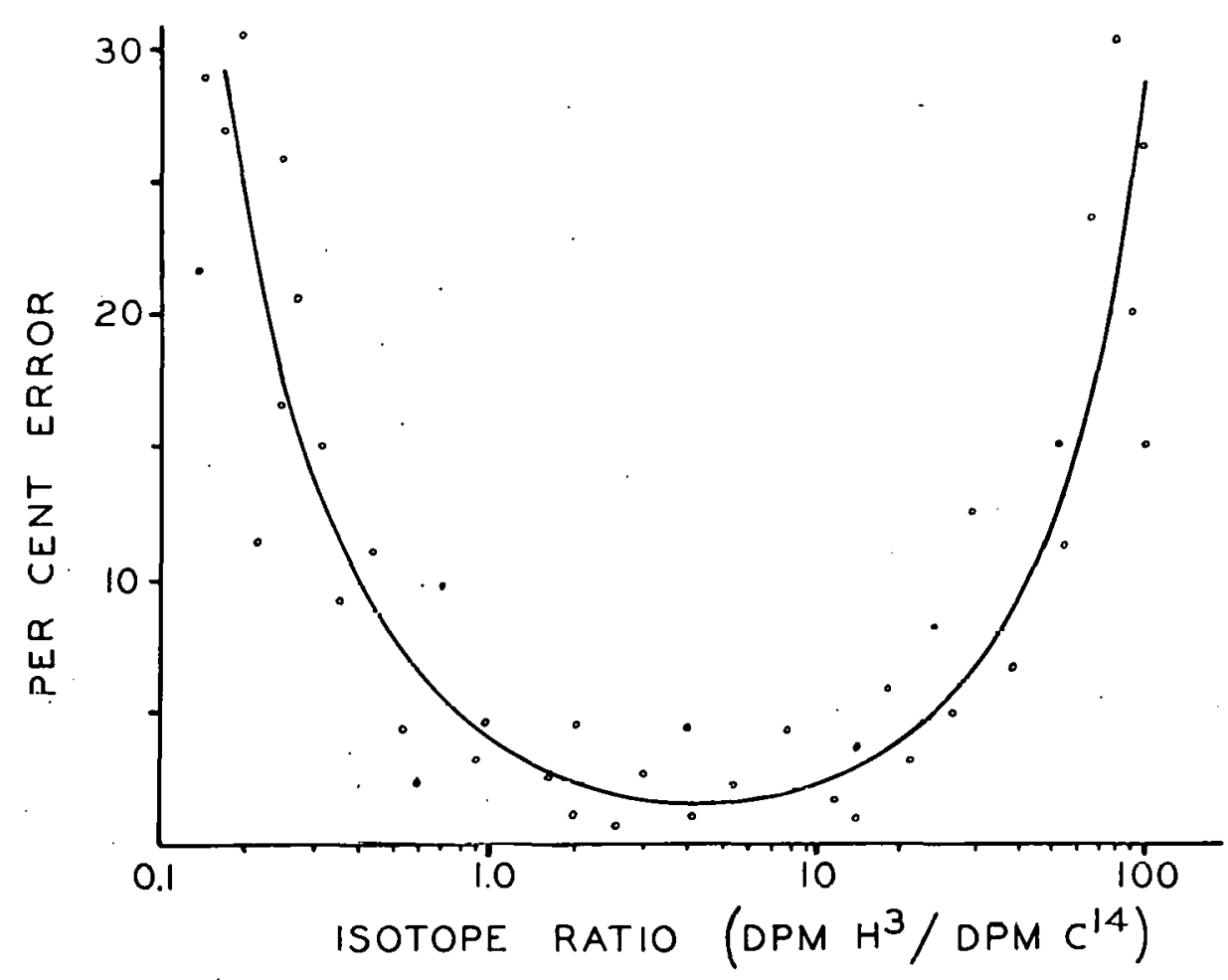

Figure 3. Effect of variation of isotope ratio on accuracy of assay.

It is posibible to assay, both isotopes simultaneously if certain variables are controlled. To obtain maximum reproducibility, it is essential that the optimum photomultiplier voltage and discriminator bias settings be carefully selected. Other conditions necessary to keep errors to a minimum require the use of the discriminator-ratio method of calculating isotope activities, maintaining proper tritium to carbon-14 isotope ratio in the sample; and having sufficient radioactivity in the sample to obtain a suitable sample-to-background counting rate ratio. If these precautions are taken, the standard error of the assay was found to be less than 5 per cent.

\section{ACKNOWLEDGMENT}

The authors wish to acknowledge the technical assistance of Mr. Roger Pating and Mr. Roh-Leong Tan.

\section{LITERATURE CITED}

1. Wilzbach, K. E., L. Kaplan, and W. G. Brown. Science, 118:522, 1953 .

2. Brownell, G. L. and H. S. Lockhart. Nucleonics, 10:No. 2, 26, 1952.

3. Hayes, F. N. and R. G. Gould. Science, 117:480, 1953.

4. Farmer, E. C. and S. A. Berstein. Science, 117:279, 1953.

5. Okita, G. T., J. L. Spratt, and G. V. LeRoy. Nucleonics, 14:No. 3, 76, 1956. 


\section{THEORETICAL STUDIES OF THE ACRH LINEAR \\ ELECTRON ACCELERATOR}

By

G. T. Wood and L. S. Skaggs

\section{INTRODUCTIOIN}

The Argonne Cancer Research Hospital (ACRH) linear electron accelerator consists of two 8-foot waveguide sections, each fed from separate klystron amplifiers with about 10 megawatts peak power. The relative phases between the RF inputs to each section can be varied as a means for controlling the maximum electron beam energy. Also, provision has been made for heating the first 2 -foot subsection of the accelerator waveguide in order to improve the electron energy spectrum. It is the purpose of this paper to make a theoretical study of the effect of these variables on the shape of the electron energy spectrum and beam current.

\section{REVIEW OF THEORY}

The motion of an electron along the axis of a linear accelerator ${ }^{1,2}$ is determined from the equation of motion:

$$
\frac{d p}{d t}=-e \epsilon(z, t)
$$

where $p$ is the electron momentum $\frac{m_{0} v}{\sqrt{1-\frac{v^{2}}{c^{2}}}}$, and $\epsilon(z, t)$ is the electric field at a time $t$ and at the point on the accelerator axis measuring a distance $\mathrm{z}$ from the point of injection. The electric field $\epsilon(z, t)$ can be written $\epsilon o \sin \Delta$ (see Figure 1 for the phase angle sign convention) in terms of the wave amplitude, $\epsilon,{ }$, and the phase position of the particle relative to the traveling wave, $\Delta=\frac{2 \mid \pi}{\lambda_{w}}\left(\mathrm{z}-\mathrm{v}_{\mathrm{w}} \mathrm{t}\right)$, where $\lambda_{\mathrm{w}}$ is the waveguide wave length and $\mathrm{v}_{\mathrm{w}}$ is the phase velocity of the wave. Provided $v_{w}$ and $\epsilon_{0}$ are constant along the accelerator tube, a time dependent Hamiltonian function $\mathrm{H}$ for the electron motion relative to the traveling wave is given by ${ }^{1,2}$

$$
\mathrm{K}_{1}=\sqrt{\mathrm{K}_{2}^{2}+1}-\mathrm{K}_{2} \beta_{\mathrm{w}}-\frac{a}{2 \pi} \cos \Delta=\sqrt{\mathrm{K}_{20}^{2}+1}-\mathrm{K}_{20} \beta_{\mathrm{w}}-\frac{a}{2 \pi} \cos \Delta_{\mathrm{O}^{\prime}}
$$

where $\mathrm{K}_{1}=\frac{\mathrm{H}}{\mathrm{m}_{\mathrm{o}} \mathrm{c}^{2}} ; \mathrm{K}_{2}=\frac{\mathrm{p}}{\mathrm{m}_{\mathrm{o}} \mathrm{c}}, \beta_{\mathrm{w}}=\frac{\mathrm{v}_{\mathrm{w}}}{\mathrm{c}}, a=\frac{\mathrm{e} \epsilon_{\mathrm{o}}{ }^{\lambda} \mathrm{w}}{\mathrm{m}_{\mathrm{o}} \mathrm{c}^{2}}$, and $\mathrm{K}_{20}$ and $\Delta_{\mathrm{o}}$ are, respectively, the electron momentum and phase angle at the time of injection into the RF wave. From equation $2, \mathrm{~K}_{2}$ is determined as a function of $\Delta$ and the initial conditions $\mathrm{K}_{20}$ and $\Delta_{0}$. When 
$\beta_{\mathrm{w}}=1$ and $\mathrm{K}_{2} \rightarrow \infty, \Delta$ approaches an asymptotic phase angle $\Delta_{\mathrm{A}}$ given by

$$
\cos \Delta_{\mathrm{A}}=\cos \Delta_{\mathrm{o}}-\mathrm{C}\left(\alpha, \beta_{\mathrm{eo}}\right) \text {, }
$$

where $\mathrm{C}\left(a, \beta_{\mathrm{eo}}\right)=\frac{2 \pi}{\alpha} \cdot \sqrt{\frac{1-\beta_{\mathrm{eo}}}{1+\beta_{\mathrm{eo}}}}$. The quantity $\beta_{\text {eo }}$ is the electron velocity at injection in $c$ units. Although equation 3 is derived on the assumption that $a$ is constant, a reasonably good approximation can be obtained by replacing the field strength parameter $a$ by its input value $a_{1}$. That is, it is assumed that $\alpha$ does not decrease significantly in the region required for the electron to approach $\Delta_{A}$. This approximation, of course, applies best to the high energy portion of the electron spectrum that is also the main region of interest.

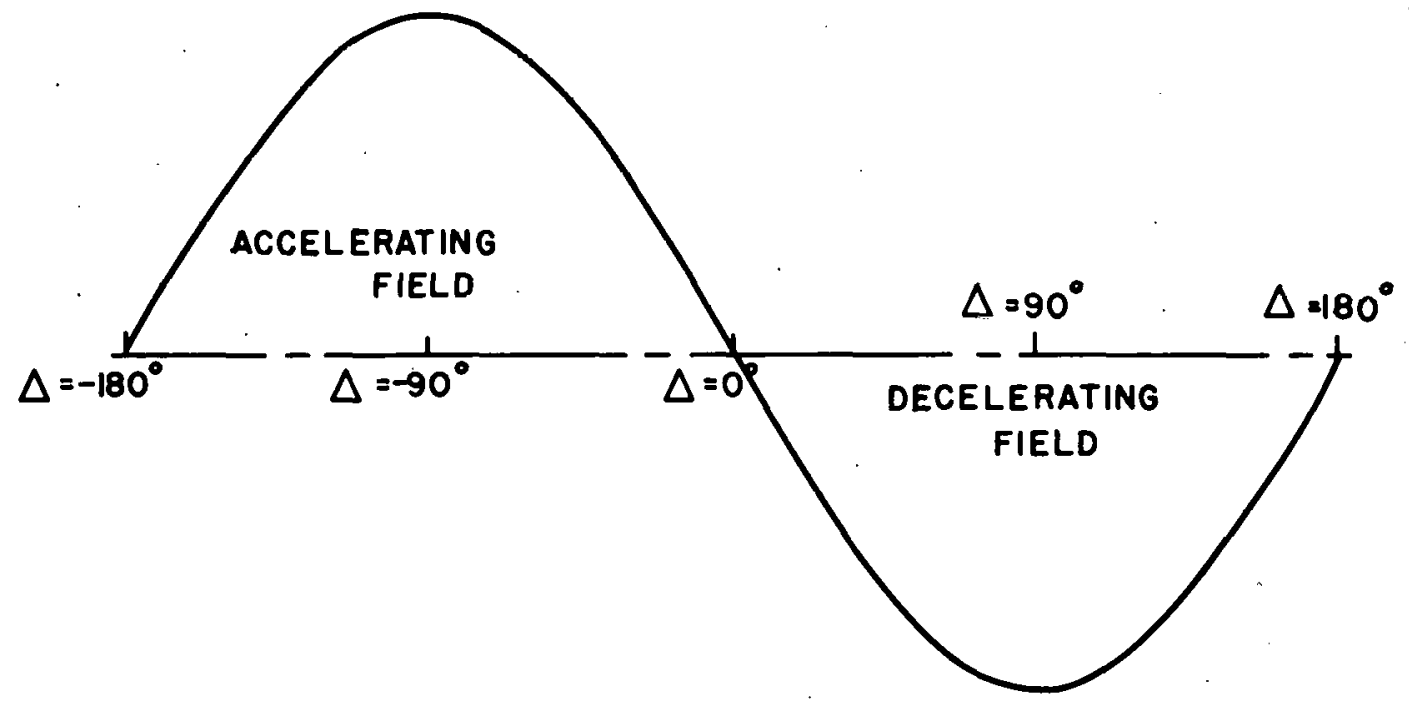

Figure 1. The longitudinal electric field versus the phase angle position on the wave showing the sign convention used.

For a long accelerator having $n$ equal sections of length $L$ with individual $R F$ inputs to each section, the final energy is given by

$$
E=-E_{0} \sin \Delta_{A}
$$

where $\mathrm{E}_{\mathrm{o}}$ is the energy an electron would obtain by traveling on the peak of the wave over the entire length of the accelerator and is given by

$$
\frac{E_{o}}{m c^{2}}=n \int_{0}^{L} \frac{\epsilon_{o}}{m c^{2}} d z=n \int_{0}^{L} \frac{a_{1}}{\lambda_{w}} e^{-I z} d z=n a_{1} \frac{L}{\lambda_{w}}\left(\frac{1-e^{-I L}}{I L}\right)
$$

provided all RF inputs are in phase. The quantity $I$ is the voltage attenuation constant. The field strength parameter has the value $a_{1}$ at the beginning of each section. As an approximation, equation 4 will be applied to the two 8-foot sections of the ACRH linear accelera- 
tor. Some considerations show that these approximations are adequate for predicting the general behavior of the energy spectrum although precise results could hardly be expected from these calculations.

Where there is no pre-bunching, the electrons are injected-randomly with all phase angles. From equations 3 and 4 , it is apparent that a bunch of electrons arriving at the end of a long accelerator will have phase angles between $-180^{\circ}$ and $\Delta_{\mathrm{Am}}$. The maximum phase angle of the bunch, $\Delta_{\mathrm{Am}}$, is associated with an electron of initial phase $\Delta_{\mathrm{O}}=0^{\circ}$ and has the value

$$
\Delta_{\mathrm{Am}}=\cos ^{-1}\left[1-\mathrm{C}\left(a_{1}, \beta_{\mathrm{eo}}\right)\right]
$$

in a uniform $\beta_{\mathrm{w}}=1$ accelerator. Depending on the value $\mathrm{C}\left(a_{1}, \beta_{\mathrm{eo}}\right), \Delta_{\mathrm{Am}}$ can in principle be set anywhere between $-180^{\circ}$ and $0^{\circ}$. Since an electron with $\Delta_{A}=-90^{\circ}$ attains the maximum energy possible, it is advantageous to make $\Delta_{A m}$ somewhat greater than $-90^{\circ}$ (see Figure 1) in order to maximize the fraction of electrons accelerated in the region near the peak of the wave. A beam of maximum energy and optimum energy spectrum results under these conditions.

In the ACRH linear accelerator, maximum permissible values of $\alpha$ and $\beta_{\text {eo }}$ are approximately $\pi$ and $1 / 2$, respectively; and, consequently, $\Delta_{A m} \leqslant-99^{\circ}$. This limit is unfortunately lower than desirable. However, as discussed in the next section, $\Delta_{A m}$ can be increased further to an optimum value by heating the first subsection of the accelerator waveguide. Likewise, in a later section it is shown that producing a phase shift between the two main accelerator sections is to a certain extent equivalent in effect to changing ${ }^{\Delta} \mathrm{Am}$. Thus, these two parameters provide the additional flexibility required for the adjustment of an optimum ene rgy spectrum.

\section{HEA TING FIRST SUBSECTION}

Heating the first subsection brings about a decrease in the phase velocity of the wave (i.e., the main Fourier component or accelerating mode) propagated in this region owing to the increase in waveguide dimensions. The effect is derived from the principle of similitude ${ }^{3}$ as follows:

Although the dimensions of the waveguide are increased, no change occurs in the frequency of the wave. However, the increase in dimensions can be considered equivalent to the sum of the following steps involving frequency changes: 1) An increase in dimensions together with an equal fractional decrease in frequency, and 2) an increase in frequency back to the initial value. Now, according to the principle of similitude, the phase velocity of the main Fourier component is not affected by the first change above. The full change in phase velocity comes in the second change and can be written in terms of the phase velocity $\mathrm{v}_{\mathrm{w}}=\frac{\omega}{\mathrm{k}_{\mathrm{zo}}}$, the group velocity $\mathrm{v}_{\mathrm{g}}=\frac{\mathrm{d} \omega}{\mathrm{dk}_{\mathrm{zo}}}$, the coefficient of linear expansion $\mathrm{g}$, and the increase in temperature $\delta \mathrm{T}$ through the expression 


$$
\frac{\delta v_{w}}{v_{w}}=\left(1-\frac{v_{w}}{v_{g}}\right) \frac{\delta \omega}{\omega}=-\left(1-\frac{v_{w}}{v_{g}}\right) g \delta T
$$

where $\omega$ is the angular frequency and $k_{z 0}$ is the propagation constant. of the main Fourier component.

In the ACRH linear accelerator, $v_{w}=c, v_{g}=0.01 \mathrm{c}, g=1.6 \times 10^{-5} /{ }^{\circ} \mathrm{C}$ (Copper), and

$$
\frac{\delta \mathrm{v}_{\mathrm{w}}}{\mathrm{v}_{\mathrm{w}}}=1.58 \times 10^{-3} \delta \mathrm{T},
$$

where $\delta \mathrm{T}$ is in centigrade degrees. Thus, a $12.7^{\circ} \mathrm{C}$ increase in temperature is required to reduce $\beta_{\mathrm{w}}=\frac{\mathrm{v}_{\mathrm{w}}}{\mathrm{c}}$ from 1 to 0.98 .

In order to analyze the electron motion, we shall assume for the sake of simplicity that the first subsection can be heated uniformly, giving a constant phase velocity of $\beta_{w 1}$, in this section. The remaining subsections have $\beta_{w}=1$ as usual. Also, it is assumed that the field strength parameter is constant in the first subsection. Based on a value of $I=$ $2.98 \times 10^{-3} \mathrm{~cm}^{-1 *}$, it is known that a actually decreases to about $0.833 \alpha_{1}$ at the end of the first subsection due to the attenuation of the wave. It appears, then, that the analysis, though not corresponding exactly with the actual conditions, should give a reasonably good indication of the energy spectrum and its response to temperature changes in the first subsection.

Using equation 2 , electron orbits for various injected phases are plotted in phase space in Figure 2 . The injected velocity $\beta_{\text {eo }}$ is assumed to be $0.375, \beta_{w 1}=0.98$, and $a=$ $\pi$. It is seen that the electrons move clockwise along elliptic-like phase space orbits in the first subsection. For comparison, an orbit has also been drawn in Figure 2 for the case $\beta_{\mathrm{w}}=1$ with an initial phase angle $\Delta_{\mathrm{o}}=0^{\circ}$. Both the $\beta_{\mathrm{w} 1}=1$ and the $\beta_{\mathrm{w} 1}=0.98$ orbits for $\Delta_{0}=0^{\circ}$ are initially the same for low energies; but, whereas the electron gains energy indefinitely in the $\beta_{\mathrm{w} 1}=1$ case, it eventually catches up with the wave in the $\beta_{\mathrm{w} 1}$ $=0.98$ case so that the phase angle begins to increase. After passing through the $\beta_{\mathrm{w} 1}=$ 0.98 subsection, the electron phase angle again decreases approaching an asymptotic phase angle $\Delta_{A}$ as shown in Figure 2. The net effect of heating the first subsection is now apparent. Without heating, $\Delta_{A}$ varies from $-180^{\circ}$ to $-110^{\circ}$. With heating, $\Delta_{A}$ varies from $-180^{\circ}$ to $-69^{\circ}$. Thus, the electron bunch has been stretched to overlap the peak of the wave, giving rise to an improved energy spectrum.

To find the momentum at the end of the first subsection, it is necessary to integrate equation 1. Then it can be shown that the distance traveled when the electron reaches momentum $\mathrm{K}_{2 \mathrm{f}}$ is given by the integral

This is a value determined at Stanford University for similar waveguides (see reference 2, p. 139). 
73

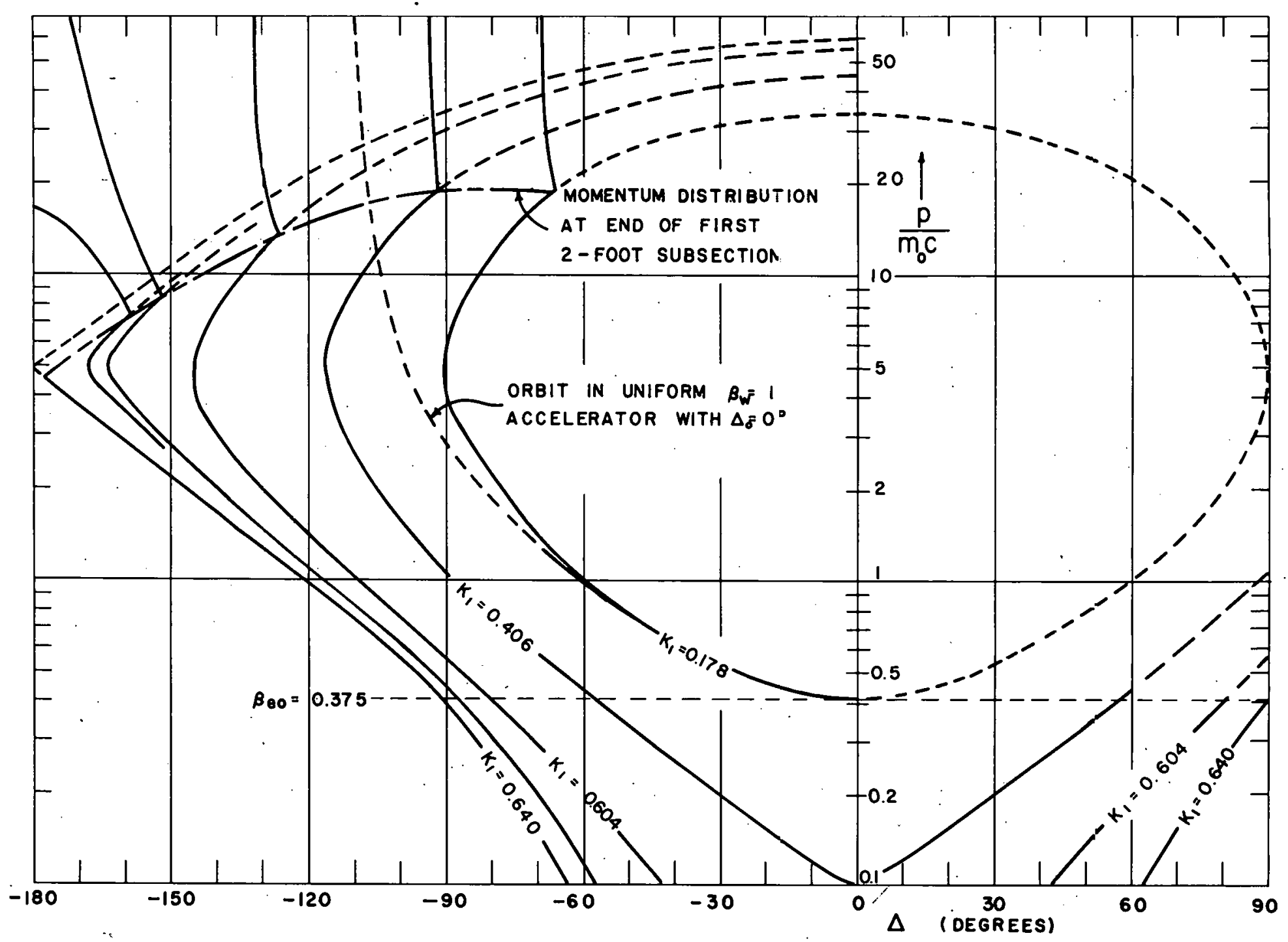

Figure 2. Phase space for $\beta_{\mathrm{w}}=0.98$ in the first two-foot subsection; $\beta_{\mathrm{W}}=1$ in remaining sections; $a=\pi$. 


$$
\mathrm{z}\left(\mathrm{K}_{2 \mathrm{f}}\right)=\int_{\mathrm{K}_{2 \mathrm{i}}}^{\mathrm{K}_{2 \mathrm{f}}} \frac{2 \pi \beta_{\mathrm{w}} \mathrm{cd \textrm {K } _ { 2 }}}{\sin \Delta \sqrt{1+\frac{1}{\mathrm{~K}_{2}^{2}}}}
$$

where $\Delta$ can be expressed as a function of $\mathrm{K}_{2}$, using equation 2 . The integral was evaluated graphically for various values of $\mathrm{K}_{2 \mathrm{f}}$ enabling one to obtain by interpolation the value of $\mathrm{K}_{2 \mathrm{f}}$ at the end of the first subsection for each value of $\Delta_{\mathrm{o}}$. The phase angle $\Delta_{\mathrm{f}}$ at the end of the first subsection can then be read off Figure 2 and the final asymptotic phase angle $\Delta_{A}$ can be calculated from $\cos \Delta_{A}=\cos \Delta_{f}-\frac{2 \pi}{a}\left[\left(K_{2 f}^{2}+1\right)^{1 / 2}-K_{2 f}\right]$ for each orbit. Assuming again the long accelerator approximation, the final relative energy is calculated from equation 4 and plotted in Figure 3 versus the initial phase for $\beta_{w 1}=1,0.99$ and 0.98 . The energy spectrum can be derived immediately from Figure 3 . Since the electrons initially are distributed uniformly in phase with respect to the wave, the fraction of electrons

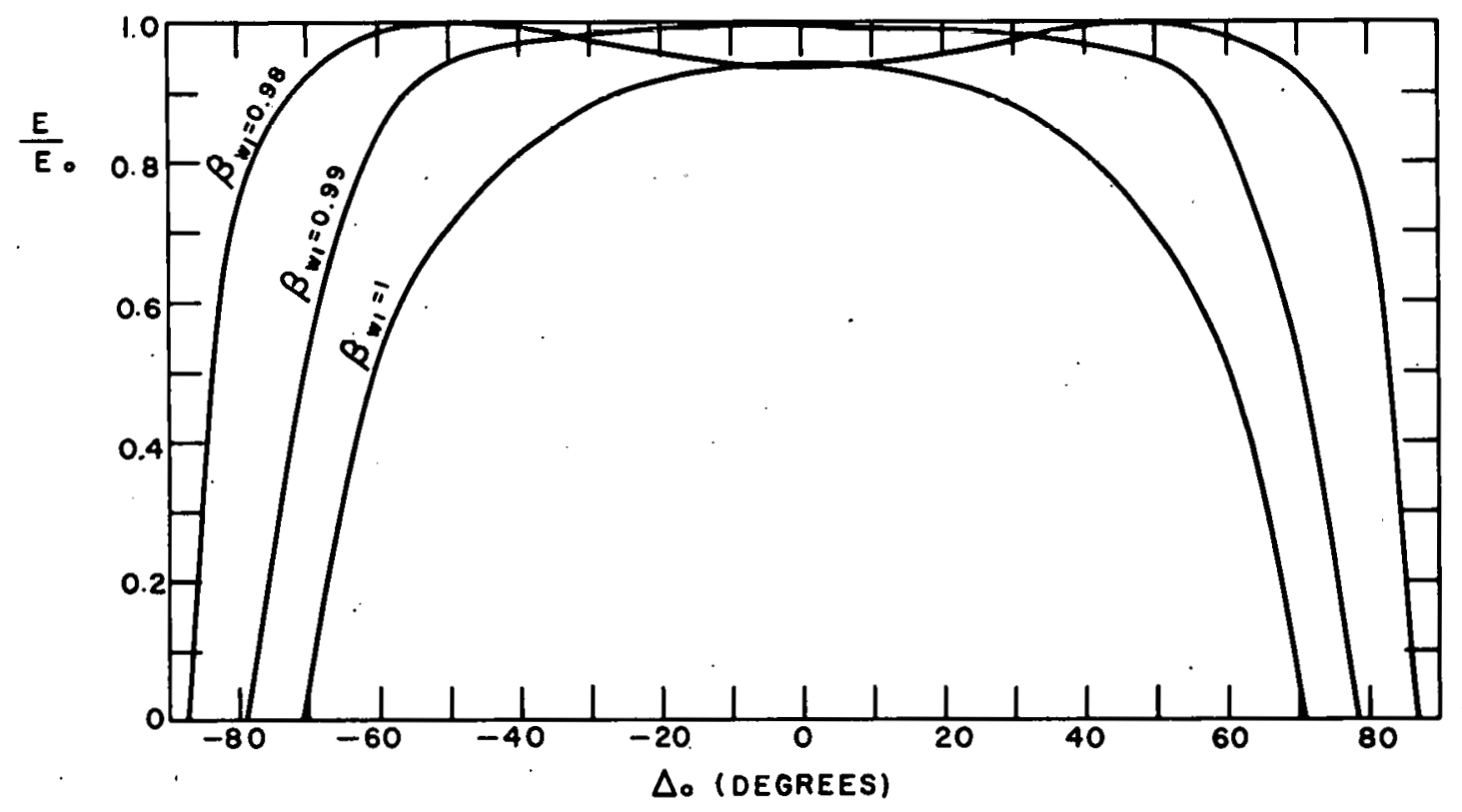

Figure 3. Relative electron energy $\frac{E}{E_{0}}$ at the end of a long accelerator versus the initial phase angle for three values of $\dot{\beta}_{\mathrm{W}}$ in the first twofoot subsection; $\beta_{\mathrm{W}}=1$ in remaining sections; $\alpha=\pi ; \beta_{\mathrm{eo}}=0.375$.

at the output with energy greater than some value $E$ is given by $\frac{\phi(E)}{\phi(O)}$ where $\phi(E)$ is the angular width of the range of initial phase angles that give rise to energies greater than $\mathrm{E}$. One must sum over two regions in the case when $\Delta_{O}$ is a quadruple-valued function of $E$, as occurs with the $\beta_{w 1}=0.98$ curve in Figure 3 for $\frac{E}{E_{0}}>0.933$ due to the central dip in the curve. The integral energy spectra calculated in this way are plotted in Figure 4 for the three cases. The improvement in energy spectrum obtained by reducing $\beta_{\mathrm{w} 1}$ is seen to be substantial. 


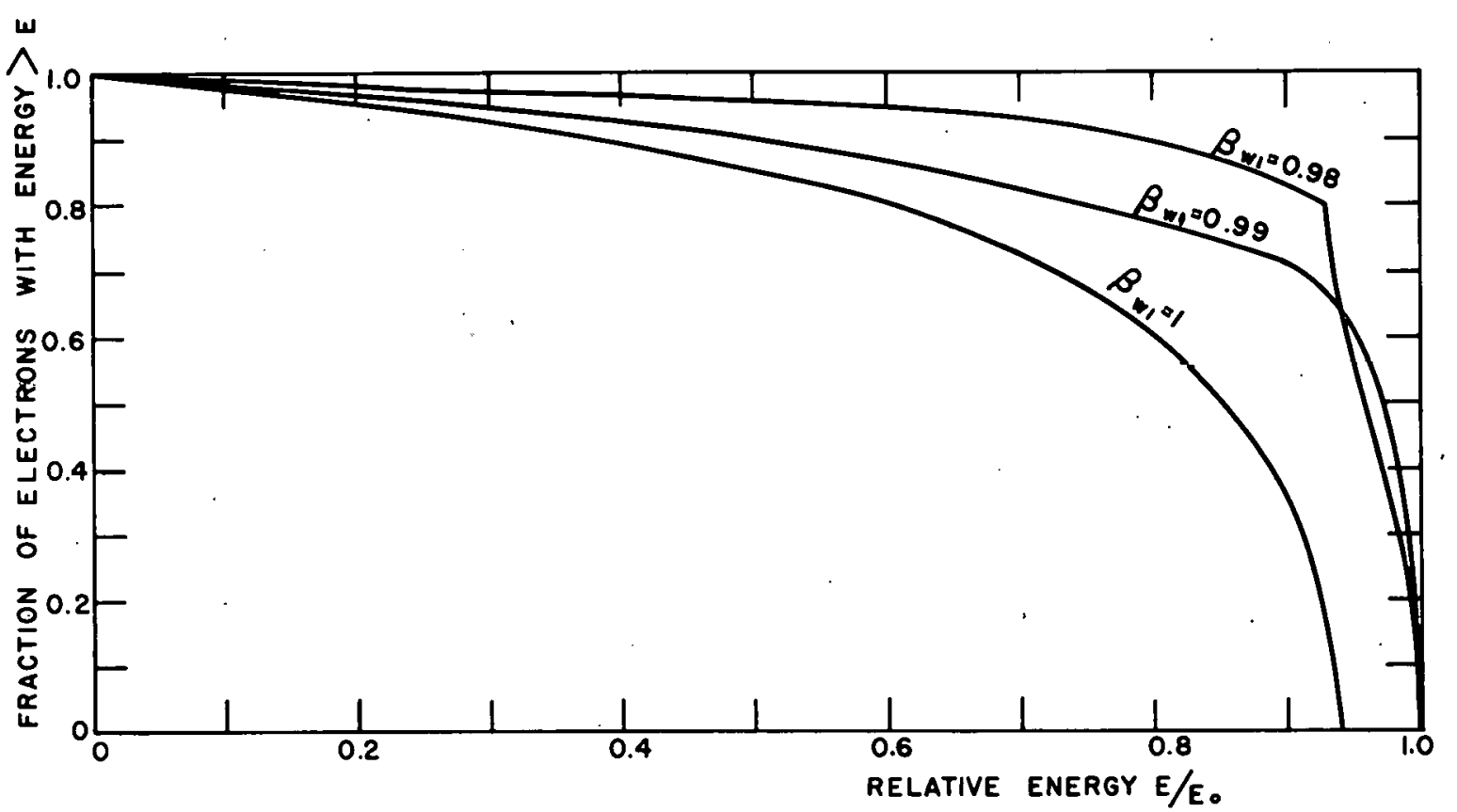

Figure 4. Integral electron energy spectrum at the end of a long accelerator for various values of $\beta_{w}$ in the first two-foot subsection; $\beta_{\mathrm{W}}=1$ in remaining sections; $a l=\pi ; \beta_{\mathrm{eo}}=0.375$.

The curves in Figure 4 are differentiated in order to give the electron current versus energy as shown in Figure 5. It is noted that in all cases the current peaks at the maximum energy. When $-90^{\circ} \leqslant \Delta_{\text {Am }} \leqslant 0^{\circ}$, an additional peak occurs at an energy $\delta \mathrm{E}$ below $\mathrm{E}_{\max }$ as in the case when $\beta_{\mathrm{w} 1}=0.98$.

The optimum choice of $\Delta_{i} A m, E_{\text {max' }}$, and $\delta E$ depend, of course, on the application. When the acceleration is used in conjunction with a magnetic analyzer, for example, only electrons from.a given energy interval will be selected. It is apparent that the energy interval $\mathrm{E}_{\max }-\delta \mathrm{E}_{\text {to }} \mathrm{E}_{\max }$ should be made to coincide with the interval to be selected by the magnetic analyzer. Either an increase or decrease of $\delta \mathrm{E}$ from this value will result in less current from the analyzer.

The double peak width $\delta \mathrm{E}$ can be expressed explicitly in terms of $\Delta_{\mathrm{Am}}$ through the expression

$$
\frac{\delta E}{E_{\max }}=1+\sin \Delta_{A m}
$$

and is plotted in Figure 6 . The points corresponding.to $\beta_{\mathrm{wl}}=0.99$ and 0.98 are indicated by the vertical arrows for the special case $a=\pi, \beta_{\text {eo }}=0.375$. The ACRH magnetic analyzer will select electrons over a 2 per cent energy interval. Therefore, it is estimated from Figure 6 that $\beta_{\mathrm{w} 1} \cong 0.986$ would be optimum for this application. Then the fraction of the output current in the upper 2 per cent energy interval would be $\sim 0.55$ as compared with $\sim 0.22$ in the $\beta_{\mathrm{w} 1}=1$ case. 


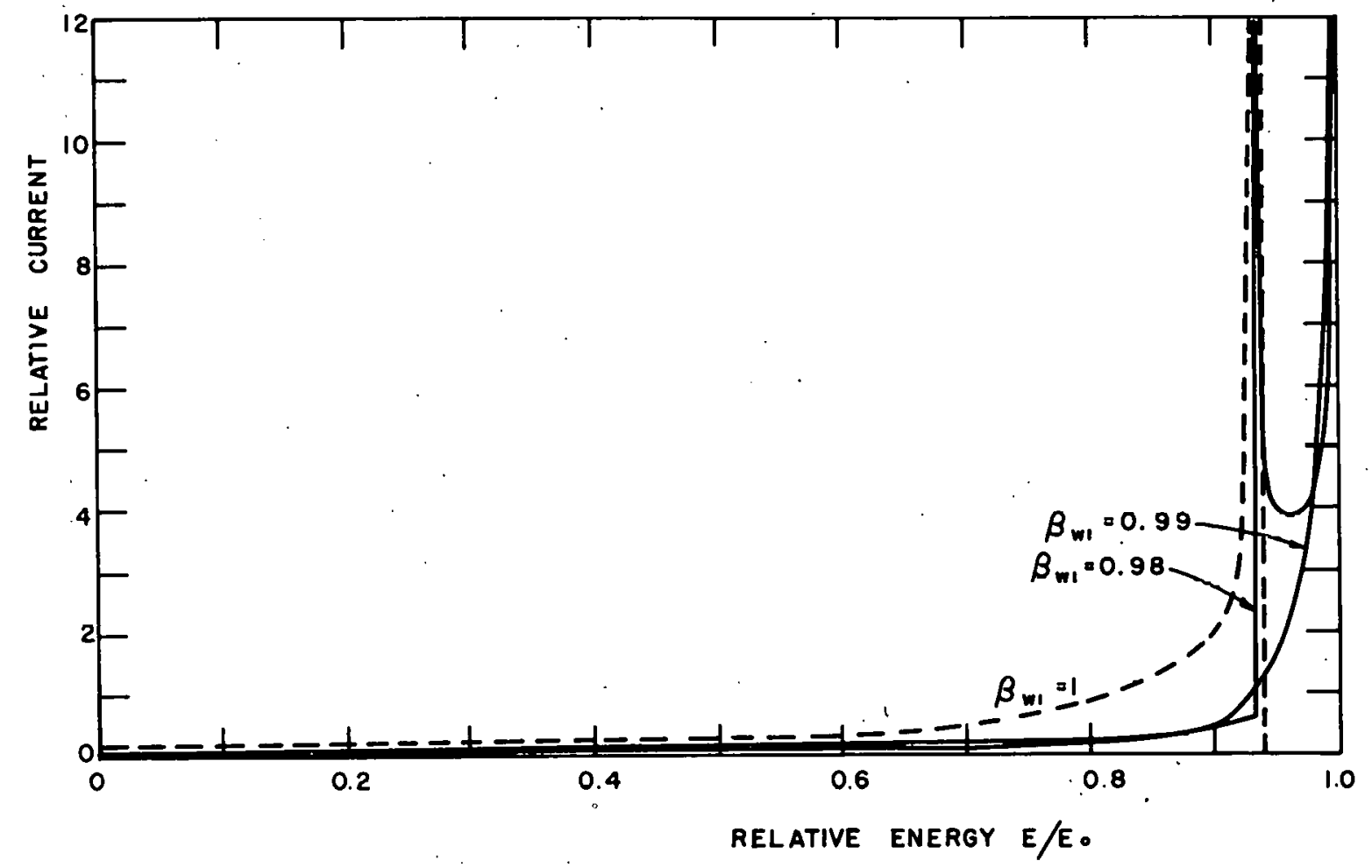

Figure 5. Differential energy spectrum at the end of a long accelerator for various values of $\beta_{\mathrm{wl}} ; a=\pi ; \beta_{\mathrm{eu}}=0.375$.

\section{PHASE SHIFTING WAVEGUIDE SECTIONS}

The facility for shifting the phases between the RF inputs to the two 8-foot waveguide sections provides a convenient way for varying the maximum energy of the electron beam. Since the shape of the energy spectrum and the magnitude of the electron current also depend on the phase shift between sections, it is important to study this problem in some detail with and without heating of the first.subsection.

In these calculations, we shall assume the long accelerator approximation for each waveguide section. The two main sections will be assumed equivalent except for possible heating of the first 2-foot subsection in the first main section. Then the final electron energy as a function $\Delta_{w}$, the phase shift between sections, is given from equation 4 by the expression

$$
E\left(\Delta_{w}\right)=-\frac{E_{0}}{2}\left[\sin \Delta_{A 1}+\sin \Delta_{A 2}\right]
$$

where $\Delta_{A 1}$ and $\Delta_{A 2}$ are the asymptotic phase angles, respectively, for the two sections and $\mathrm{E}_{\mathrm{O}}$ is defined as before. The phase shift between sections is related to the asymptotic phase angles in the long accelerator approximation by

$$
\Delta_{\mathrm{w}}=\Delta_{\mathrm{A} 2}-\Delta_{\mathrm{A} 1} \text {. }
$$

It should be pointed out that $\Delta_{A 2}$ may have a value between $0^{\circ}$ and $180^{\circ}$, causing the elec- 


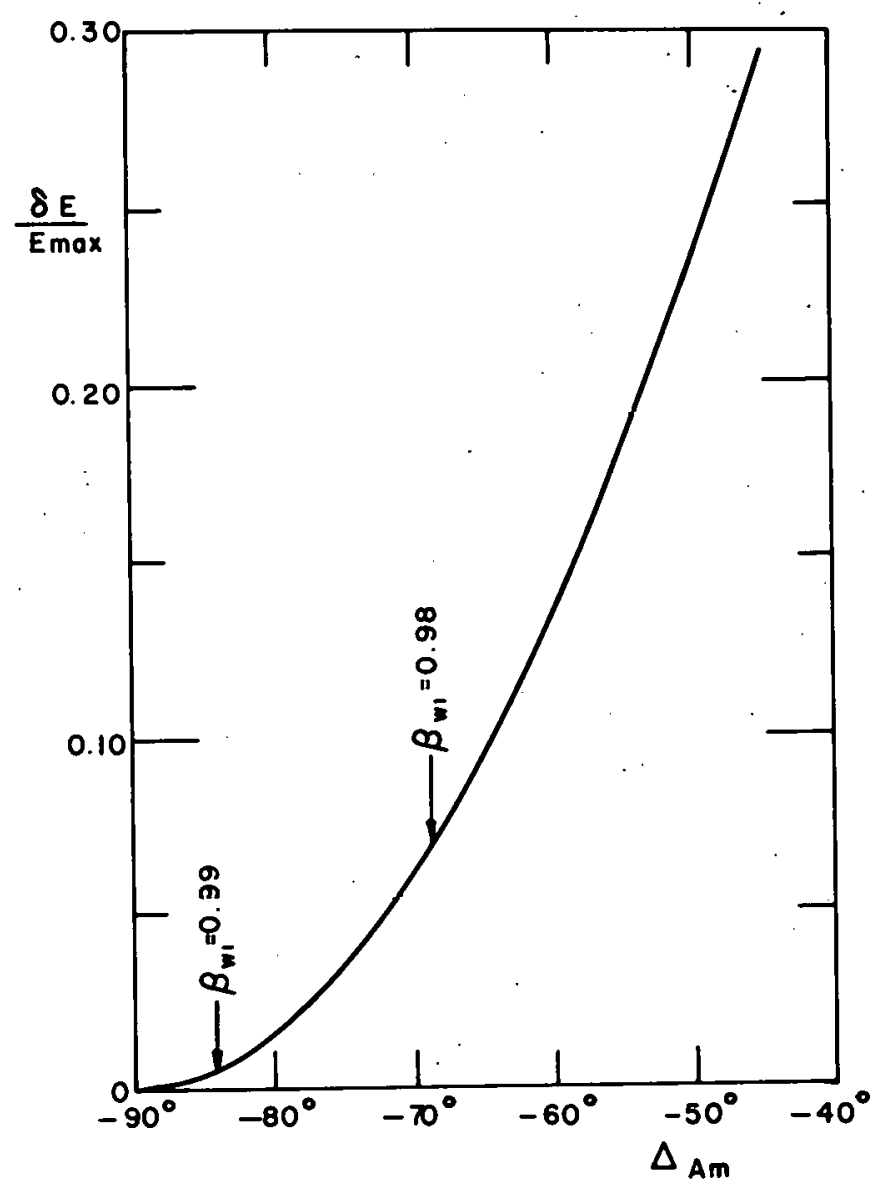

Figure 6. The width of the double energy peak in fraction of maximum energy versus the maximum asymptotic phase angle $\Delta^{\prime} \mathrm{Am}$. The points corresponding to $\beta_{\mathrm{w} 1}=0.98$ and 0.99 are marked off as calculated for the special case with $\alpha=\pi$ and $\beta_{\text {eo }}=0.375$.

tron to be decelerated in section 2 . In this case, $\Delta_{A 2}$ refers to the asymptotic phase angle from whence the electron came.

By combining equations 8 and 9 , we obtain

$$
\frac{E\left(\Delta_{\mathrm{w}}\right)}{\mathrm{E}_{\mathrm{O}}}=-\left(\sin \Delta_{\mathrm{A} 1}\right)\left(\frac{1+\cos \Delta_{\mathrm{W}}}{2}\right)-\left(\cos \Delta_{\mathrm{A} 1}\right)\left(\frac{\sin \Delta_{\mathrm{W}}}{2}\right) \text {. }
$$

Thus, if a given electron obtains energy $E(O)$ for $\Delta_{w}=0^{\circ}$, changing $\Delta_{w}$ will have the result of shifting the electron energy to $E\left(\Delta_{w}\right)$ as given by

$$
E\left(\Delta_{w}\right)=\left\{\begin{array}{c}
E^{+}\left(\Delta_{w}\right) \text { if }-180^{\circ} \leqslant \Delta_{A 1} \leqslant-90^{\circ} \\
E^{-}\left(\Delta_{w}\right) \text { if }-90^{\circ} \leqslant \Delta_{A 1} \leqslant 0^{\circ}
\end{array}\right.
$$


where $\frac{E^{ \pm}\left(\Delta_{w}\right)}{E_{o}} \equiv \frac{E(O)}{E_{o}} \cos ^{2} \frac{\Delta_{w}}{2} \pm \sqrt{1-\frac{E(O)^{2}}{E_{o}}} \sin \frac{\Delta_{w}}{2} \cos \frac{\Delta_{w}}{2}$

The function $\frac{E^{+}\left(\Delta_{w}\right)}{E_{O}}$ is plotted in Figure 7 versus $\frac{E(O)}{E_{0}}$. To determine $E^{-}\left(\Delta_{w}\right)$, one uses the relationship

$$
E^{-}\left(\Delta_{w}\right)=E^{+}\left(-\Delta_{w}\right)
$$

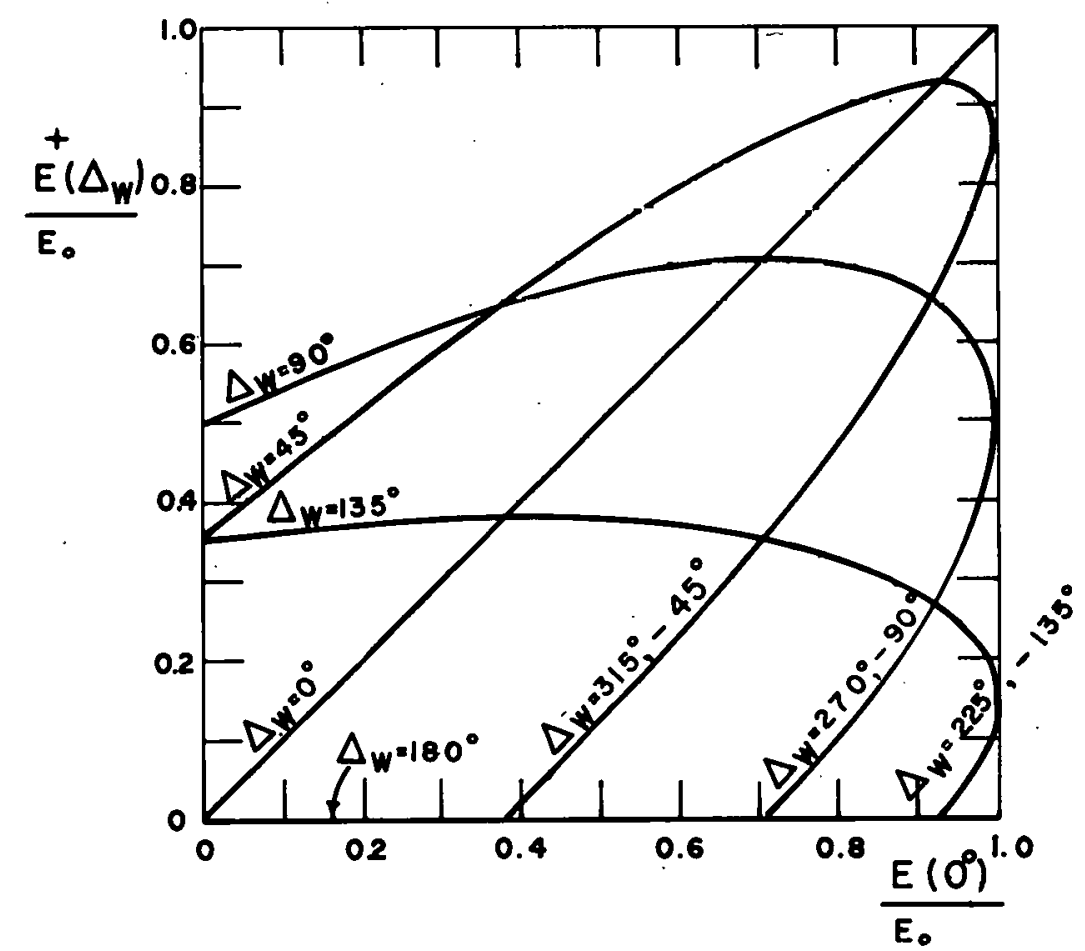

Figure 7. Relative energy of an electron reaching the end of an accelerator consisting of two equivalent sections with a phase shift $\Delta_{\mathrm{w}}$ between them versus the energy the electron would have when $\Delta_{\mathrm{W}}=0^{\circ}$. The curves apply directly when $-180^{\circ} \leqslant \Delta_{A}: \leqslant-90^{\circ}$. When $-90^{\circ} \leqslant \Delta_{A} \leqslant 0^{\circ}$, each curve applies for a value of $\Delta_{W}$ equal to the negative of the angle indicated.

Through multiplication of each ordinate of the curves in Figure 3 by the factor $\frac{E\left(\Delta_{w}\right)}{E(O)}$ obtained from Figure 7 , we can determine $\frac{E\left(\Delta_{w}\right)}{E}$ versus $\Delta_{0}$ for each $\Delta_{W}$ as shown in Figure 8 for the uniform $\beta_{\mathrm{w}}=1$ accelerator case. The integral spectrum can be derived from the plot of $\frac{E\left(\Delta_{W}\right)}{E_{O}}$ versus $\Delta_{0}$ as shown in Figure 9 for the $\beta_{w 1}=1$ case. A differential spectrum is also plotted for $\beta_{\mathrm{w} 1}=1$ in Figure 10. Figures 9 and 10 show that the shape of the energy spectrum depends markedly on $\Delta_{w}$. It is seen, for example, that considerably more electrons are concentrated at the top of the spectrum for $\Delta_{w}=45^{\circ}$ than for $\Delta_{w}=0^{\circ}$. Double energy peaks occur in the $\Delta_{\mathrm{w}}=135^{\circ}$ and $90^{\circ}$ cases, whereas the other curves plotted have single peaks. 


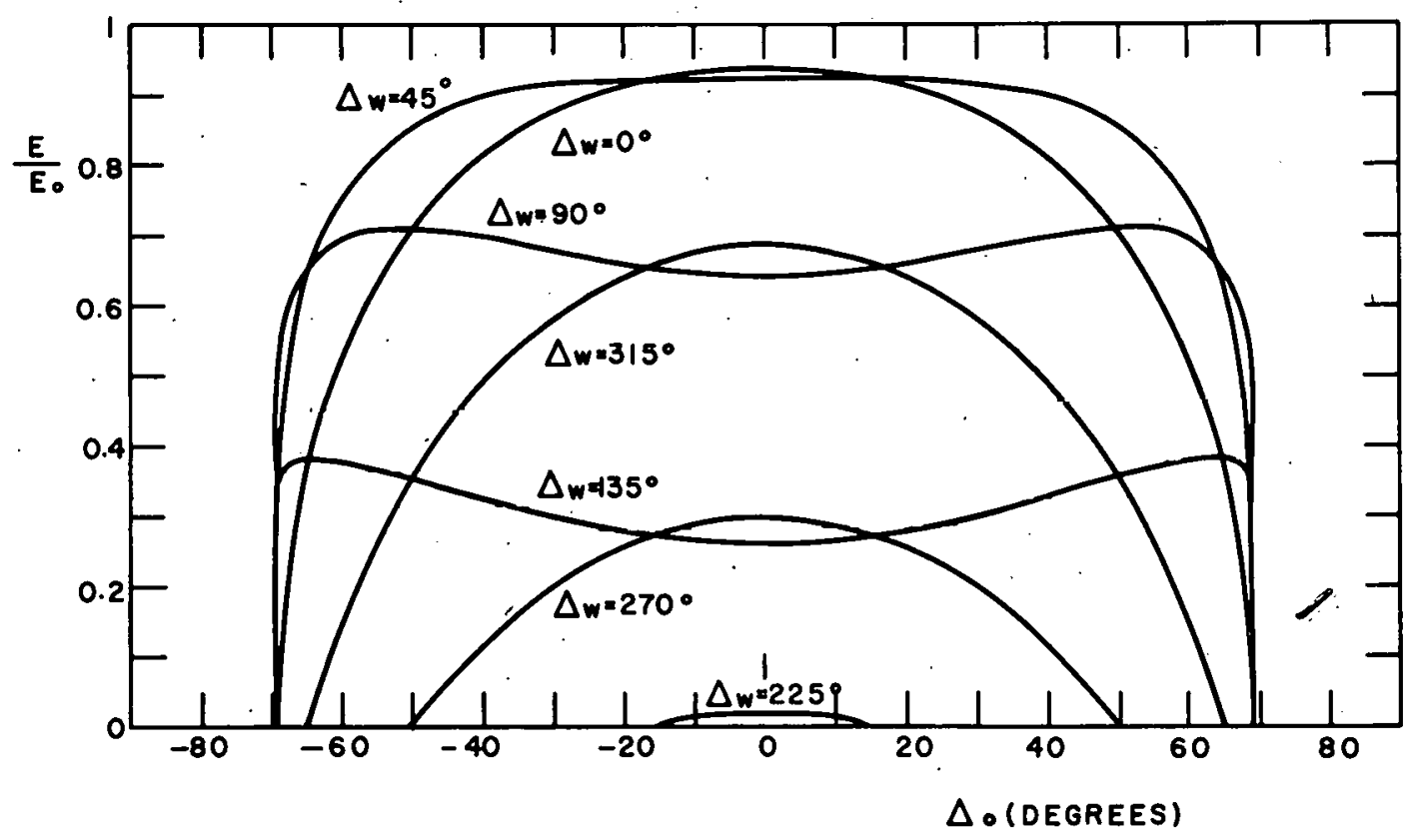

Figure 8 . Relative electron energy at the end of a long accelerator versus the initial phase for various values of $\Delta_{\mathrm{W}} ; a=\pi ; \beta_{\mathrm{eo}}=$ $0.375 ; \beta_{\mathrm{w}}=1$.

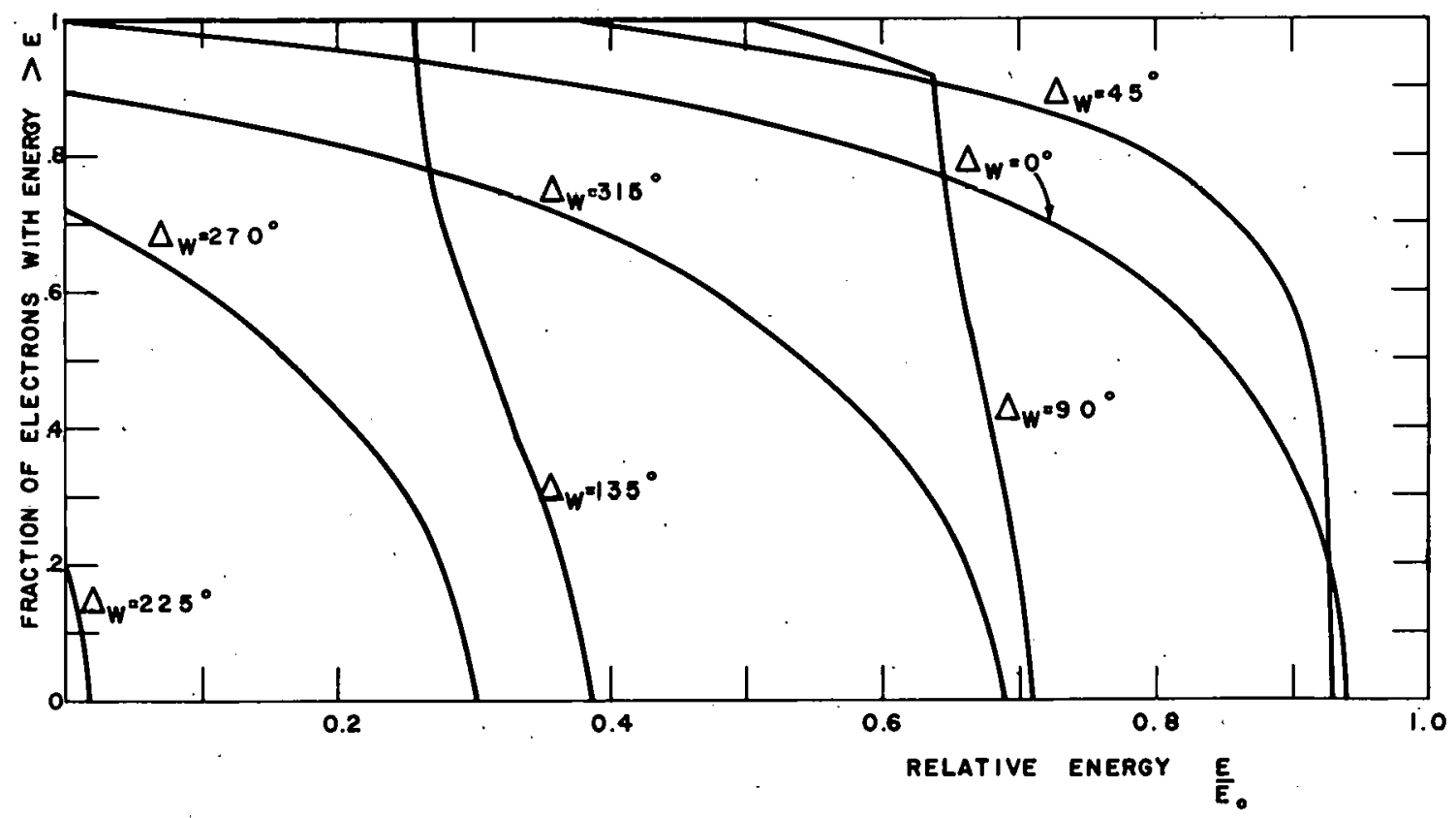

Figure 9. Integral energy spectrum of electron beam for various values of $\Delta_{\mathrm{w}} ; a=\pi ; \beta_{\mathrm{eo}}=0.375 ; \beta_{\mathrm{w}}=1 ; \beta_{\mathrm{w} 1}=1$. 


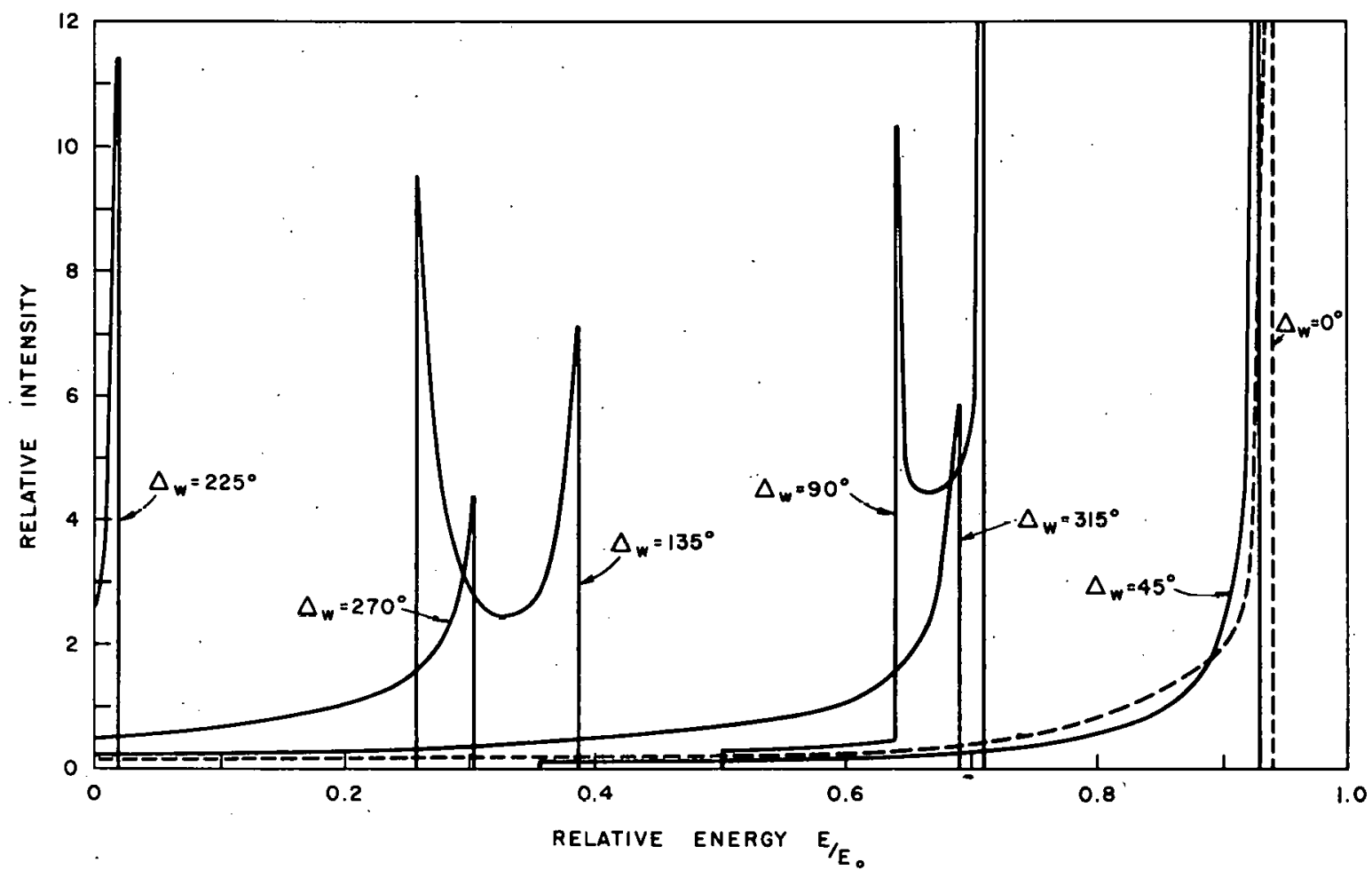

Figure 10. Differential energy spectrum of electron beam for various values of $\Delta_{\mathrm{W}} ; a=\pi ; \beta_{\mathrm{eo}}=0.375 ; \beta_{\mathrm{W}}=1 ; \beta_{\mathrm{W} 1}=1$.

For the special $\beta_{\mathrm{w} 1}=1$ case considered, one can obtain a plot of the maximum beam electron energy, $E_{\text {max }}$, versus $\Delta_{w}$ from the integral spectra in Figure 9 . However, this function can be derived simply for general conditions as follows:

Equation 10 can be transformed to

$$
\frac{E\left(\Delta_{W}\right)}{E_{\mathrm{O}}}=-\cos \frac{\Delta_{\mathrm{w}}}{2} \sin \Delta_{\mathrm{A}}^{\prime}
$$

where

$\Delta_{A}^{\prime}=\Delta_{A 1}+\frac{\Delta_{\mathrm{W}}}{2}$ and $-180^{\circ} \leqslant \Delta_{A}^{\prime} \leqslant 0^{\circ}$.

Define

$\Delta_{\mathrm{Am}}^{\prime} \equiv \Delta_{\mathrm{A} 1 \mathrm{~m}}+\frac{\Delta_{\mathrm{w}}}{2}$

and

$$
\Delta_{\text {wo }} \equiv-180^{\circ}-2 \Delta_{\mathrm{A} 1 \mathrm{~m}}
$$

where ${ }^{\Delta} \mathrm{A} 1 \mathrm{~m}$ is the maximum asymptotic phase angle of the electron bunch in section 1. When $-180^{\circ} \leqslant \Delta_{w} \leqslant \Delta_{w 0^{\prime}}$, the condition $-180^{\circ} \leqslant \Delta_{A m}^{\prime} \leqslant-90^{\circ}$ also holds and the electron with $\Delta_{A}^{\prime}=\Delta_{A m}^{\prime}$ obtains the maximum energy. However, when $\Delta_{\text {wo }} \leqslant \Delta_{w} \leqslant 180^{\circ}$, we have $-90^{\circ} \leqslant \Delta_{A m}^{\prime} \leqslant 0^{\circ}$ and the maximum energy comes from electrons with $\Delta_{A}^{\prime}=$ $-90^{\circ}$. Finally, using equation 12 , we deduce 


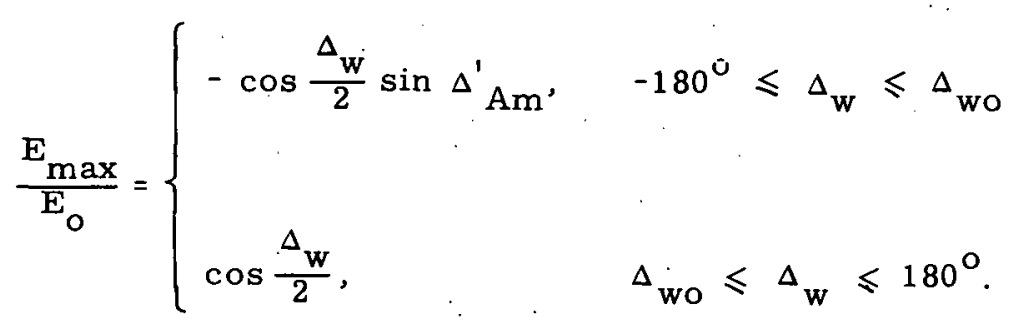

The maximum energy $\mathrm{E}_{\max }$ is plotted in Figure 11 versus $\Delta_{w}$ for various values of $\Delta_{\Lambda 1 \mathrm{~m}}$. It is important to note that for a given $\Delta_{\mathrm{W}}, \mathrm{E}_{\max }$ depends only on $\Delta_{\mathrm{A} 1 \mathrm{~m}}$. The quantity ${ }^{\Delta} \mathrm{A} 1 \mathrm{~m}$ can be varied over a wide range through appropriate adjustment of $\alpha, \beta_{\mathrm{eo}}$, and $\beta_{\mathrm{w} 1}$.

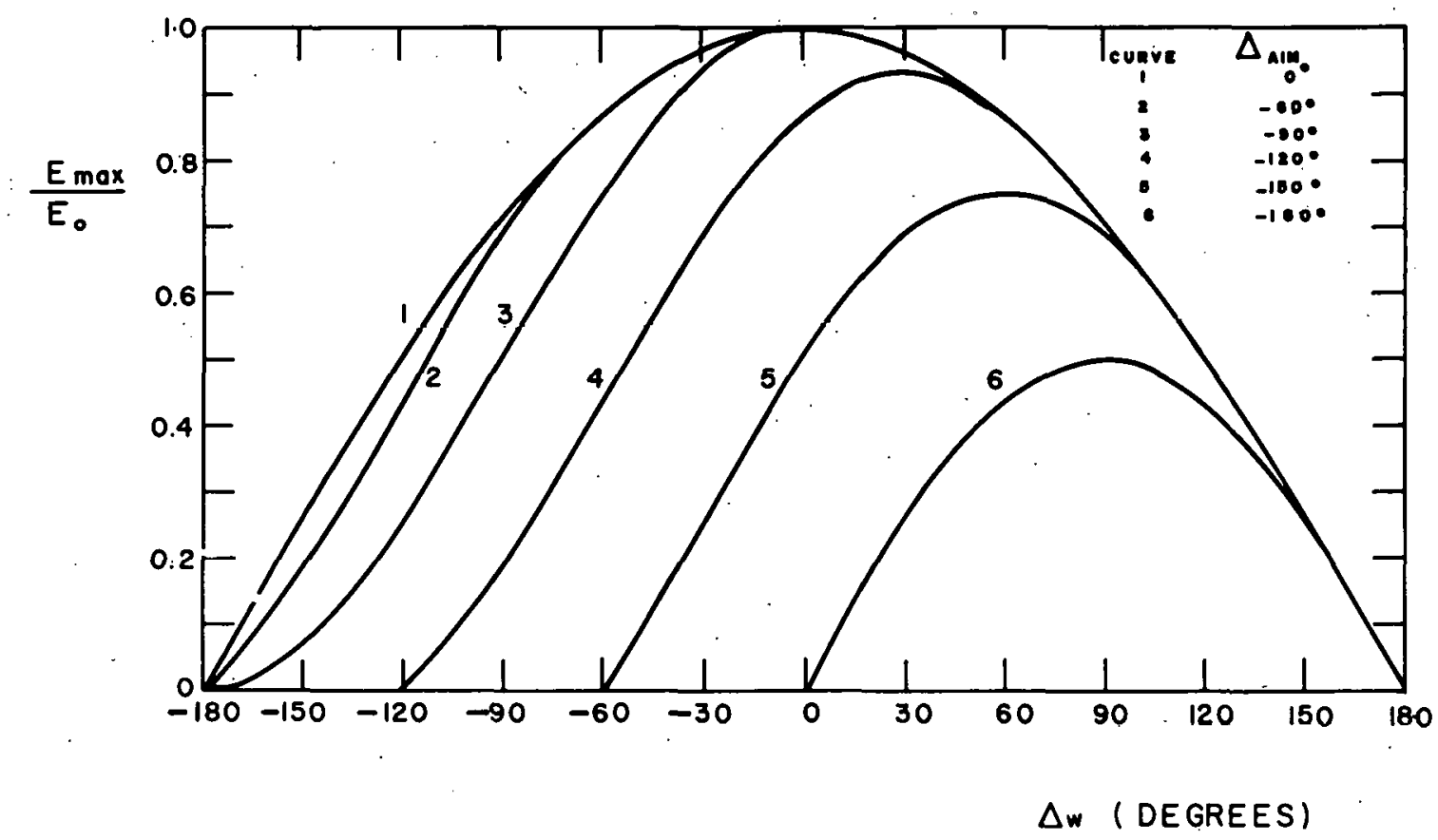

Figure 11. Relative maximum energy of electron beam versus phase shift between main eight-foot sections for various values of ${ }^{\Delta} \mathrm{Alm}$.

Measurements of $\mathrm{E}_{\max }$ versus $\Delta_{\mathrm{w}}$ can be useful for determining the position of the phase-shifter control corresponding to $\Delta_{\mathrm{w}}=0^{\circ}$. The phase shifter is easily calibrated for relative phase shifts, but the absolute phase is not easily determined by microwave techniques. In Figure 11, it is seen that the peak of $E_{\max }$ versus $\Delta_{\mathrm{w}}$ appears at $\Delta_{\mathrm{w}}=0^{\circ}$ provided $\Delta_{\mathrm{A} 1 \mathrm{~m}} \geqslant-90^{\circ}$. Thus, if the quantities $\alpha$ and $\beta_{\text {eo }}$ are increased and $\beta_{\mathrm{w} 1}$ decreased, $\Delta_{\mathrm{A} 1 \mathrm{~m}}$ will eventually become greater than $-90^{\circ}$ and the position of the peak will become fixed at $\Delta_{\mathrm{w}}=0^{\circ}$, thereby serving to calibrate the $\Delta_{\mathrm{w}}=0^{\circ}$ position of the phase-shifter control.

The conditions required for maximizing the current in a given energy interval have been discussed already for the case $\Delta_{w}=0^{\circ}$. In an analogous manner we can extend the 
discussion to include any $\Delta_{w}$. From equation 12 , it can be seen that a double energy peak will occur in the spectrum for $\Delta_{\text {wo }} \leqslant \Delta_{\mathrm{w}} \leqslant 180^{\circ}$ since this corresponds to $-90^{\circ} \leqslant \Delta^{\prime}$ Am $\leqslant 0^{\circ}$. The width $\delta \mathrm{E}$ of the double peak is given by

$$
\frac{\delta E}{E_{\max }}=1+\sin \Delta^{\prime} \mathrm{Am}
$$

which is identical to equation 7 , except that $\Delta_{A m}$ is replaced by $\Delta^{\prime}{ }_{A m}$.

The quantities $\mathrm{E}_{\max }$ and $\delta \mathrm{E}$ are completely determined from $\Delta_{\mathrm{A} 1 \mathrm{~m}}$ and $\Delta_{\mathrm{w}}$. Therefore, a convenient mode of representation of equations 13 and 14 is obtained by plotting the contours of constant $\frac{E_{\max }}{E_{O}}$ and $\frac{\delta E}{E_{\max }}$ on a plane with axes $\Delta_{A 1 \mathrm{~m}}$ and $\Delta_{w}$, respectively, as is done in Figure 12.

Also plotted in Figure 12 are contours of constant current, or specifically 1) the fraction $I_{T}$ of the injected current still bound to the RF wave at the cnd of the accelerator waveguide, and 2) the fraction $I_{\delta E}$ of the output current with energy between $E_{\max }-\delta \mathrm{E}$ and $E_{\max }$. In these calculations, transverse focusing effects are neglected and it is assumed that $a_{1}$ is small enough so that none of the bound electrons attain negative velocities at the beginning of their orbits. As before, the long accelerator approximation is assumed and the contours are calculated for $\beta_{\mathrm{w} 1}=1$. Under these conditions, the analytical expressions for $\mathrm{I}_{\mathrm{T}}$ and $\mathrm{I}_{\delta \mathrm{E}}$ are found to be as follows.

When $-90^{\circ} \leqslant \Delta_{A 1 \mathrm{~m}} \leqslant 0^{\circ}$,

$$
\mathrm{I}_{\mathrm{T}}=\left\{\begin{array}{l}
1+\frac{\Delta_{\mathrm{A} 1 \mathrm{~m}}}{180^{\circ}}, 0^{\circ} \leqslant \Delta_{\mathrm{w}} \leqslant-2 \Delta_{\mathrm{A} 1 \mathrm{~m}} \\
1+\frac{\Delta_{\mathrm{A} 1 \mathrm{~m}}}{180^{\circ}}+\frac{\cos ^{-1}\left[1+\cos \frac{\Delta_{\mathrm{w}}}{2}-\cos \Delta_{\mathrm{A} 1 \mathrm{~m}}\right]}{180^{\circ}},-2 \Delta_{\mathrm{A} 1 \mathrm{~m}} \leqslant \Delta_{\mathrm{w}} \leqslant 180^{\circ} \\
\frac{\cos ^{-1}\left[1-\cos \frac{\Delta_{\mathrm{w}}}{2}-\cos \Delta_{\mathrm{A} 1 \mathrm{~m}}\right]}{-180^{\circ}},-180^{\circ} \leqslant \Delta_{\mathrm{w}} \leqslant 0^{\circ}
\end{array}\right.
$$

When $-180^{\circ} \leqslant \Delta_{\mathrm{A} 1 \mathrm{~m}} \leqslant-90^{\circ}$,

$$
I_{T}=\left\{\begin{array}{l}
1+\frac{\Delta_{A 1 m}}{180^{\circ}}, 0^{\circ} \leqslant \Delta_{\mathrm{w}} \leqslant 180^{\circ} \\
0 \quad,-180^{\circ} \leqslant \Delta_{\mathrm{w}} \leqslant 360^{\circ}-2 \Delta_{\mathrm{A} 1 \mathrm{~m}} \\
\frac{\cos ^{-1}\left[1-\cos \frac{\Delta_{\mathrm{w}}}{2}-\cos \Delta_{\mathrm{A} 1 \mathrm{~m}}\right]}{-180^{\circ}},-360^{\circ}-2 \Delta_{\mathrm{A} 1 \mathrm{~m}} \leqslant \Delta_{\mathrm{w}} \leqslant 0^{\circ} .
\end{array}\right.
$$

Defining $\mathrm{Q}=1-\cos \left(\Delta_{\mathrm{A} 1 \mathrm{~m}}+\Delta_{\mathrm{W}}\right)-\cos \Delta_{\mathrm{A} 1 \mathrm{~m}}$, we obtain 


\section{3}

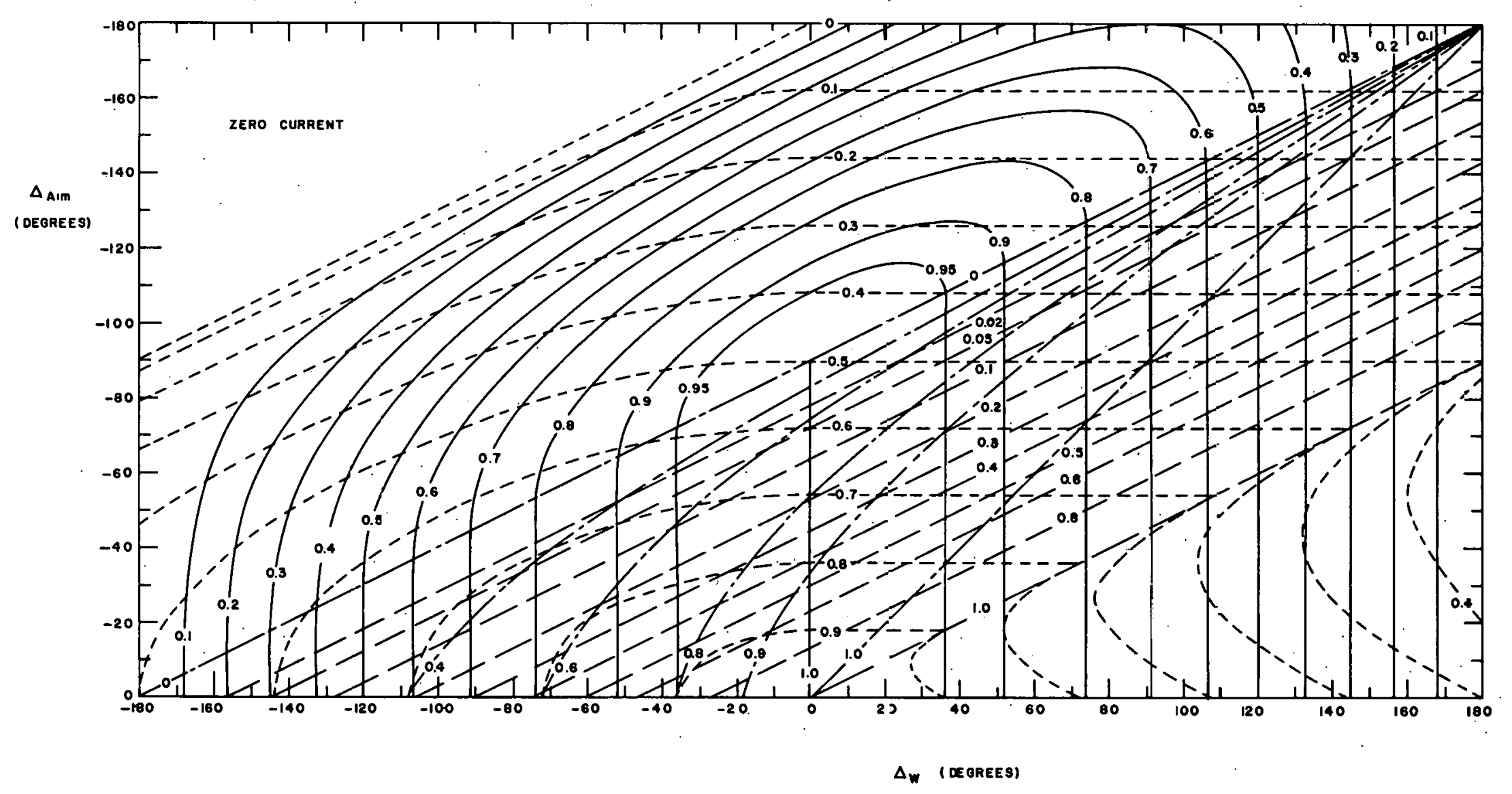

Figure 12. Contour map of $\frac{E_{\max }}{E_{O}}$ (solid line), $\frac{\delta E}{E_{\max }}$ idashed line), $I_{T}$ (dotted line), and $I_{\delta} \mathrm{E}$ (dot-dash line) on the $\Delta_{\mathrm{A} 1 \mathrm{~m}}, \Delta_{\mathrm{W}}$ plane. The $\mathrm{I}_{\mathrm{T}}$ and $\mathrm{I}_{\delta \mathrm{E}}$ quantities are cal-. culated for $\beta_{\mathrm{w} 1}=1$, whereas the $\mathrm{E}_{\max }$ and $\delta \mathrm{E}$ calculations are independent of : $\beta_{\mathrm{w} 1}$. 
$I_{\delta E}= \begin{cases}\frac{\cos ^{-1} Q}{-180^{\circ}-\Delta_{A 1 m}}, \cos ^{-1} Q>-180^{\circ}-\Delta_{A 1 m} \\ 1, & \cos ^{-1} Q \leqslant-180^{\circ}-\Delta_{A 1 m} .\end{cases}$

All the arc cosine quantities above are angles between $-180^{\circ}$ and $0^{\circ}$.

The effect of reducing $\beta_{\mathrm{w} 1}$ for a given $\Delta_{\mathrm{A} 1 \mathrm{~m}}$ and $\Delta_{\mathrm{w}}$ is to shift all the $\mathrm{I}_{\delta \mathrm{E}}$ contours upward in Figure 12 except $I_{\delta E}=0$ and $I_{\delta E}=1$, which are not.changed. Since $\frac{E_{\max }}{E_{O}}$ and $\frac{\delta E}{E_{\max }}$ contours are independent of $\beta_{\mathrm{w} 1}$ for given values of $\Delta_{\mathrm{A} 1 \mathrm{~m}}$ and $\Delta_{\mathrm{w}^{\prime}}$ it is concluded that $I_{\delta}$ can be increased for a given $E_{\max }$ and $\delta \mathrm{E}$ by reducing $\beta_{\mathrm{w} 1}$ ( $\beta_{\text {eo }}$ must be reduced also, of course, in order to maintain the same value of $\Delta_{A 1 \mathrm{~m}}$ ). For example, at $\Delta_{\mathrm{w}}=0^{\circ}$ and $\Delta_{\mathrm{A} 1 \mathrm{~m}}=-69^{\circ}, \mathrm{I}_{\delta \mathrm{F}}$ is increased from 0.66 to 0.79 when $\beta_{\mathrm{w} 1}$ is reduced from 1 to 0.98 . In a similar manner, decreasing $\beta_{\mathrm{w} 1}$ has the effect of lowering the $\mathrm{I}_{\mathrm{T}}$ contours in Figure 12. For example, at $\Delta_{\mathrm{W}}=0^{\circ}$ and $\Delta_{\mathrm{A} 1 \mathrm{~m}}=-69^{\circ}$, $\mathrm{I}_{\mathrm{T}}$ is reduced from 0.62 to 0.48 when $\beta_{\mathrm{w} 1}$ is decreased from 1 to 0.98 . As these examples show, Figure 12 can be used for predicting roughly $I_{T}$ and $I_{\delta E}$ even when $\beta_{\mathrm{w} 1}$ differs slightly from unity.

\section{CONCLUSIONS}

The basic features of the electron spectrum from a linear accelerator consisting of two identical sections with variable phase shift between their RF inputs are plotted for a wide variety of conditions in Figure 12 . Since approximations have been made in these calculations, precise predictions are not expected. However, the type of behavior to be expected from variation of the various parameters is made clear. It is seen that two basic parameters determine the essential characteristics of the energy spectrum: the maximum asymptotic phase angle $\Delta_{A 1 m}$ in the first section, and the phase shift $\Delta_{w}$ between sections. The quantity $\Delta_{\mathrm{A} 1 \mathrm{~m}}$ can be adjusted over a rather wide range through proper adjustment of the injected electron energy, the RF power, and the degree of heating of the first 2-foot accelerator subsection.

To adjust $\Delta_{\mathrm{A} 1 \mathrm{~m}}$ to a predetermined value, one can set $\Delta_{\mathrm{w}}=0^{\circ}$ and measure $\mathrm{E}_{\max }$ and $\delta \mathrm{E}$ versus $\beta_{\mathrm{eo}}$ and $\beta_{\mathrm{w} 1}$ with $\alpha$ set to give the desired value of $\mathrm{E}_{\mathrm{o}}$. As shown in Figure 12, $\mathrm{E}_{\max }$ increases from 0 to $\mathrm{E}_{\mathrm{o}}$ as $\Delta_{\mathrm{A} 1 \mathrm{~m}}$ increases from $-180^{\circ}$ to $-.90^{\circ}$ and remains constant at $\mathrm{E}_{\mathrm{O}}$ from $-90^{\circ}$ to $0^{\circ}$. The quantity $\frac{\delta \mathrm{E}}{\mathrm{E}_{\max }}$ varies from 0 to 1 in the $-90^{\circ}$ to $0^{\circ}$ range. Thus, ${ }^{\Delta} \mathrm{A} 1 \mathrm{~m}$ can be determined from the measured value of $\frac{\mathrm{E}_{\max }}{\mathrm{E}_{\mathrm{O}}}$ in the $-180^{\circ}$ to $-90^{\circ}$ range and from $\frac{\delta E}{E_{\max }}$ in the $-90^{\circ}$ to $0^{\circ}$ range.

With so many parameters at one's disposal, there is the question concerning the best procedure for varying these parameters when changing the beam energy. To maximize the electron current, it seems desirable to choose $\delta \mathrm{E}$ equal to the energy interval of the magnetic beam analyzer. If, for example, the magnetic analyzer selects a 2 per cent energy width, $\frac{\delta \mathrm{E}}{\mathrm{E}_{\max }}$ should be adjusted to 0.02 . When one attempts to change $\mathrm{E}_{\max }$ either by vari- 
ation of $\Delta_{w}$ or $a$, it is apparent from Figure 12 that $\frac{\delta \mathrm{E}}{\mathrm{E}_{\max }}$ will also change. In either case, however, the change in $\frac{\delta \mathrm{E}}{\mathrm{E}_{\max }}$ can be compensated for by variation of $\Delta_{\mathrm{A} 1 \mathrm{~m}}$, using the parameters $\beta_{\mathrm{eo}}$ or $\beta_{\mathrm{w} 1}$. A third possibility is to vary $a$ and $\Delta_{\mathrm{w}}$ together in an appropriate fashion, keeping $\beta_{\text {eo }}$ and $\beta_{\mathrm{w} 1}$ constant. In this way, $\frac{\delta \mathrm{E}}{\mathrm{E}_{\max }}$ can be kept constant while varying $\mathrm{E}_{\max }$.

It can be noted that Figure 12 predicts a change of electron current when energy is varied. The actual fraction of injected current passing through the $\delta E$ energy interval is

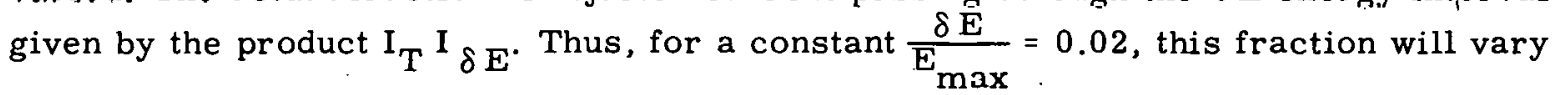
from 0.30 to 0.20 when $E_{\max }$ is reduced from $E_{0}$ to $1 / 2 E_{0}$. It is seen that the decrease of $\mathrm{I}_{\mathrm{T}}$ is partially compensated for by an increase in $\mathrm{I}_{\delta \mathrm{E}}$.

\section{ACKNOWLEDGMENT}

We wish to acknowledge the assistance of Rosemarie Wahl in performing some of the numerical calculations.

\section{LITERATURE CITED}

1. Slater, J. C. Rev. Modern Phys., 20:473, 1948.

2. Chodorow, M., E. L. Ginston, W. W. Hansen, R. L. Kyhl, R. B. Neal, W. K. H. Panof sky, et al. Rev. Sci. Instr., 26:134, 1955.

3. Stratton, J. A. Electromagnetic Theory, McGraw-Hill Book Co., New York, p. 488, 1941.

4. Terrall, J. R. and J. C. Slater. J. Appl. Phys., 23:66, 1952. 


\section{STAFF PUBLICATIONS}

Fried, W., L. O. Jacobson, L. Plzak, and E. Goldwasser. The dynamic equilibrium of the erythron. Proc. of the Institute of Medicine of Chicago, 21:244, 1957.

Fried, W., L. F. Plzak, L. O. Jacobson, and E. Goldwasser. Studies on erythropoiesis. III. Factors controlling erythropoietin production. Proc. Soc. Exp. Biol. Med., 94:237, 1957.

Goldwasser, E., L. O. Jacobson, W. Fried, and L. Plzak. Mechanism of erythropoietic effect of cobalt. Science, 125:1085, 1957.

Jacobson, L. O. Added comment. The Leukemias: Etiology, Pathophysiology, and treatment. Academic Press, New York, 1957, p. 183.

Jacobson, L. O., E. Goldwasser, W. Fried, and L. Plzak. Kole of the kidney in erythropoiesis. Nature, 179:633, 1957 .

Jacobson, L. O., E. Goldwasser, L. F. Plzak, and W. Fried. Studies on erythropoiesis. Part IV. Reticulocyte response of hypophysectomized and polycythemic rodents to erythropoietin. Proc. Soc. Exp. Biol. Med., 94:243, 1957.

Kubota, C., S. O. Schwartz, and F. W. Putnam. Multiple myeloma: correlation of the clinical, the marrow, and electrophoretic findings. Acta Haematologica, 16:105, 1956.

Okita, G. Studies with radioactive digitalis. J. Am. Geriatrics Soc., 5:163, 1957.

Okita, G., J. J. Kabara, F. Richardson, and G. V. LeRoy. Simultaneous radioassay of compounds containing tritium and carbon-14 using a liquid scintillation counter. Nucleonics, $15:$ No. $6,111,1957$.

Davis, M. E., E. J. Plotz, G. V. LeRoy, R. G. Gould, and H. Werbin. Hormones in human reproduction. I. Metabolism of progesterone. Am. J. Obstet. Gynecol , 72:740, 1956.

Putnam, F. W. and A. Miyake. Proteins in multiple myeloma. Arch Biochem. Biophys., $65: 39,1956$.

Werbin, H., D. M. Bergenstal, R. G. Gould, and G. V. LeRoy. Evaluation of tritium cholesterol as a tracer in man. J. Clin. Endocrinol. Metabolism, 17:337, 1957.

Werbin, H., E. J. Plotz, G. V. LeRoy, and M. E. Davis. Cholesterol-a precursor of estrone in vivo. J. Am. Chem. Soc., 79:1012, 1.957. 


$$
\begin{aligned}
& -6=5.5 \times 10 \\
& 1-86
\end{aligned}
$$

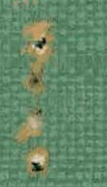
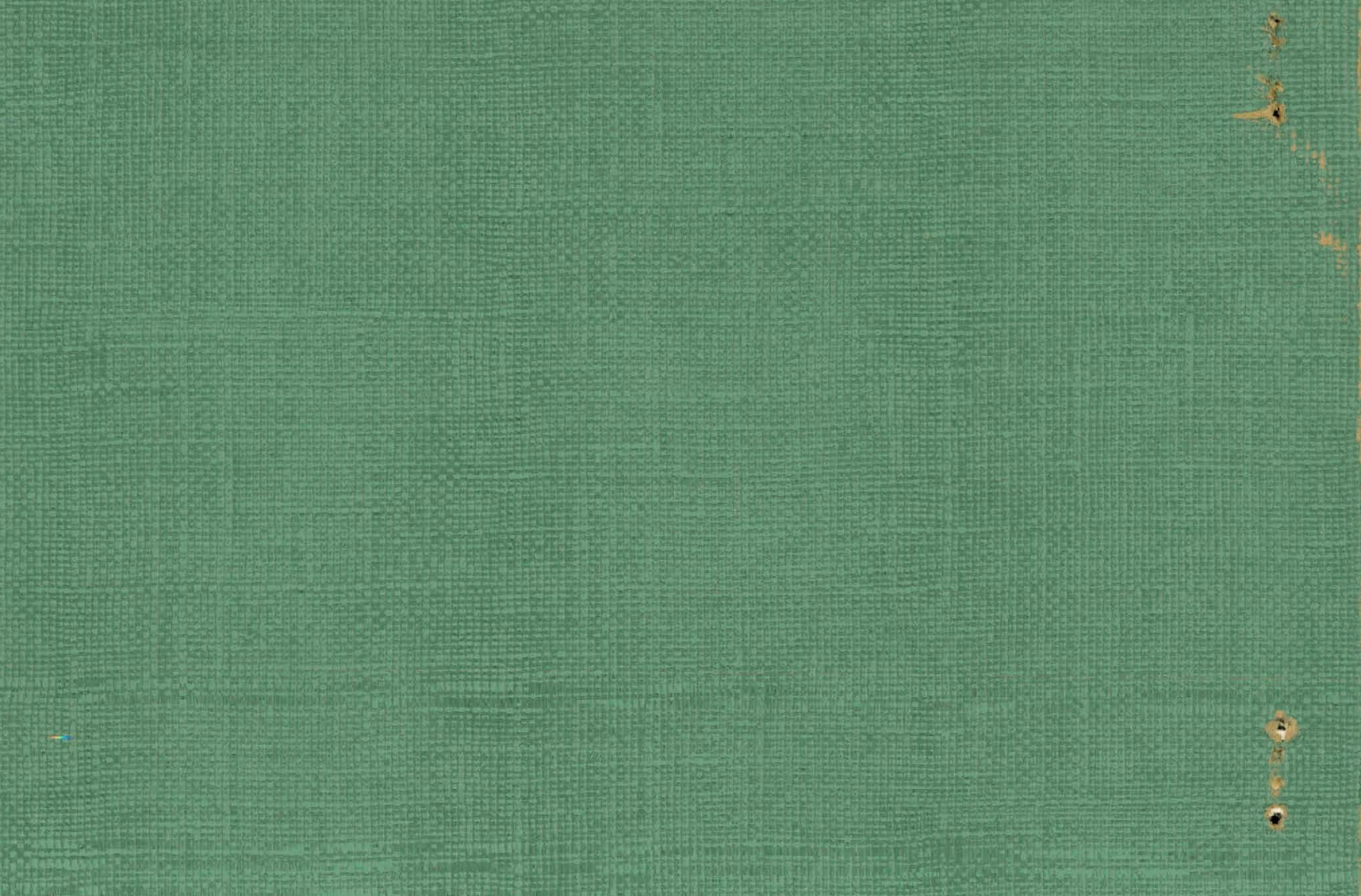